Aus der Abteilung Kardiologie und Pneumologie

(Prof. Dr. med. G. Hasenfuß)

im Zentrum Innere Medizin

der Medizinischen Fakultät der Universität Göttingen

\title{
Neurohumorale Aktivierung in einem \\ kardiovaskulären Risikokollektiv - Einfluss von diastolischer oder systolischer Dysfunktion
}

\section{NAUG URAL - DISSERTATION}

\author{
zur Erlangung des Doktorgrades \\ der Medizinischen Fakultät \\ der Georg-August-Universität zu Göttingen
}

vorgelegt von

Ingmar Rahn

aus

Göttingen

Göttingen 2009 
Dekan: Prof. Dr. med. C. Frömmel

I. Berichterstatter: Prof. Dr. med. B. Pieske

II. Berichterstatter: Priv.-Doz. Dr. med. Seipelt

III. Berichterstatter: Priv.-Doz. Dr. med. Sigler

Tag der mündlichen Prüfung: 17.01.2011 


\section{Inhaltsverzeichnis}

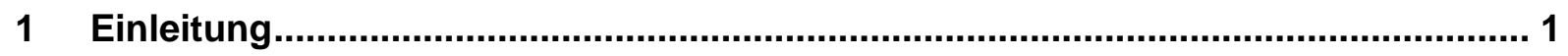

1.1 Definition der diastolischen Dysfunktion ........................................................... 1

1.2 Definition der diastolischen Herzinsuffizienz ..................................................... 1

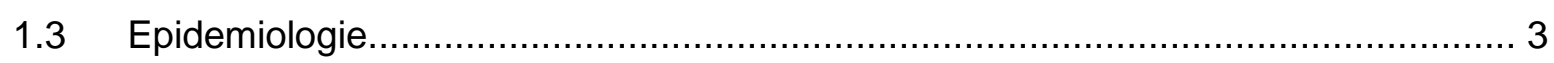

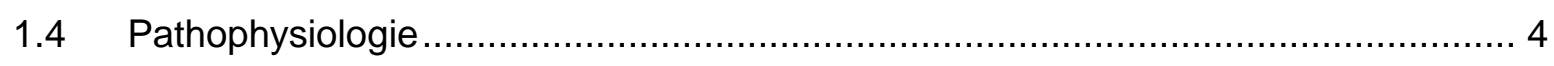

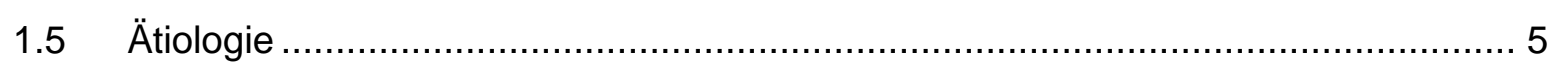

1.6 Stellenwert der neurohumoralen Regulation bei Patienten mit diastolischer Dysfunktion und diastolischer Herzinsuffizienz ........................................................ 6

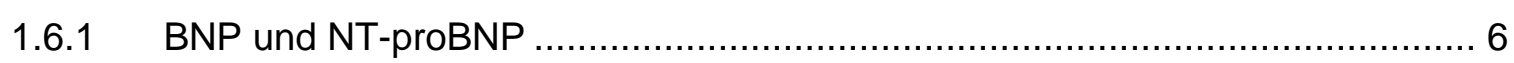

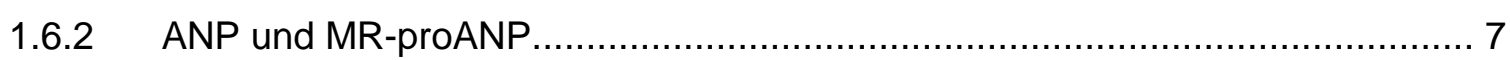

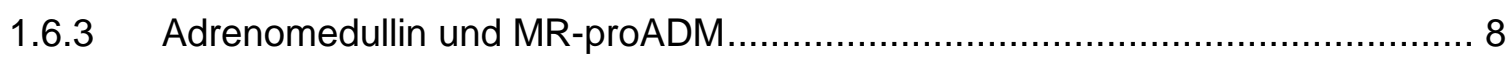

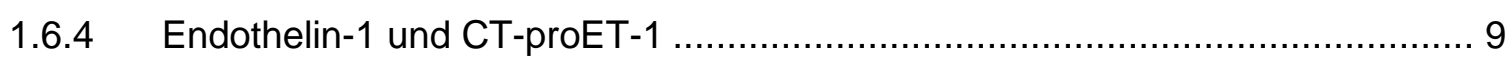

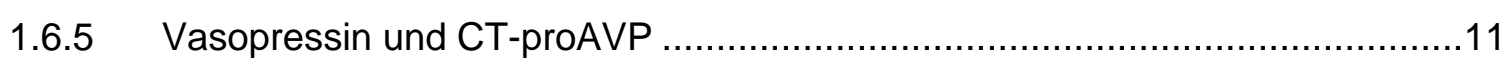

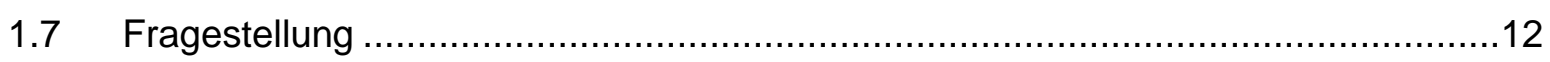

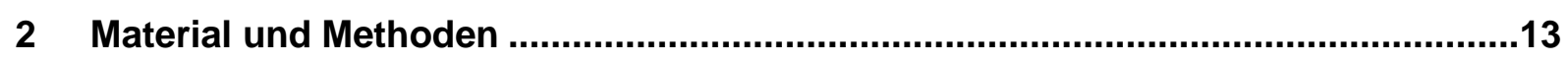

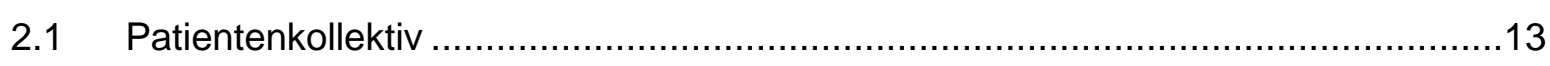

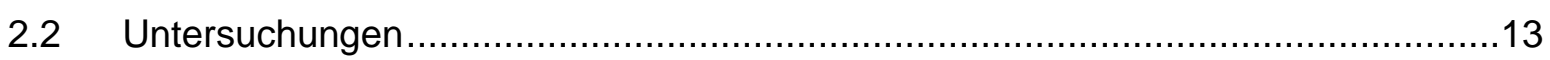

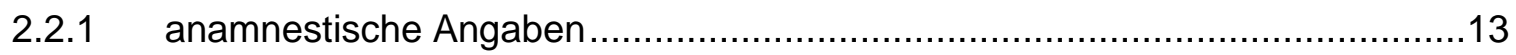

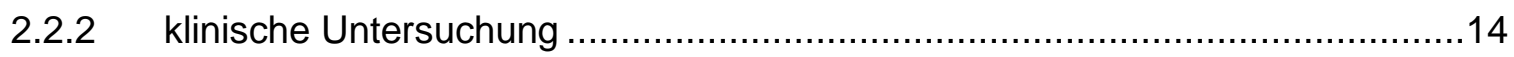

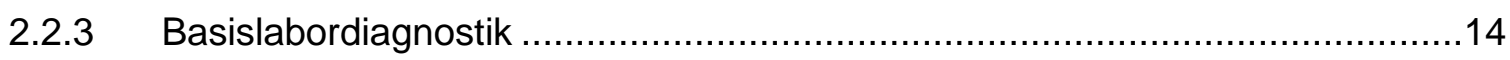

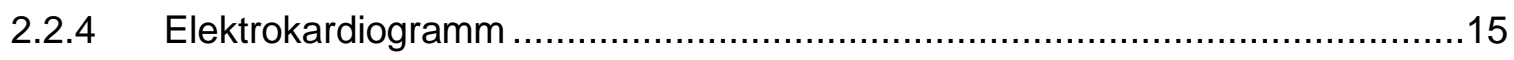

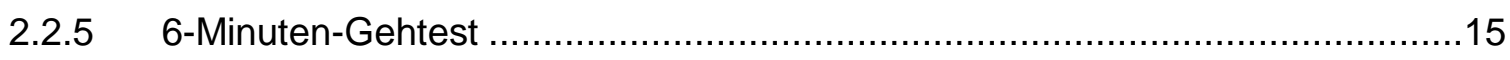

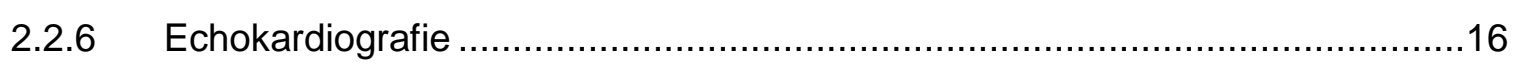

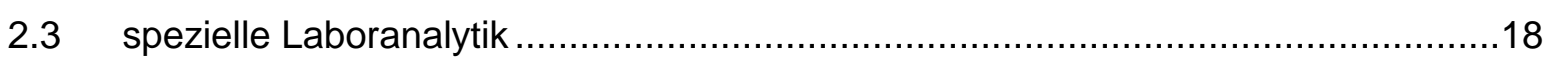

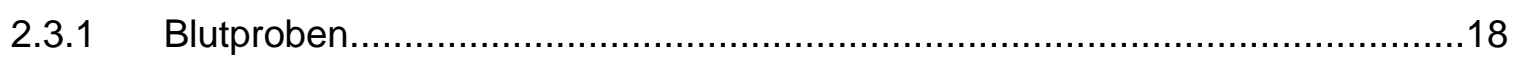

2.3.2 Bestimmung von BNP und NT-proBNP ..................................................18

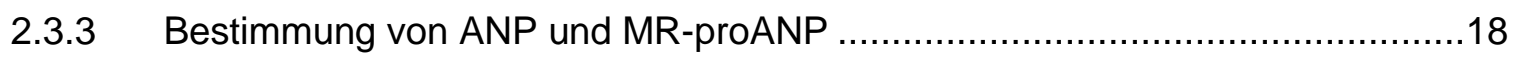

2.3.4 Bestimmung von Adrenomedullin und MR-proADM ....................................19

2.3.5 Bestimmung von Endothelin-1 und CT-proET-1 …..................................20

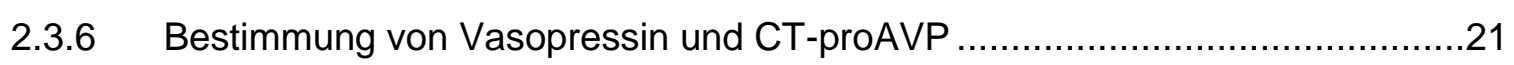

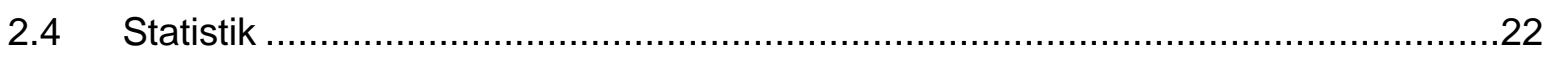

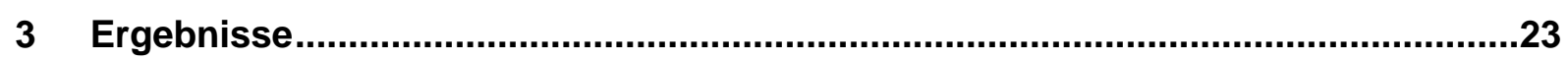

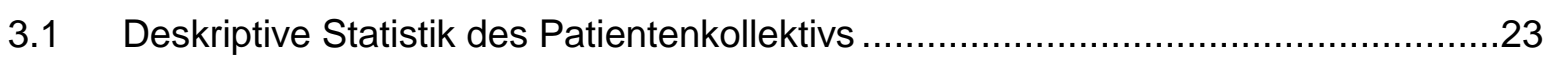

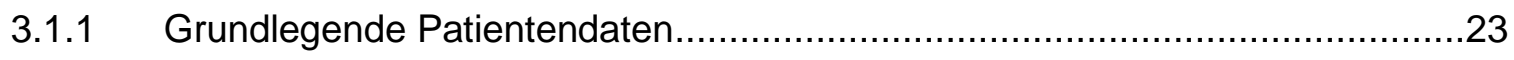

3.1.2 Risikofaktoren im Patientenkollektiv .........................................................23

3.1.3 Symptome der Herzinsuffizienz im Patientenkollektiv .....................................24 


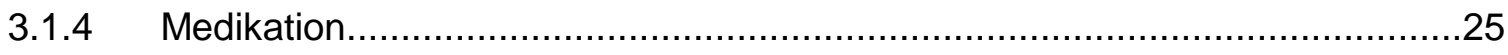

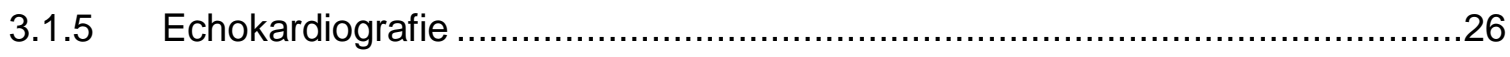

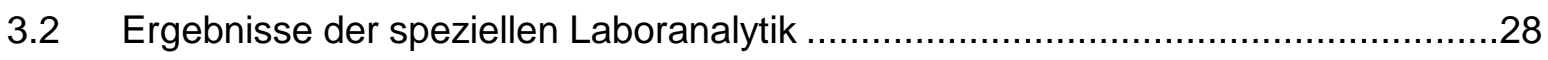

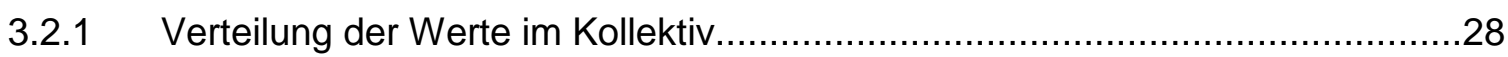

3.2.2 Regulation der Peptide in Abhängigkeit von diastolischer und systolischer Dysfunktion

3.2.3 Zusammenhang zwischen den speziellen Laborparametern und Parametern der linksventrikulären Geometrie, der diastolischen Funktion und der

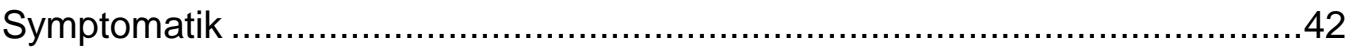

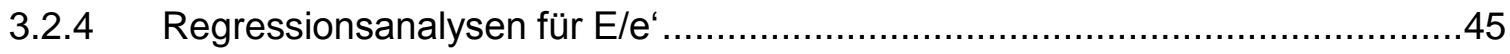

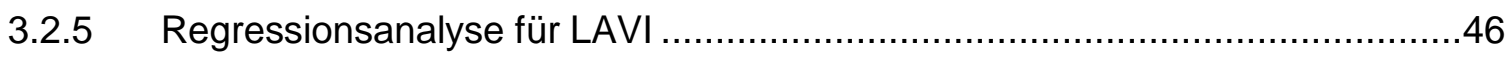

3.2.6 Regressionsanalyse für Symptome ......................................................47

3.2.7 Diskrimination von Anwesenheit und Abwesenheit einer ventrikulären Dysfunktion anhand der Laborparameter

3.2.7.1 Diskrimination zwischen Abwesenheit einer DD und Anwesenheit einer diastolischen Dysfunktion Grad I.

3.2.7.2 Diskrimination zwischen Vorliegen einer diastolischen Dysfunktion Grad I und II-III.

3.2.7.3 Diskrimination zwischen Abwesenheit einer diastolischen Dysfunktion und Vorliegen einer diastolischen Dysfunktion jeglichen Grades

3.2.7.4 Diskrimination zwischen eingeschränkter und nicht eingeschränkter linksventrikulärer Ejektionsfraktion ..................................................52

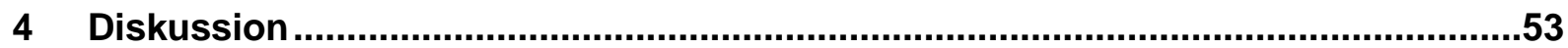

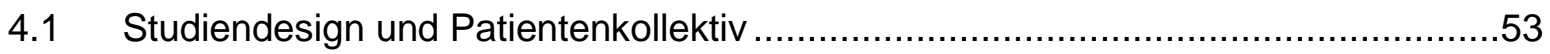

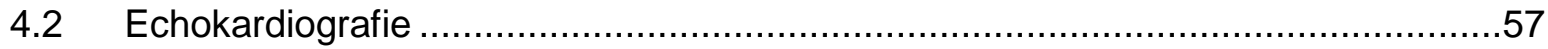

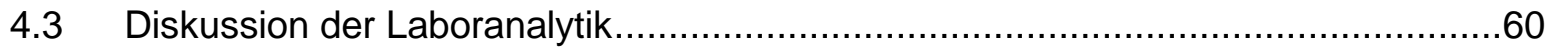

4.3.1 Erhöhung der Werte bei Vorliegen einer Dysfunktion und Stadienabhängigkeit .

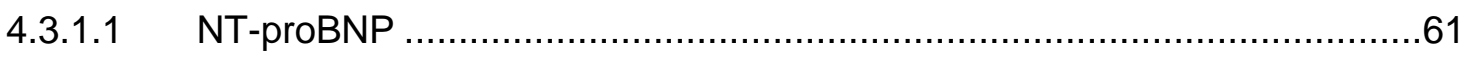

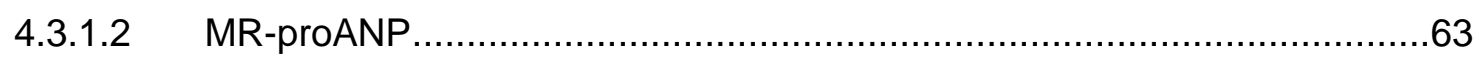

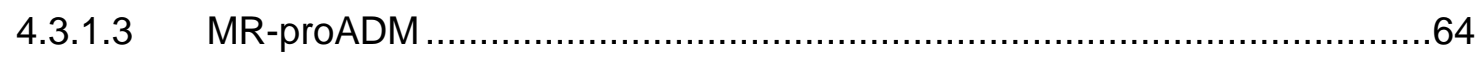

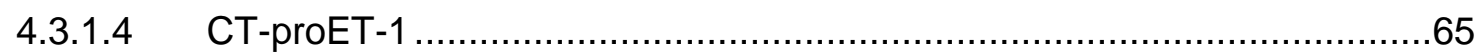

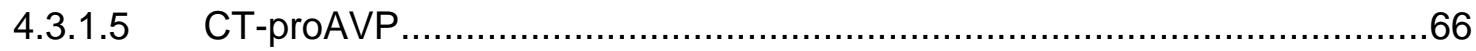

4.3.2 Erhöhung der Parameter in Gegenwart einer Symptomatik der Herzinsuffizienz

4.3.3 Korrelationen der Laborwerte mit echokardiografischen und klinischen Parametern

4.3.4 Fähigkeit zur Detektion einer kardialen Dysfunktion der einzelnen Parameter 70 


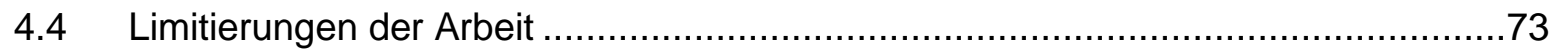

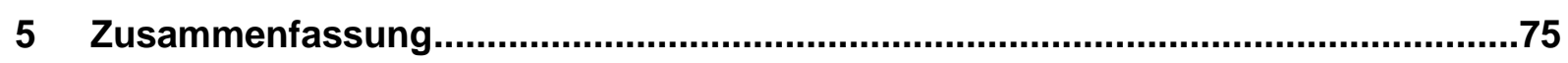

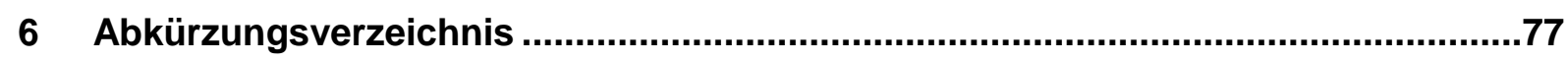

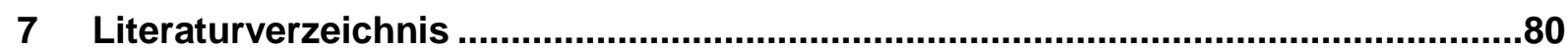




\section{Einleitung}

\subsection{Definition der diastolischen Dysfunktion}

Die diastolische Dysfunktion (DD) ist eine Störung der Dehnbarkeit des linken Ventrikels, die grundsätzlich auch unabhängig von Symptomen messbar ist. Hinweise auf eine DD können dabei sowohl mit invasiven, als auch mit nichtinvasiven Methoden erhoben werden. Bei symptomatischen Patienten gelten eine Erhöhung der Konstante der linksventrikulären Relaxation $(\mathrm{T})>48 \mathrm{~ms}$, des linksventrikulären enddiastolischen Druckes (LVEDP) auf $>16$ $\mathrm{mmHg}$ oder des mittleren pulmonalen Verschlussdruckes (mPCW) auf $>12 \mathrm{mmHg}$ als beweisend für das Vorliegen einer DD. Diese Parameter werden mittels invasiver Diagnostik bestimmt. Da dies nicht in jedem Falle möglich oder erwünscht ist, wird seit Jahren versucht, die Echokardiografie als nichtinvasive Alternative zu etablieren. Hier gibt es verschiedene Konzepte beziehungsweise Schemata, die miteinander konkurrieren, allerdings selten eine hämodynamische Validierung erfahren (Paulus et al. 2007).

Garcia et al. (1998) stellten eines der ersten Schemata zur nichtinvasiven Diagnose der DD auf. Sie beurteilen dabei zunächst das Verhältnis von frühdiastolischer (E) zu spätdiastolischer oder atrialer (A) Einstromgeschwindigkeit. Anhand des Quotienten dieser Paramter, des E/A-Verhältnisses, teilen sie die DD in verschiedene Schweregrade ein. Weiterhin ziehen sie zur Diagnosefindung und Einteilung unter anderem die Dezelerationszeit (DT), die isovolumetrische Relaxationszeit (IVRT) sowie das Verhältnis von systolischem zu diastolischem pulmonalvenösem Fluss (S/D) heran.

Neuere Konzepte beziehen zusätzlich den Gewebedoppler in die Diagnosefindung ein. Wegweisend ist hier die Bestimmung des Verhältnisses von E zur frühdiastolischen Mitralanulusgeschwindigkeit (e') sowie deren Quotient. Auch hier existieren verschiedene Grenzwerte und diagnostische Schemata, die untereinander nur bedingt vergleichbar sind.

Ein endgültiges diagnostisches Konzept, das den bisherigen überlegen ist, existiert also bisher nicht. Es sind weitere Studien erforderlich, um langfristig gültige Diagnoserichtlinien für die DD zu finden.

\subsection{Definition der diastolischen Herzinsuffizienz}

Der Begriff Herzinsuffizienz (HF) beschreibt ein klinisches Syndrom, bei dem ein Unvermögen des Herzens besteht, das für die Blutversorgung des Körpers nötige Herzzeitvolumen zu fördern. Die HF lässt sich, neben anderen Kriterien wie der Lokalisation oder der Unterteilung in akut und chronisch, in eine systolische und eine diastolische Form 
unterteilen. Bei der systolischen Herzinsuffizienz (SHF) kommt es primär zu einer Dilatation des Ventrikelvolumens und zu einer verminderten Kontraktilität. Daraus resultiert eine verminderte Ejektionsfraktion (LVEF).

Die chronische DHF dagegen ist ein klinisches Syndrom mit definierten Symptomen und Zeichen der Herzinsuffizienz auf dem Boden einer diastolischen Dysfunktion (DD) bei erhaltener LVEF. Sie wird klar von der isolierten DD abgegrenzt. Allerdings gibt es für die DHF mehrere verschiedene Definitionen. Die einfachste, die etwa in den epidemiologischen Studien von Vasan et al. (1995) angewendet wurde, betrachtet das Vorliegen von typischen Symptomen einer HF bei nicht reduzierter LVEF als DHF. Andere Arbeitsgruppen fordern in ihrer Definition zusätzlich zu diesen Kriterien das Vorliegen von beispielsweise echokardiografischen Zeichen einer DD. Bursi et al. (2006) etwa interpretieren das Vorliegen von $E / A<0,75$ und $E / e^{،}<10$ als milde $D D$ und ziehen zur Charakterisierung der Patienten mit anderen E/A-Verhältnissen zusätzlich die DT heran. Nach Paulus et al. (2007) schließlich müssen zur Stellung der Diagnose DHF drei Bedingungen erfüllt sein:

1. Symptome der HF: Dies kann subjektiv über eine Einordnung der Belastbarkeit in das Schema der New York Heart Association (NYHA) geschehen. Als objektive Kriterien gelten eine signifikante Einschränkung der maximalen Sauerstoffaufnahme $\left(\mathrm{VO}_{2 \max }\right)$ auf $<25 \mathrm{ml} / \mathrm{kg} / \mathrm{min}$ in der Spiroergometrie oder eine auf $<300 \mathrm{~m}$ verminderte Gehstrecke im 6-Minuten-Gehtest.

2. Uneingeschränkte systolische Funktion: Es ist der Nachweis einer normalen oder nur leichtgradig eingeschränkten systolischen Ventrikelkontraktilität in Form einer LVEF $>50 \%$ und eines linksventrikulären enddiastolischen Volumenindex (LVEDVI) $<97$ $\mathrm{ml} / \mathrm{m}^{2}$ erforderlich.

3. Nachweis der DD: Dazu wird die Erfassung einiger Parameter mittels des Gewebedopplers benötigt. Ein E/e'-Verhältnis von $>15$ wird als Beweis für eine DD angesehen, im Bereich von 8 bis 15 ist die Bestimmung zusätzlicher Werte erforderlich. Dazu zählen zum Beispiel die Kombination aus E/A <0,5 und DT >280 ms oder über einen bestimmten Grenzwert erhöhte Konzentrationen natriuretischer Peptide im Blut des Patienten. 
Die Diagnose chronische DHF benötigt also eine Bestimmung sowohl der systolischen als auch der diastolischen Parameter. Bestehen die Symptome bei Überwiegen oder alleinigem Vorliegen einer Störung der diastolischen Funktion, spricht man vom Syndrom der DHF. Die diastolische Dysfunktion kann also mit dem Syndrom HF vergesellschaftet sein, aber auch isoliert auftreten. Auch kann sowohl eine systolische, als auch eine diastolische Funktionsstörung zum gleichen Zeitpunkt bei einem Patienten vorhanden sein (Zile and Brutsaert 2002).

\subsection{Epidemiologie}

Die HF allgemein ist eine Erkrankung von hoher Prävalenz, wobei sich in der Literatur unterschiedliche Zahlen darüber finden, wie hoch der Anteil der Patienten mit erhaltener LVEF ist. Noch vor einigen Jahren ging man davon aus, dass diese gegenüber den Patienten mit reduzierter LVEF deutlich in der Unterzahl sind (Vasan et al. 1995). Nach neueren Studien zeigen allerdings über $50 \%$ der Patienten mit Zeichen und Symptomen der HF eine erhaltene LVEF (Owan et al. 2006). In dieser Arbeit zeigte sich auch, dass die Erkrankung eine stark altersabhängige Prävalenz besitzt. Dieses Phänomen ist im Kollektiv der HF allgemein im Rahmen der Framingham-Studie ebenfalls beschrieben. Zu deren Beginn fand sich bei 3 von 1000 Patienten eine HF. Im Verlauf des 34-jährigen Beobachtungszeitraumes stieg diese bis auf 91 von 1000 Fällen (McMurray and Stewart 2000).

Außerdem wird nach neueren Studien davon ausgegangen, dass die Überlebensrate von Patienten mit Symptomen der HF bei erhaltener LVEF mit der von Patienten mit SHF zumindest vergleichbar ist (Bhatia et al. 2006). Zu einem ähnlichen Ergebnis kamen Tribouilloy et al. (2008) in ihrer Studie zur Prognose der HF mit erhaltener LVEF. Sie ermittelten eine 1-Jahres-Überlebensrate von $78 \%$ und eine 5-Jahres-Überlebensrate von $43 \%$. Allerdings haben auf die Überlebensrate verschiedene Faktoren wie Alter, Geschlecht und Komorbidität Einfluss, was einen direkten Vergleich erschwert. Dennoch ist die Datenlage aufgrund der konkurrierenden Diagnoseschemata heterogen. Redfield et al. (2003) konnten auch für die isolierte DD eine deutlich erhöhte Mortalität nachweisen. Dennoch ist die Prognose hier eine bessere als im Falle der manifesten symptomatischen DHF. Wahrscheinlich aufgrund der höheren Mortalität ist die DD deshalb auch häufiger als die DHF.

Unklar ist die geschlechtsspezifische Prävalenz von DD und DHF. Häufig wird eine Bevorzugung des weiblichen Geschlechts berichtet, die Daten sind hier aber widersprüchlich. Während beispielsweise Klapholz et al. (2004) eher eine Häufung bei 
Frauen fanden, besagen die Untersuchungen von Fischer et al. (2003), dass diastolische Abnormalitäten eher Männer betreffen.

Zur Epidemiologie von DD und DHF sind also bereits einige Untersuchungen durchgeführt worden. Es zeichnet sich ab, dass es sich um Krankheiten mit hoher Prävalenz und niedriger Überlebensrate handelt und vor allem ältere Patienten betroffen sind. Da die Daten mit verschiedenen Methoden erhoben wurden und vor allem weil bei den Diagnosekriterien kein einheitliches und verbindliches System existiert, ist das Bild allerdings noch uneinheitlich.

\subsection{Pathophysiologie}

Als DD werden Relaxations-, Füllungs- und Dehnbarkeitsstörung des Ventrikels bezeichnet. Die kontrahierten Myofibrillen kehren nicht komplett oder zu langsam in ihre ursprüngliche Länge zurück. Dies beeinträchtigt die Füllung des linken Ventrikels in der Diastole, meist auf dem Boden einer konzentrischen linksventrikulären Hypertrophie (Katz and Zile 2006). Bei niedrigen linksatrialen Drücken nimmt der Ventrikel eine zu geringe Menge Blut auf. Die beschriebenen Relaxationsstörungen führen zu einer Verschiebung der enddiastolischen Druck-Volumen-Kurve nach links und oben. Bei einem bestimmten linksventrikulären Volumen wird also im Vergleich zur normalen linksventrikulären Funktion ein höherer Druck erreicht, was einem erhöhten enddiastolischen Druck entspricht.

Verschiedene Einflussfaktoren können zu dem beschriebenen pathophysiologischen Zustand führen. Diese können myokardialer oder extramyokardialer Genese sein (Zile and Brutsaert 2002). Myokardiale Ursachen sind beispielsweise eine vermehrte Expression der weniger dehnbaren Isoform des Zytoskelettproteins Titin, wie sie bei Patienten mit DHF nachgewiesen werden konnte (van Heerebeek et al. 2006), oder eine Veränderung in der Kalziumhämostase der Kardiomyozyten, die zu erhöhten Kalziumkonzentrationen während der Diastole führen (Zile and Brutsaert 2002). Veränderungen der extrazellulären Matrix werden ebenfalls zu den myokardialen Ursachen gerechnet. Beispielsweise konnten Veränderungen im Gleichgewicht zwischen den kollagenabbauenden Enzymen der Familie der Matrixmetalloproteinasen (MMP) und ihren Inhibitoren (TIMP) festgestellt werden. Durch erhöhte Expression von TIMP-1 kommt es zu einer vermehrten Hemmung der MMP, was zu einem verminderten Kollagenabbau führt. Dabei korreliert die Schwere der Erkrankung mit den Spiegeln der Enzyme im Blut der Patienten (Ahmed et al. 2006).

Auch hormonelle Dysregulation kann zu einer Verschlechterung der DD beitragen. Das Mineralokortikoidhormon Aldosteron spielt im Rahmen des Renin-Angiotensin-AldosteronSystems (RAAS) eine wesentliche Rolle bei der Regulation des Salz- und Wasserhaushaltes 
sowie des Blutdruckes. Eine ständige Überaktivierung dieses Systems führt aldosteronvermittelt zu einer Steigerung der Kollageneinlagerung am Herzen und damit zu einer erhöhten Steifigkeit und folglich Relaxationsstörung des Herzens (Schunkert et al. 1997). Die Einlagerung des Kollagens beginnt zunächst in der Adventitia der intramyokardialen Arterien, schreitet dann aber im Verlauf auch in die interzellulären Räume zwischen den Myozyten fort (Jalil et al. 1989). Bereits früh wurde nachgewiesen, dass auch Angiotensin II, ein weiteres Hormon aus dem RAAS, am Myokard eine Hypertrophie bewirkt (Dempsey et al. 1971). Somit kann es ähnlich wie Aldosteron zur Entwicklung einer DD beitragen, da die Effekte der beiden Hormone bezüglich linksventrikulärer Umbauprozesse synergistisch sind und Angiotensin II einen wesentlichen Stimulus der Freisetzung von Aldosteron aus der Nebennierenrinde darstellt.

\section{5 Ätiologie}

Es sind einige mit der Entwicklung einer DD assoziierte Risikofaktoren beschrieben, von denen auch jeweils das Quotenverhältnis bezüglich der Entwicklung einer DD bestimmt wurde. Meist handelt es sich dabei um etablierte kardiovaskuläre Risikofaktoren. Im Einzelnen handelt es sich um eine linksventrikuläre Hypertrophie (Quotenverhältnis 7,6), die Anamnese eines Myokardinfarktes (4,3), die arterielle Hypertonie $(2,8)$, Diabetes $(2,3)$ sowie Übergewicht (1,6) (Fischer et al. 2003). Bei gesunden älteren Menschen mit einem inaktiven Lebensstil konnte eine im Vergleich zu jüngeren inaktiven Kontrollprobanden erniedrigte Dehnbarkeit des Ventrikels festgestellt werden. Außerdem konnte kein Unterschied in der Druck-Volumen-Kurve zwischen älteren und sportlich sehr aktiven Menschen im Vergleich zu jungen und inaktiven Probanden festgestellt werden. Daraus lässt sich schließen, dass Ausdauertraining die Dehnbarkeit des Ventrikels auch im Alter erhält und der Entwicklung einer HF entgegenwirken kann (Arbab-Zadeh et al. 2004).

Ein weiterer Risikofaktor, der mit der Entwicklung einer DD, aber auch der SHF und anderen kardiovaskulären Erkrankungen wie der arteriellen Hypertonie in Verbindung gebracht wird, ist das obstruktive Schlafapnoesyndrom (OSAS) (Naughton 2003). Im Falle der SHF fand sich unter Therapie des OSAS mit einem Beatmungsgerät auch eine signifikante Verbesserung der LVEF, des linksventrikulären Kammerdurchmessers und eine Senkung des Blutdruckes (Kaneko et al. 2003). In ihrer Studie zur Koinzidenz von DD und OSAS kamen Arias et al. (2005) zu dem Schluss, dass dieses einen unabhängigen Risikofaktor zur Entwicklung einer DD darstellt und eine Therapie mittels eines Beatmungsgerätes mit nasalem kontinuierlichem positivem Atemwegsdruck (nCPAP) die Progression der Erkrankung aufhalten kann. Darüber hinaus stellen sie die Hypothese auf, dass es 
zumindest im Anfangsstadium unter dieser Therapie sogar zu einer Rückbildung dieser Strukturveränderungen kommen könnte.

\subsection{Stellenwert der neurohumoralen Regulation bei Patienten mit diastolischer Dysfunktion und diastolischer Herzinsuffizienz}

Der Stellenwert der neurohumoralen Aktivierung in der DD und DHF ist bisher nur teilweise untersucht worden. Die natriuretischen Peptide haben neben ihrem Nutzen in der Diagnostik, Prognoseabschätzung und Therapiekontrolle der SHF auch in der DHF teilweise ähnliche Bedeutung erlangen können. Die Rolle der vasokonstriktorisch wirkenden Hormone Endothelin-1, Vasopressin und des vasodilatatorisch wirkenden Adrenomedullin in der Entwicklung von DD und DHF ist dagegen noch nicht hinreichend erforscht. Auch hier liegen bezüglich der SHF bereits einige Daten vor.

\subsubsection{BNP und NT-proBNP}

BNP wurde erstmals im Jahre 1988 in Schweinegehirnen entdeckt, daher wird es auch brain natriuretic peptide genannt (Sudoh et al. 1988). Es wird allerdings auch in menschlichen Myozyten des Ventrikels synthetisiert. Die humane Form besteht aus 32 Aminosäuren.

Aus dem aus 134 Aminosäuren bestehenden präproBNP entsteht durch Spaltung proBNP, das wiederum in das biologisch aktive C-terminale Fragment BNP und das inaktive $\mathrm{N}$ terminale Fragment, genannt NT-proBNP, zerlegt wird. Letzteres hat eine wesentlich längere Halbwertszeit und wird daher auch zur Quantifizierung im Blut dem BNP selbst vorgezogen. Die Freisetzung wird ähnlich wie im Falle von ANP durch Wanddehnung gefördert. Auch die Wirkung ist analog der des ANP (Piechota et al. 2008).

BNP und NT-proBNP sind für die SHF etablierte nichtinvasive Marker und werden bereits zur Diagnosefindung, Prognoseabschätzung, Verlaufs- und Therapiekontrolle herangezogen. Auch für die DD und DHF ist der Nutzen dieser Parameter im Vergleich zu den vorgenannten besser untersucht. Allerdings können nichtkardiale Ursachen der Dyspnoe, die nicht mit einer Erhöhung von BNP oder NT-proBNP einhergehen, besser von kardialen Ursachen differenziert werden.

Im Gegensatz zu den bisher besprochenen Hormonen gibt es im Falle von NT-proBNP bereits Untersuchungen zur DD. Tschöpe et al. (2005) etwa untersuchten symptomatische Patienten mit DD bezüglich ihrer NT-proBNP-Werte. Hierbei zeigte sich, dass die Werte im Vergleich zu Kontrollpatienten mit normaler diastolischer Funktion nicht nur erhöht waren, 
sondern auch mit der Schwere der Erkrankung korrelierten. Bei Patienten mit höherer NYHAKlasse fanden sich also auch höhere Werte. Bei einem Schwellenwert von $110 \mathrm{pg} / \mathrm{ml}$ zeigte NT-proBNP im Vergleich zu beispielsweise dem E/A-Verhältnis oder dem LVEDP den höchsten negativen prädiktiven Wert und eine insgesamt hohe Sensitivität und Spezifität. Allerdings ist eine Unterscheidung zwischen SHF und DHF allein anhand von NT-proBNP nicht möglich. Bezüglich der Sensitivität und Spezifität kamen Lubien et al. (2002) bei einem Schwellenwert vom $62 \mathrm{ng} / \mathrm{ml}$ für BNP zu einem ähnlichen Ergebnis. Allerdings wurde hier das Vorliegen einer DD lediglich durch verändertes E/A-Verhältnis definiert.

BNP und NT-proBNP sind also bereits teilweise mit morphologischen Kriterien und diagnostischen Parametern der DD und der DHF in Verbindung gebracht worden. Allerdings ist auch hier der Stellenwert für die Progression der Erkrankungen weitgehend unerforscht.

\subsubsection{ANP und MR-proANP}

Das aus 28 Aminosäuren bestehende atriale natriuretische Peptid (ANP) wurde erstmals 1981 entdeckt (de Bold et al. 1981). Es wird vor allem im linken Vorhof synthetisiert und auf einen Dehnungsreiz hin ausgeschüttet. An der Niere bewirkt es, ähnlich wie BNP, vor allem eine Diurese und Natriurese sowie im Gegensatz zu Endothelin-1 (ET-1) und Vasopressin eine Vasodilatation. Am Herzen erfolgt eine Senkung der Vorlast und der Nachlast. Weiterhin erfolgt unter Einfluss von natriuretischen Peptiden eine Verminderung der Hormonfreisetzung aus der Nebennierenrinde, etwa von Aldosteron. Zwischen den natriuretischen Peptiden und Endothelin-1 (ET-1) besteht eine Wechselwirkung. So hemmen ANP und BNP die Produktion von ET-1, während dieses die Synthese von natriuretischen Peptiden stimuliert (Emori et al. 1993).

Ähnlich den anderen in dieser Arbeit besprochenen Hormonen entsteht auch in der Synthese von ANP ein Spaltprodukt, dessen Konzentration Rückschlüsse auf die des ANP erlaubt. Zunächst wird ein biologisch inaktives Propeptid synthetisiert, das aus 126 Aminosäuren bestehende proANP. Durch eine Endoprotease wird das biologisch aktive C-terminale Fragment abgespalten (Piechota et al. 2008). Der N-terminale Teil des ANP, genannt NTproANP, besitzt eine wesentlich längere Halbwertszeit als ANP und wurde deshalb als verlässlicherer Marker als ANP selbst vorgeschlagen (Buckley et al. 1999).

ANP war im Vergleich zu BNP relativ selten Gegenstand klinischer Studien zur SHF, zeigte in diesen Fällen mit BNP tendenziell vergleichbare Ergebnisse, die aber weniger deutlich ausfielen. Beispielsweise ist für ANP eine Korrelation mit dem Vorhandensein eines idiopathischen arteriellen Hypertonus beschrieben. Auf dem Boden einer zusätzlichen konzentrischen Hypertrophie fand sich eine weitere Steigerung der Werte gegenüber den 
Kontrollen (Irzmański et al. 2007). Somit könnten erhöhte Werte von ANP auf das Vorhandensein einer linksventrikulären Hypertrophie hinweisen, die häufig mit einer DD assoziiert ist (Fischer et al. 2003).

Das ANP kann ebenfalls als diagnostisches und prognostisches Mittel sowohl der Dysfunktion als auch der manifesten HF dienen. In einer Studie von Lerman et al. (1993) zeigte das Fragment NT-proANP eine Sensitivität von 90\% und eine Spezifität von 92\% bezüglich der Erkennung einer symptomlosen linksventrikulären Dysfunktion, die mit Radionuklidangiografie nachgewiesen worden war. Bei manifester HF konnten bereits früh erhöhte Werte dieses Markers gemessen werden, die mit der Schwere der Erkrankung korrelierten (Burnett et al. 1986). Eine neuere Studie untersuchte, neben BNP, die Werte für ANP bei hypertensiven Patienten mit LVEF $\leq 40 \%$ der NYHA-Klasse III-IV und dilatativer Kardiomyopathie. Im Vergleich zu gesunden Kontrollpatienten waren die Werte für ANP signifikant erhöht und korrelierten negativ mit der LVEF. Unter Therapie mit dem Angiotensinrezeptorblocker Irbesartan kam es nach 6 Monaten zu einer Reduktion der ANPKonzentration und zu einer Verbesserung der NYHA-Klasse und der LVEF. Damit kommt ANP und BNP eine Bedeutung als Therapiekontrolle dieser Patienten zu (Falcão et al. 2004). Aufgrund des berichteten Wertes des ANP für die SHF und der Korrelation mit der linksventrikulären Hypertrophie liegt es also nahe, dass das ANP auch bei Diagnosefindung und Prognoseabschätzung der DD und DHF einen Stellenwert besitzt.

\subsubsection{Adrenomedullin und MR-proADM}

Das Peptid Adrenomedullin (ADM) besteht aus 52 Aminosäuren und hat eine starke vasodilatatorische und hypotensive Wirkung und wurde erstmals im menschlichen Phäochromozytom entdeckt (Kitamura et al. 1993). Es findet sich im menschlichen Körper im Mark der Nebenniere, dem Vorhof und der Lunge (Ichiki et al. 1994). Dabei gilt das Endothel der Gefäße als Hauptort von Synthese und Sekretion (Sugo et al. 1994).

Neben anderen Erkrankungen wie der Sepsis finden sich erhöhte Werte für Adrenomedullin auch bei HF. So fanden etwa Kobayashi et al. (1996) bei 49 Patienten mit HF erhöhte Werte im Vergleich zu gesunden Kontrollprobanden. Mit steigender NYHA-Klasse traten dabei signifikant höhere Werte auf. Bei Patienten mit koronarer Herzkrankheit zeigten Elmas et al. (2007) eine negative Korrelation zwischen den Spiegeln des mittregionalen proAdrenomedullin (MR-proADM) und der LVEF. Unklar ist der prognostische Wert.

Auch mit der DD wurde Adrenomedullin bereits in Verbindung gebracht (Yu et al. (2001). Diese Arbeitsgruppe untersuchte ein Kollektiv mit insgesamt 77 Patienten mit HF, wovon 31 Patienten eine isolierte DD mit LVEF $>50 \%$ und 46 mit LVEF $<50 \%$ aufwiesen. Dabei zeigte 
sich, dass die Werte für Adrenomedullin bei isolierter DD gegenüber Kontrollprobanden signifikant erhöht waren. Bei Vorliegen einer Kombination aus restriktivem Füllungsmuster und LVEF $<50 \%$ waren die Werte nochmals erhöht. Das E/A-Verhältnis zeigte eine positive Korrelation mit der Konzentration des Adrenomedullin. Eine Korrelation zwischen LVEF oder NYHA-Klasse und den Adrenomedullinspiegeln war in dieser Studie nicht nachweisbar.

Trotz dieser Erkenntnisse ist die Bedeutung des Adrenomedullins für das Auftreten und die Prognose der DD und der DHF bisher kaum untersucht und soll im Rahmen dieser Arbeit betrachtet werden..

\subsubsection{Endothelin-1 und CT-proET-1}

Bei den Endothelinen (ET) handelt es sich um vasoaktive Polypeptide. Bisher wird von Endothelin-1, -2 und -3 berichtet, wobei das aus 21 Aminosäuren bestehende ET-1 als die biologisch aktivste Form angesehen wird (Inoue et al. 1989). Ursprünglich wurde es aus aortalen Endothelzellen von Schweinen isoliert, stellt einen der potentesten Vasokonstriktoren dar und führt zu Hypertension (Yanagisawa et al. 1988). Es besitzt nur eine kurze Halbwertszeit von 1-2 Minuten (Weitzberg et al. 1991). Der Effekt am Zielort ist allerdings von wesentlich längerer Dauer, da die Bindung des ET-1 an den Rezeptor fast irreversibel ist. Seinen Effekt bewirkt Endothelin vor allem in der Umgebung seines Syntheseortes im Endothel. Außerdem handelt es sich um ein Hormon, das nur wenig oder gar nicht im Kreislauf zirkuliert. Der Hauptbildungsort ist das Endothel der Gefäße selbst, ET1 wird aber auch in anderen Geweben wie dem Herzen, der Leber oder Astrozyten sezerniert (Shah 2007).

ET-1 entsteht aus einem größeren Propeptid, präproET-1, aus dem zunächst durch proteolytische Aktivität das biologisch inaktive bigET-1 gebildet wird. Durch das EndothelinKonversionsenzym entsteht schließlich aus bigET-1 das ET-1 (Xu et al. 1994). Seine Wirkung besteht in einer starken Vasokonstriktion sowohl in den Arterien als auch in den Venen. Dies geschieht auf autokrinem oder parakrinem Wege bei Bindung an den $\mathrm{ET}_{\mathrm{A}^{-}}$ Rezeptor der glatten Gefäßmuskelzellen, wodurch es zu einer Erhöhung des intrazellulären Kalziumspiegels kommt (Yanagisawa et al. 1988). Des Weiteren findet sich an Endothelzellen ein $\mathrm{ET}_{\mathrm{B}}$-Rezeptor, über den, sobald Endothelin bindet, eine Vasodilatation erfolgt, die unter anderem durch Stickstoffmonoxid vermittelt wird. Außerdem erfolgt eine positive Rückkopplung auf die Synthese von Endothelin. Allerdings überwiegt der über den $E T_{A}$-Rezeptor vermittelte vasokonstriktive Effekt (Iglarz and Schiffrin 2003). In experimentellen Studien wurde außerdem ein ET $_{C^{-}}$-Rezeptor beschrieben, der ET-3 mit einer 
höheren Affinität bindet als ET-1 oder ET-2 (Masaki et al. 1994). Bisher ist das Klonen dieses Rezeptors lediglich in Amphibien gelungen, nicht aber in Säugetieren (Masaki 2004).

In einigen klinischen Studien konnte gezeigt werden, dass die ET-1-Spiegel im Blut der Patienten zur Abschätzung der Stadien einer SHF sowie deren Mortalität und Prognose geeignet sind. Schon früh konnten McMurray et al. (1992) zeigen, dass bei Patienten mit SHF im Vergleich zu gesunden Menschen gleichen Alters und Geschlechts erhöhte Werte von ET-1 gemessen werden können. Es fand sich etwa eine Verdoppelung der Werte, die von vorhergehender körperlicher Aktivität unabhängig war. Dabei blieb allerdings unklar, ob die erhöhten Werte durch eine gesteigerte Synthese oder eine verminderte Eliminierung entstanden sind.

Auch zur Abschätzung der Morbidität der SHF hat sich ET-1 als nützlich erwiesen. So kamen Van Beneden et al. (2004) zu dem Schluss, dass ET-1 ein sehr guter unabhängiger Prädiktor des Überlebens von Patienten mit chronischer HF mit reduzierter LVEF und NYHA-Klasse III-IV ist, sogar besser als die natriuretischen Peptide oder deren Propeptide. In einer weiteren Studie zeigte sich, dass bigET-1 einen unabhängigen Marker der Mortalität und Morbidität darstellt und außerdem mit der NYHA-Klasse und dem Körpermasseindex (BMI) positiv korreliert (Masson et al. 2006). Zu einem ähnlichen Schluss kamen Khan et al. (2007) in einer Studie, in der sie die Plasmakonzentrationen des C-terminalen Fragments von proET-1 (CT-proET-1) und NT-proBNP von Patienten nach einem Myokardinfarkt untersuchten. Dabei stellten beide Werte unabhängige Prädiktoren der Mortalität und der Entwicklung einer HF dar.

Auch für klinische Parameter sind teilweise bereits Korrelationen mit ET-1 beschrieben. Maeda et al. (2006) etwa fanden eine signifikante Reduktion der Werte für ET-1 nach einer niedrigkalorischen Diät übergewichtiger Patienten. Auch eine positive Korrelation zumindest des systolischen Blutdruckes und des linksventrikulären systolischen Druckes mit BigET-1 ist in der Literatur beschrieben (Bergler-Klein et al. 2006). Adipositas und Hypertonie stellen auch für DHF Risikofaktoren dar und sind möglicherweise mit ET-1 assoziiert.

Somit kann abschließend bemerkt werden, dass der Stellenwert einer Erhöhung von ET-1 im Rahmen der DD und DHF bisher ungeklärt ist. Auf Grund der beschriebenen Assoziationen von ET-1 und SHF beziehungsweise klinischen Parametern liegt es allerdings nahe, dass ET-1 sich auch in Diagnostik und Verlaufskontrolle der DD und DHF als nützlich erweisen könnte. 


\subsubsection{Vasopressin und CT-proAVP}

Bei Vasopressin, auch antidiuretisches Hormon (ADH) genannt, handelt es sich um ein Peptidhormon, das im Hypothalamus synthetisiert und in der Hypophyse gespeichert wird. Während es an der Niere eine Wasserretention bewirkt, hat es an den peripheren Gefäßen einen vasokonstriktorischen und damit blutdrucksteigernden Effekt (Singh Ranger 2002). Des Weiteren bewirkt es an der Muskulatur des Herzens eine Hypertrophie (Tahara et al. 1998). Die Freisetzung wird durch Abfall des Blutvolumens und erhöhte Osmolalität getriggert. Aber auch ET-1 wirkt als Stimulus für die Freisetzung (Yamamoto et al. 1992).

Vasopressin geht aus einem Propeptid hervor, dem präproVasopressin. Dies geschieht zusammen mit zwei anderen Peptiden, dem Neurophysin II und dem Copeptin, dem 39 Aminosäuren umfassenden C-terminalen Teil des Vorläuferhormons. Dieses Fragment wird auch CT-proAVP genannt. Die Sekretion erfolgt im äquimolaren Verhältnis zu Vasopressin selbst. Die genaue Funktion dieses Peptids ist unklar (de Bree and Burbach 1998). Auch bei Vasopressin findet sich das Problem der Instabilität und der schnellen Eliminierung, was die exakte Messung der Konzentration im Blut erschwert. Außerdem sind bis zu 90\% des Vasopressins im Plasma an Thrombozyten gebunden (Preibisz et al. 1983).

Ähnlich wie im Falle von ET-1 ist für Vasopressin bezüglich der SHF eine Relevanz für Diagnosestellung und eine positive Korrelation mit der Mortalität eindeutig belegt. Inwieweit diese Ergebnisse auch auf die DHF übertragen werden können, ist bisher unklar. In einem Kollektiv von Patienten mit LVEF $\leq 35 \%$ beispielsweise zeigten Francis et al. (1990), dass Patienten mit systolischer Funktionsstörung signifikant höhere Werte für Vasopressin aufwiesen als Kontrollpatienten mit normaler linksventrikulärer Funktion. Sobald Symptome einer HF hinzutraten, waren nochmals höhere Werte feststellbar. In einer anderen Studie (Gegenhuber et al. 2007) fand ein Vergleich zwischen NT-proBNP und CT-proAVP bezogen auf die prognostische Relevanz in der akut dekompensierten HF statt. Das Ergebnis bezüglich ihres prognostischen Wertes der 1-Jahres-Mortalität war zumindest eine Vergleichbarkeit dieser Marker. Bei Stoiser et al. (2006) zeigte sich, dass CT-proAVP dem NT-proBNP bezüglich des Wertes als Prädiktor des Todes überlegen war. Diese Studie untersuchte 268 Patienten mit fortgeschrittener HF der NYHA-Klassen III-IV.

Die Rolle von Vasopressin für das Auftreten und die Progression von DD und DHF ist bisher nur unzureichend untersucht worden. Aufgrund des vasokonstriktorischen Effektes und der beschriebenen prognostischen und diagnostischen Relevanz in der SHF kommt Vasopressin aber ebenfalls als serologischer Marker der DHF in Frage. 


\subsection{Fragestellung}

Auf Grund des Fehlens eines einheitlichen Diagnoseschemas für die Echokardiografie und der Tatsache, dass invasive Maßnahmen nicht immer durchführbar sind, ist es wünschenswert, einen einfachen, nichtinvasiven und verlässlichen Test für die DD und DHF zu finden. Bisher ist wenig über verlässliche Marker der diastolischen Dysfunktion und Herzinsuffizienz im Blut bekannt. Das Ziel dieser Arbeit ist deshalb die Untersuchung solcher Parameter auf Korrelationen mit echokardiographischen Werten der diastolischen Funktionsstörung. Ferner sollen die Marker in ihrem Wert für die frühzeitige Diagnose einer noch asymptomatischen Dysfunktion evaluiert werden. Dazu sollen die Spaltprodukte des ANP und BNP sowie des Adrenomedullins als vasodilatativ wirkende Stoffe sowie die Spaltprodukte von Vasopressin und ET-1 als vasokonstriktiv wirkende Stoffe untersucht werden. 


\section{Material und Methoden}

\subsection{Patientenkollektiv}

Das Kollektiv umfasst Patienten der Studie „Prävalenz und Verlauf der diastolischen Dysfunktion und der diastolischen Herzinsuffizienz" (Diast-CHF) an der Universitätsmedizin Göttingen. Diese Studie wird im Rahmen des Teilprojektes 7 (TP7) Diastolische Dysfunktion des Kompetenznetzes Herzinsuffizienz (KNHI) durchgeführt (http://www.knhi.de). Diese epidemiologische Untersuchung ist als prospektive und multizentrische Kohortenstudie angelegt. Neben Göttingen sind Lübeck, Würzburg und Berlin weitere Studienzentren. Die Rekrutierungszeit erstreckte sich vom 05.07.2004 bis zum 22.12.2006.

Als Studienpatienten kamen Männer und Frauen zwischen 50 und 85 Jahren in Betracht. Alle Patienten gaben nach Aufklärung durch den Arzt ihr schriftliches Einverständnis zur Teilnahme an der Studie. Ein positives Votum der Ethikkommission der Medizinischen Fakultät der Universität Göttingen liegt vor. Einschlusskriterium für die Studie war die Tatsache, dass mindestens ein Risikofaktor für das Auftreten einer diastolischen Funktionsstörung vorlag oder bereits die ärztlich gestellte Diagnose HF bestand. Als Risikofaktoren waren eine arterielle Hypertonie, ein Diabetes mellitus, ein Schlafapnoesyndrom sowie Zeichen der Arteriosklerose definiert. Dazu zählten eine angiografisch nachgewiesene koronare Herzkrankheit (KHK) oder ein stattgefundener Myokardinfarkt, eine symptomatische periphere arterielle Verschlusskrankheit (pAVK), eine Karotisstenose oder ein Apoplex in der Krankengeschichte. Die Rekrutierung der Patienten erfolgte über Praxisdaten von Hausärzten beziehungsweise den Basisdatensatz der Abteilung Allgemeinmedizin anhand der erwähnten Risikofaktoren. Dazu wurde eine Suche nach dem entsprechenden ICD-Schlüssel oder im Freitext durchgeführt.

\subsection{Untersuchungen}

\subsection{1 anamnestische Angaben}

Von jedem Patienten wurde eine ausführliche Anamnese erhoben. Diese umfasste sowohl die Krankengeschichte als auch die aktuelle Symptomatik. Anschließend wurden eine Familien- und Sozialanamnese sowie die Lebensqualität des Patienten anhand eines standardisierten Fragebogens in Erfahrung gebracht. Außerdem wurde der Patient bezüglich der Anzahl der Kontakte zum Hausarzt und Kardiologen sowie der Zahl der Aufenthalte in Krankenhäusern und Rehabilitationseinrichtungen zur Behandlung einer HF befragt. Kardiovaskuläre Risikofaktoren wurden erfasst, namentlich Diabetes mellitus, arterielle Hypertonie, Hyperlipidämie, Hyperurikämie, familiärer Myokardinfarkt vor dem 60 . 
Lebensjahr, Raucherstatus sowie Alkoholkonsum. Die Krankengeschichte umfasste Fragen zum jetzigen oder vergangenen Vorhandensein einer koronaren Herzerkrankung, eines Myokardinfarkts, primärer Herzklappenerkrankungen, angeborener oder erworbener Herzfehler sowie Kardiomypathien und ihrer Ätiologie. Weiterhin wurden entsprechende kardiovaskuläre Therapiemaßnahmen erfasst, also koronare Revaskularisation, BypassOperationen, Herzklappen-Operationen, Schrittmacher- und Defibrillatorimplantation, Herztransplantation oder Reanimationsmaßnahmen. Der Patient wurde außerdem gebeten, über eventuelle Nebendiagnosen Auskunft zu geben. Im Detail waren es pAVK inklusive des klinischen Stadiums, zerebrovaskuläre Erkrankungen wie transistorische ischämische Attacke (TIA) oder Apoplex, chronisch obstruktive Lungenerkrankungen, primäre pulmonale Hypertonie, Infektionen wie das humane Immundefizienz-Virus (HIV) sowie Hepatitis B oder C, Depression, Leberzirrhose und maligne Erkrankungen. Bei Frauen wurde zusätzlich eine orientierende gynäkologische Anamnese erhoben, die Fragen zum Zeitpunkt der Menarche und Menopause, der Anzahl der Schwangerschaften und Lebendgeburten, Zyklusregelmäßigkeit und schließlich bisherigen gynäkologischen Operationen beinhaltete. Die aktuelle Medikation wurde mit dem Wirkstoffnamen und der Dosis in mg pro Tag erfasst.

\subsection{2 klinische Untersuchung}

Es folgte eine klinische Untersuchung, welche die Bestimmung von Körpergröße, Gewicht, Körperoberfläche nach Mosteller (1987), Blutdruck, die Frage nach Nykturie sowie eine orientierende abdominale Untersuchung mit Prüfung auf Aszites oder Hepatomegalie umfasste. Außerdem beurteilte der Untersucher das etwaige Vorliegen einer symptomatischen HF anhand der Major- und Minor-Kriterien der Framingham-Definition (Ho et al. 1993). Zu den Major-Kriterien gehören paroxysmale nächtliche Dyspnoe, Halsvenenstauung, pulmonale Rasselgeräusche, der radiologische Nachweis einer Kardiomegalie, ein akutes Lungenödem, ein dritter Herzton und hepatojugulärer Reflux. Als Minor-Kriterien sind beidseitige Knöchelödeme, nächtlicher Husten, Luftnot bei normaler Belastung, Hepatomegalie, ein Pleuraerguss sowie eine Tachykardie > 120 Schläge/min definiert. Die Voraussetzung für die Diagnose einer HF ist das Vorliegen von mindestens einem Major-Kriterium oder zwei Minor-Kriterien.

\subsubsection{Basislabordiagnostik}

Neben den erwähnten speziellen Analysen zu den neurohumoralen Laborparametern wurde von jedem Patienten ein Basislabor bestimmt. Dazu gehörten Hämoglobin, Erythrozyten-, Leukozyten- und Thrombozytenzahl sowie die Gerinnungsparameter Fibrinogen, Quick-Wert 
und International Normalized Ratio (INR). Weiterhin wurden Serumkreatinin, Harnsäure und Harnstoff, Albumin, Natrium und Kalium, das Cholesterin mit seinen Unterformen sowie die Leberwerte Aspartataminotransferase (AST), Alaninaminotransferase (ALT), und Gammaglutamyltransferase ( $\mathrm{Y}-\mathrm{GT}$ ) erfasst. Andere Parameter waren Kreatinkinase (CK) und die Unterform Kreatinkinase Muscle-Brain (CK-MB), die Troponine, sowie das C-reaktive Protein (CRP) als Entzündungswert, das Glykohämoglobin $\left(\mathrm{HbA}_{1 \mathrm{c}}\right)$ und das basale Thyroidea-stimulierende Hormon (TSH). Die glomeruläre Filtrationsrate (GFR) wurde nach der vereinfachten Formel der MDRD-Studie von Levey et al. (2000) berechnet: GFR $\left(\mathrm{ml} / \mathrm{min} / 1,73 \mathrm{~m}^{2}\right)=186 \times$ Serum-Kreatinin $^{-1,154} \times$ Alter $^{-0,203}[\mathrm{x} 0,742$ nur bei Frauen $][x 1,21$ bei Patienten mit schwarzer Hautfarbe].

\subsubsection{Elektrokardiogramm}

Bei jedem Patienten wurde über bipolare Extremitätenableitungen ein Elektrokardiogramm (EKG) nach Einthoven abgeleitet. Die drei Elektroden wurden proximal der Handgelenke und oberhalb des linken Knöchels angelegt. Zusätzlich wurden die unipolaren Extremitätenableitungen nach Goldberger erfasst, die genau in der Mitte zwischen den Einthoven-Ableitungen liegen. Aufgezeichnet wurden aVR, aVL und aVF. Schließlich waren noch die unipolaren präkordialen Ableitungen nach Wilson anzulegen, bezeichnet als V1-V6. Die Aufzeichnung der Herzströme erfolgte mit einer Geschwindigkeit von 50 mm/s.

Die Auswertung beinhaltete neben der Frequenz und dem Rhythmus die Bestimmung der PQ- und der QT-Zeit sowie der QRS-Dauer. Ferner wurde das EKG auf eventuelle Blockbilder untersucht, beispielsweise atrioventrikulärer oder Schenkelblock. Außerdem wurden ein kompletter R-Verlust, pathologische Q-Zacken, diskordante T-Negativierung, sowie ST-Senkungen und -Hebungen dokumentiert. Zusätzlich wurden der Sokolow- und der Lewis-Index beurteilt.

\subsubsection{6-Minuten-Gehtest}

Der 6-Minuten-Gehtest gilt als ein einfach durchzuführendes, aber dennoch valides Mittel, um die Leistungsfähigkeit und auch die Prognose von Patienten mit Herzinsuffizienz (HF) abschätzen zu können (Guyatt et al. 1985). Bei Standardisierung ist er ein sehr gut reproduzierbarer Test (Demers et al. 2001), der auch zur Abschätzung von Morbidität und Mortalität ein geeignetes Mittel ist (Bittner et al. 1993).

Die Patienten wurden aufgefordert, innerhalb von 6 Minuten die für sie größtmögliche Strecke zurückzulegen, ohne dabei zu rennen oder zu joggen, ein Fuß sollte stets auf dem 
Boden bleiben. Die Teilnehmer konnten die Geschwindigkeit selbst bestimmen und gegebenenfalls die für sie nötigen Pausen einlegen, wobei sie sich auch auf einen Stuhl setzen konnten. Die Patienten konnten von sich aus den Test abbrechen, falls sie es für unmöglich hielten, fortzufahren. Dies wurde entsprechend dokumentiert, inklusive genauem Zeitpunkt des Abbruches. Allerdings wurden die Patienten ermutigt, den Test fortzusetzen, sobald sie sich physisch wieder dazu im Stande fühlten. Die Zeit wurde während der Pause nicht angehalten. Der Versuchsleiter sollte alle zwei Minuten die verbleibende Zeit ansagen und alle 30 Sekunden den Patienten verbal ermutigen. Dafür waren ausschließlich folgende Formulierungen vorgesehen:

„Das machen Sie gut.“

„Immer weiter so.“

Der Untersucher blieb während der Untersuchung in der Mitte der Teststrecke stehen und lief nicht mit, um das Ergebnis nicht zu beeinflussen. Am Ende wurde die zurückgelegte Distanz dokumentiert und dabei auf ganze Meter gerundet. Zusätzlich wurde der Grund eines eventuellen Abbruches dokumentiert, beispielsweise Dyspnoe oder allgemeine Erschöpfung.

\subsubsection{Echokardiografie}

Im Rahmen der Diast-CHF-Studie wurde bei jedem Patienten ein transthorakales zweidimensionales Echo durchgeführt. Grundlage dafür waren die EchokardiografieRichtlinien für den Harmonisierten Datensatz des KNHI (Version vom 21.11.2003). Die Messungen erfolgten in Linksseitenlage des Patienten mit dem Echokardiografiegerät Philips Sonos 5500. Zur Archivierung wurden die jeweils gebräuchlichen Systeme und Medien des Studienzentrums eingesetzt, etwa Videobänder und Ausdrucke. Die Einteilung der Patienten in die Gruppen der systolischen Dysfunktion (SD) und der diastolischen Dysfunktion (DD) sowie die Beurteilung des Schweregrades der DD erfolgte durch diese Messungen.

Die SD ist mit einer LVEF $<50 \%$ nach Simpson definiert. Die DD wird unter nachstehenden Gesichtspunkten festgestellt und in vier Schweregrade eingeteilt.

Das normale Füllungsmuster (Schweregrad 0) besitzt Kennzeichen eines normalen linksventrikulären Einstroms und Pulmonalvenenflusses. Gemessen wird das Verhältnis der maximalen frühdiastolischen Einstromgeschwindigkeit zur Einstromgeschwindigkeit nach der Vorhofkontraktion über der Mitralklappe $(E / A) \geq 1$. Außerdem mussten alle drei der folgenden Kriterien erfüllt sein: Verhältnis des maximalen systolischen zum maximalen diastolischen pulmonalvenösen Fluss (S/D) $\geq 1$, Verhältnis der maximalen frühdiastolischen 
Einstromgeschwindigkeit über der Mitralklappe zur frühdiastolischen maximalen Geschwindigkeit des Mitralklappenringes im Gewebedoppler (E/e') $<10$ und das Verhältnis der maximalen frühdiastolischen Einstromgeschwindigkeit zur Einstromgeschwindigkeit nach der Vorhofkontraktion über der Mitralklappe während des Valsalvamanövers $\left(E / A_{V a l s a l v a}\right) \geq 1$.

Der Schweregrad I, die verzögerte Relaxation, ist mit $E / A<1$ definiert.

Der Schweregrad II, die Pseudonormalisierung, zeichnet sich durch ein E/A-Verhältnis $\geq 1$ und $<2$ und eines der drei folgenden Kriterien aus: Verhältnis des maximalen systolischen zum maximalen diastolischen pulmonalvenösen Fluss $(S / D)<1$, Verhältnis der maximalen frühdiastolischen Einstromgeschwindigkeit über der Mitralklappe zur frühdiastolischen maximalen Geschwindigkeit des Mitralklappenringes im Gewebedoppler (E/e') $\geq 10$ und Verhältnis der maximalen frühdiastolischen Einstromgeschwindigkeit zur Einstromgeschwindigkeit nach der Vorhofkontraktion über der Mitralklappe während des Valsalvamanövers $\left(E / A_{\text {Valsalva }}\right)<1$.

Das restriktive Füllungsmuster fasst die Schweregrade III und IV zusammen. Es liegt vor, wenn $E / A \geq 2$ ist und mindestens eines der zwei folgenden Kriterien erfült ist: Verhältnis des maximalen systolischen zum maximalen diastolischen pulmonalvenösen Fluss $(S / D)<1$, Verhältnis der maximalen frühdiastolischen Einstromgeschwindigkeit über der Mitralklappe zur frühdiastolischen maximalen Geschwindigkeit des Mitralklappenringes im Gewebedoppler (E/e") $\geq 10$.

Mittels des Valsalva-Manövers gelingt schließlich die Einteilung in die Schweregrade III und IV. Wenn $E / A_{\text {Valsalva }}<1$ ist, handelt es sich um ein reversibles restriktives Füllungsmuster (Grad III). Ein irreversibles restriktives Füllungsmuster (Grad IV) liegt vor, wenn E/A $A_{\text {Valsalva }} \geq 1$ ist. Zur Durchführung des Valsalva-Manövers wird der Patient gebeten, nach tiefer Inspiration eine Bauchpresse durchzuführen und bei geschlossener Glottis die Exspirationsmuskulatur anzuspannen. Durch diese Druckerhöhung in Thorax und Abdomen wird der venöse Rückfluss zum Herzen und damit das Schlagvolumen stark reduziert.

\begin{tabular}{|c|c|c|c|c|}
\hline & $\begin{array}{l}\text { Grad 0 } \\
\text { (nomal) }\end{array}$ & $\begin{array}{l}\text { Grad I (verzögerte } \\
\text { Relaxation) }\end{array}$ & $\begin{array}{c}\text { Grad II } \\
\text { (pseudonormale } \\
\text { Füllung) }\end{array}$ & $\begin{array}{c}\text { Grad III/IV } \\
\text { (reversible/irreversible } \\
\text { Restriktion) }\end{array}$ \\
\hline$E / A$ & $\geq 1$ & $<1$ & $\geq 1$ und $<2$ & $\geq 2$ \\
\hline & $\begin{array}{c}\text { sowie } 3 \text { von } 3 \\
\text { Kriterien }\end{array}$ & & $\begin{array}{c}\text { sowie } 1 \text { von } 3 \\
\text { Kriterien }\end{array}$ & $\begin{array}{c}\text { sowie } 1 \text { von } 2 \text { Kriterien } \\
\text { UND Valsalva }\end{array}$ \\
\hline E/e' (lateral) & $<10$ & & $\geq 10$ & $\geq 10$ \\
\hline $\mathrm{S} / \mathrm{D}$ & $\geq 1$ & & $<1$ & $<1$ \\
\hline$E / A_{\text {Valsalva }}$ & $\geq 1$ & & $<1$ & $<1$ \\
\hline
\end{tabular}

Tabelle 1: Einteilung des Schweregrades der diastolischen Dysfunktion nach KNHI TP7 


\section{3 spezielle Laboranalytik}

\subsubsection{Blutproben}

Die Blutabnahme erfolgte bei jedem Patienten in nicht nüchternem Zustand und nachdem er oder sie 30 Minuten entspannt gelegen hatte. Für die Analysen wurde ausschließlich das Plasma von in Ethylendiamintetraessigsäure-Röhrchen (EDTA-Röhrchen) gefülltem Blut verwendet. Nach Abnahme der Proben wurden diese umgehend mit der Eppendorf Zentrifuge $5702 \mathrm{R}$ für 10 Minuten zentrifugiert, der Überstand abpipettiert und bei $-80^{\circ} \mathrm{C}$ eingefroren. Ein Auftauen und erneutes Einfrieren wurde bis zur endgültigen Analyse vermieden. Während notwendiger Transporte war eine vollständige Kühlkette stets gewährleistet. Die Analysen wurden geblindet zu den Ergebnissen aus Echokardiografie und klinischer Untersuchung durchgeführt.

\subsubsection{Bestimmung von BNP und NT-proBNP}

Zur Bestimmung der NT-proBNP-Werte im Blut der Patienten kam ein Test der Firma Roche Diagnostics (Mannheim, Deutschland) zum Einsatz, genannt Elecsys ${ }^{\circledR}$ proBNP. Dieser nichtkompetitive Elektrochemilumineszenz-Immunoassy verwendet spezifische polyklonale Antikörper gegen bestimmte Regionen des Peptids. Neben dem N-terminalen Epitop der Aminosäuren 1-21 stellen die zentralen Aminosäuren 39-50 ein weiteres Epitop dar (Karl et al. 1999). Ein Biotin-gekoppelter Antikörper stellt den Capture-Antikörper dar (Aminosäuren 1-21), während ein Ruthenium-Komplex-gekoppelter Antikörper (Aminosäuren 39-50) als Detection-Antikörper dient. Der Vorteil dieses Verfahrens besteht darin, dass durch den Einsatz von Antikörpern mit zwei Epitopen kleinere Spaltprodukte nicht erfasst werden. Somit kann von präziseren Ergebnissen ausgegangen werden (Mueller et al. 2003). Der Hersteller gibt den Messbereich des Assays mit 5-35000 pg/ml an.

\subsubsection{Bestimmung von ANP und MR-proANP}

Aufgrund der kurzen Halbwertszeit von ANP ist die Messung von ANP selbst schwierig und fehleranfällig. Deshalb gab es Bestrebungen, Antikörper gegen Teile des langlebigeren Prohormons proANP einzusetzen. So kommt in dieser Arbeit ein immunoluminometrischer Assay der Firma B.R.A.H.M.S. AG (Hennigsdorf, Deutschland) zum Einsatz. Die Antikörper dieses B.R.A.H.M.S. SERISTRA® genannten Tests sind gegen einen Teil der mittleren Region, also gegen die Aminosäuren 53-90 gerichtet. Dieser wird als MR-proADM bezeichnet (Morgenthaler et al. 2004). Dabei reagiert der an das Gefäß gebundene 
polyklonale Antikörper mit der Region der Aminosäuren 73-90 des proANP, während der polyklonale Antikörper, der als Marker fungiert, gegen die Regionen 52-73 gerichtet ist.

Der Hersteller gibt die untere Nachweisgrenze mit 6,0 pmol/l an (Morgenthaler et al. 2004).

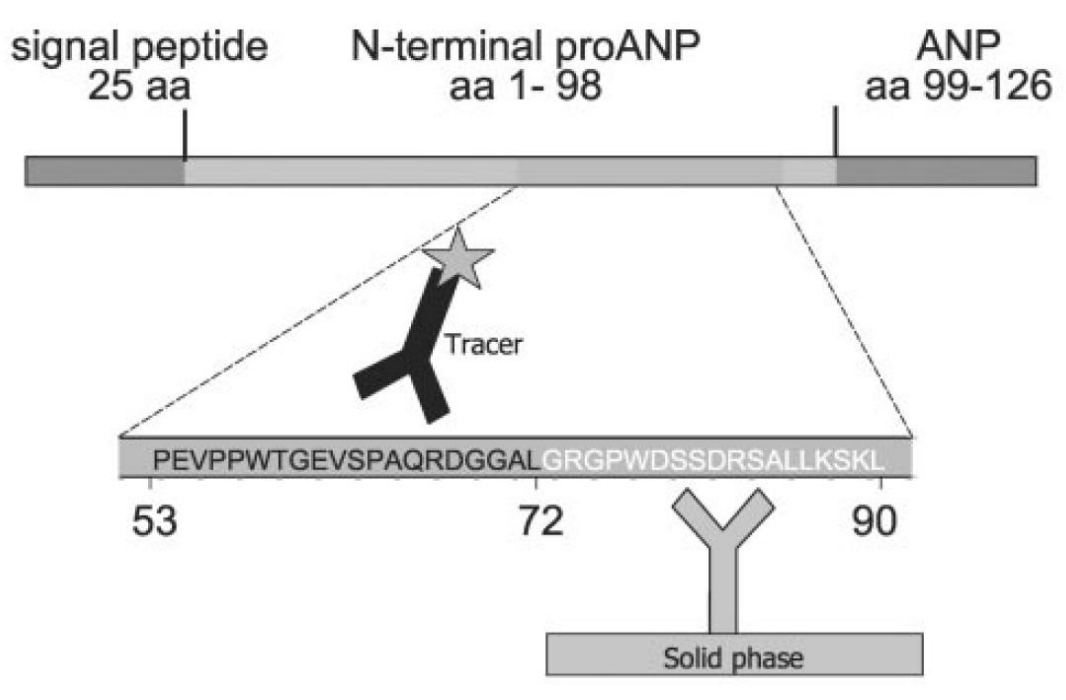

Abbildung 1: Der obere Teil der Abbildung zeigt das proANP. In der Mitte ist die Region der Aminosäuren 53-90 zu sehen, die als Angriffspunkt der Antikörper dient. Mit tracer ist der markierte Antikörper bezeichnet, während solid phase den an das Gefäß gebundenen Antikörper darstellt; aus Morgenthaler et al. (2004) S. 234.

\subsubsection{Bestimmung von Adrenomedullin und MR-proADM}

Auch bei Adrenomedullin erschweren eine kurze Halbwertszeit von etwa 22 Minuten (Meeran et al. 1997) sowie seine Bindung an den Komplementfaktor H (Pio et al. 2001) die exakte Messung der Blutkonzentration. Bei der Synthese des Hormons entsteht stöchiometrisch aus dem Vorläufer präproAdrenomedullin das proAdrenomedullin (proADM), dessen mittlere Region (MR-proADM) bestehend aus den Aminosäuren 45-92 Ziel des in dieser Arbeit verwendeten immunoluminometrischen Assays ist. Bisher ist keine physiologische Funktion des MR-proADM bekannt, es weist allerdings eine wesentlich höhere Stabilität als Adrenomedullin selbst auf. Der Test zur Bestimmung von MR-proADM im EDTA-Plasma, hergestellt von der Firma B.R.A.H.M.S. AG (Hennigsdorf, Deutschland), wird als SEVADIL LIA® bezeichnet. Die darin enthaltenen Antikörper sind gegen die Aminosäuren 68-86 beziehungsweise 83-94 gerichtet, jeweils mit einem zusätzlichen $\mathrm{N}$ terminalen Cysteinrest. 
Der Messbereich des Tests erstreckt sich von 0,12 bis $25 \mathrm{nmol} / \mathrm{l}$ bei einer Sensitivität von $0,12 \mathrm{nmol} / \mathrm{l}$ (Morgenthaler et al. 2005).

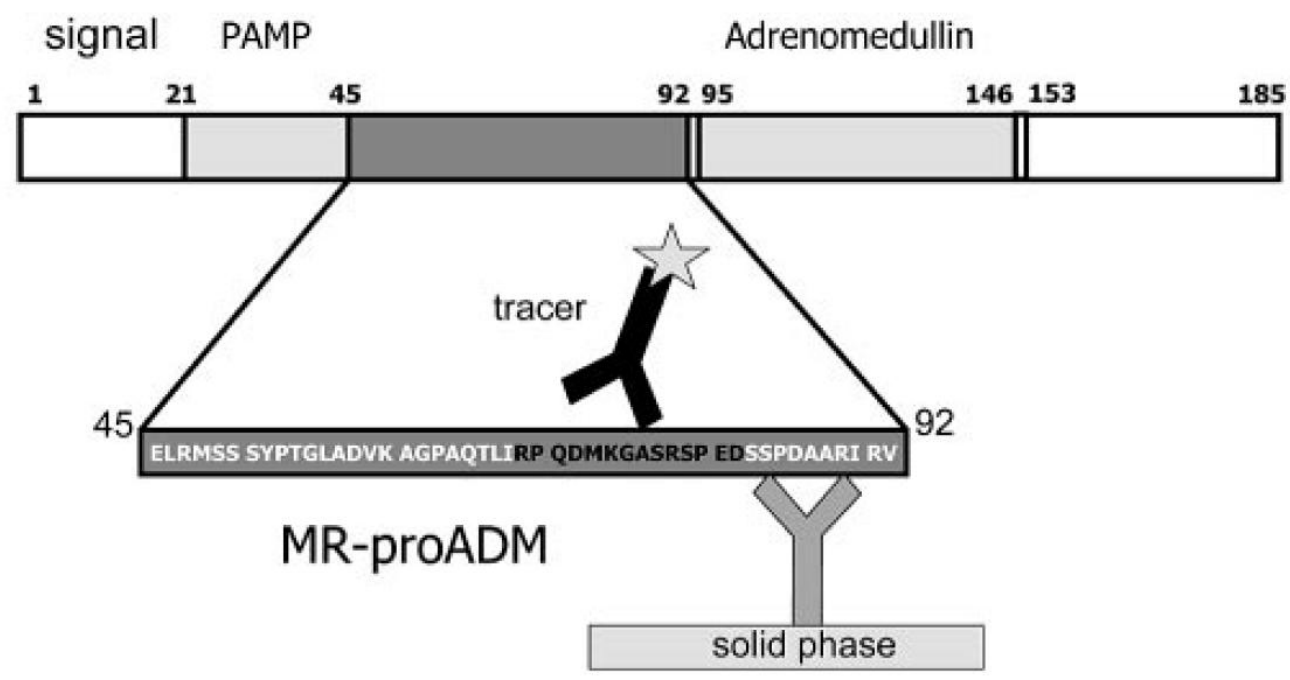

Abbildung 2: Die Struktur des präproAdrenomedullins ist oben im Bild zu sehen. MRproADM kennzeichnet den mittregionalen Teil des entstehenden proAdrenomedullin. Als tracer ist der markierte Antikörper bezeichnet, der gegen die Aminosäuren 68-86 gerichtet ist. Solid phase bezeichnet den gebundenen Antikörper, dessen Ziel die Regionen 83-94 sind; aus Morgenthaler et al. (2005) S. 1824.

\subsubsection{Bestimmung von Endothelin-1 und CT-proET-1}

Durch die geringe Halbwertszeit von Endothelin-1 von nur 1-2 Minuten (Weitzberg et al. 1991) sowie andere Faktoren, zum Beispiel der schnelle Umsatz des Hormons, ist die Bestimmung von Endothelin selbst schwierig. Außerdem bindet Endothelin vorwiegend an Rezeptoren, die in der Nähe des eigenen Sezernierungsortes liegen. Es ist also kein Hormon, das den kompletten Kreislauf durchläuft (Masaki 2004). Dies erschwert die Messung sowie Rückschlüsse auf die tatsächliche Synthesemenge zusätzlich. Deshalb wird in dieser Arbeit die Messung des C-terminalen Fragments von proEndothelin-1 (proET-1) bestimmt, genannt CT-proET-1. Das Fragment unterliegt im Gegensatz zu ET-1 und bigEndothelin- 1 (bigET-1) keinem schnellen Umsatz (Struck et al. 2005).

In dieser Arbeit kommt ein Verfahren der Firma B.R.A.H.M.S AG (Hennigsdorf, Deutschland) zum Einsatz, genannt B.R.A.H.M.S. SEVACON LIA®. Dabei handelt es sich um einen Sandwich-Assay, der zwei polyklonale Antikörper gegen die Aminosäuren 168-212 des präproET-1 verwendet. Der als tracer beichnete markierte Antikörper bindet dabei an die 
Aminosäuren 168-181 des präproEndothelin-1 (präproET-1), während der feste Antikörper an den Aminosäuren 200-212 angreift.

Die untere Nachweisgrenze wird vom Hersteller mit 0,4 pmol/l angegeben (Papassotiriou et al. 2006).

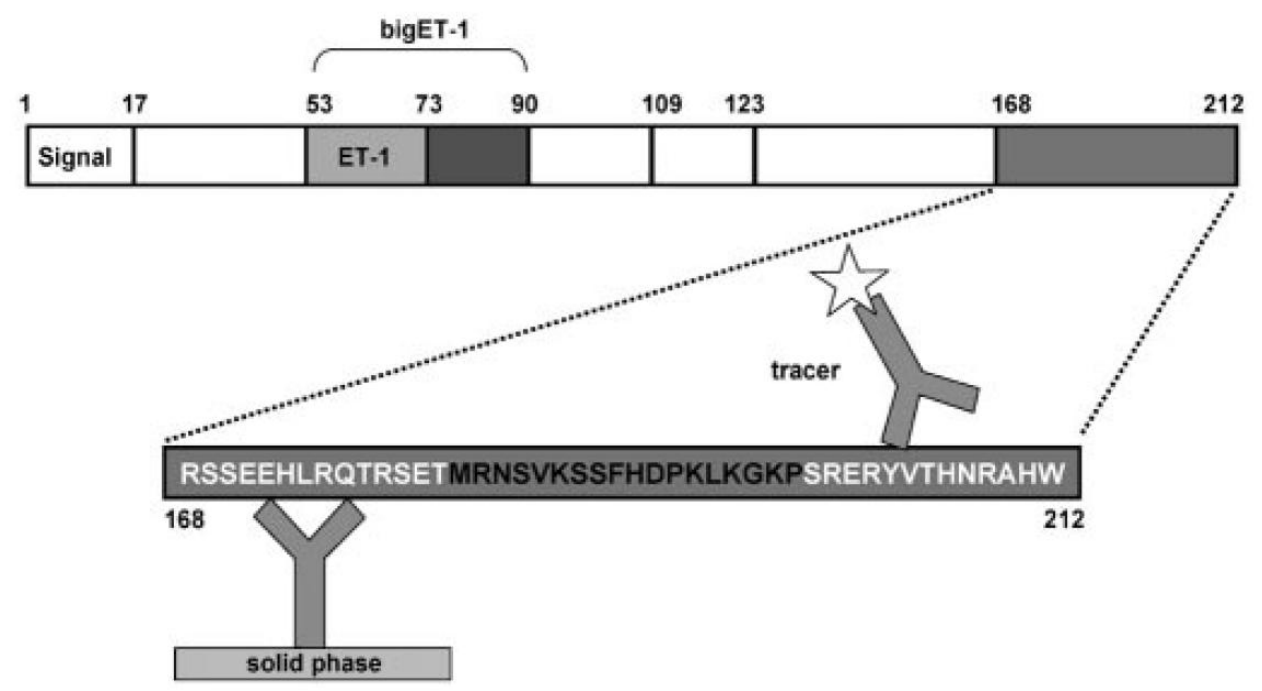

Abbildung 3: Diese Abbildung zeigt das Prinzip des Assays zum Nachweis von CT-proET-1. Oben im Bild die Sequenz des präproET-1, die Bindungsstellen des markierten Antikörpers (tracer) und des gebundenen (solid phase) an präproET-1; aus Papassotiriou et al. (2006) S. 1145).

\subsubsection{Bestimmung von Vasopressin und CT-proAVP}

Auch bei Vasopressin, auch antidiuretisches Hormon (ADH) genannt, findet sich das Problem der Instabilität und der schnellen Eliminierung, wenn seine Konzentration im Blut gemessen werden soll. Außerdem sind bis zu 90\% des Vasopressins im Plasma an Thrombozyten gebunden (Preibisz et al. 1983). Deswegen wird in dieser Arbeit das Copeptin als stöchiometrisches Äquivalent des ADH gemessen. Copeptin repräsentiert also die Sezernierung von Vasopressin (Morgenthaler et al. 2006). Dabei handelt es sich um den 39 Aminosäuren umfassenden C-terminalen Teil des Vorläuferhormons von Vasopressin. Aus diesem Grund wird auch die Bezeichnung CT-proAVP verwendet.

Für die Bestimmung der Werte in dieser Arbeit wurde ein Sandwich-Assay der Firma B.R.A.H.M.S. AG (Hennigsdorf, Deutschland) verwendet. Dabei kommen zwei polyklonale Antikörper zum Einsatz, die gegen die Regionen der Aminosäuren 132-164 des präproVasopressins gerichtet sind. Der Antikörper anti-PLAY17 ist gegen die Region 149- 
164 gerichtet und stellt den markierten Antikörper dar. Der gegen die Region 132-147 gerichtete Antikörper anti-PATV17 wird an die Röhrchenwand gebunden.

Der Messbereich wird vom Hersteller mit 2,25 bis $1215 \mathrm{pmol} / \mathrm{l}$ angegeben (Morgenthaler et al. 2006).

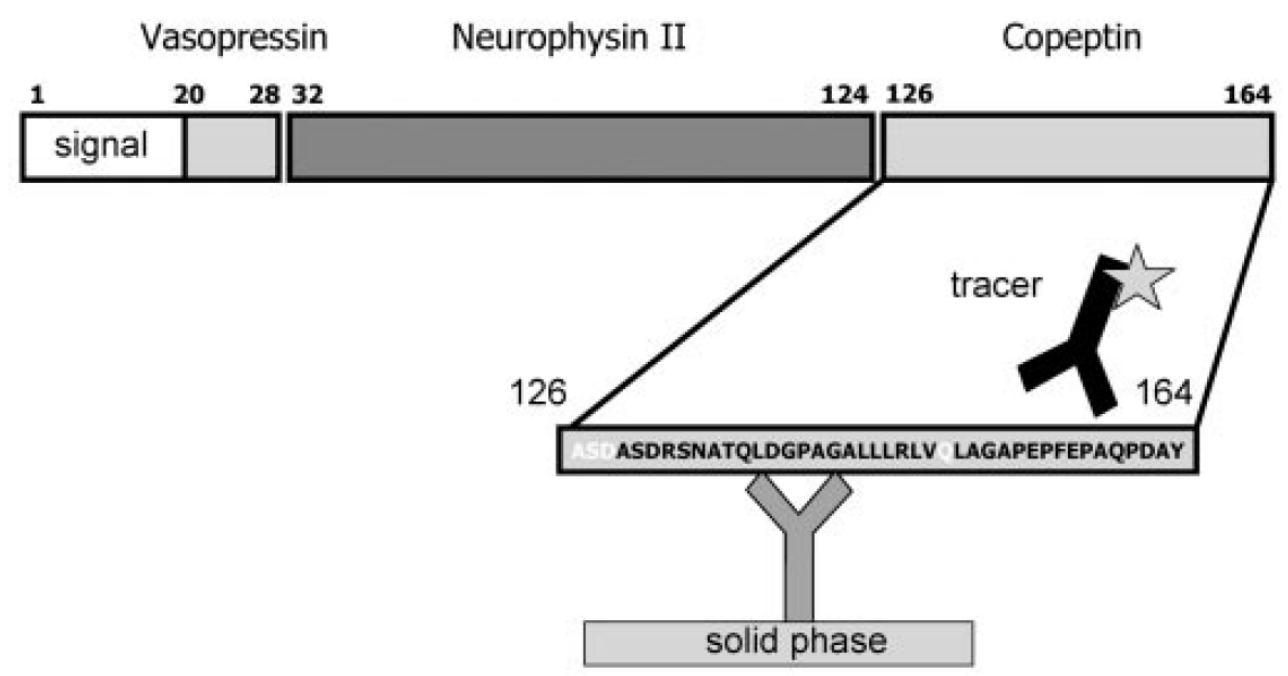

Abbildung 4: Struktur des präproVasopressins. Außerdem wird das Prinzip des Assays verdeutlicht. Mit tracer ist der markierte Antikörper bezeichnet, während solid phase den an das Gefäß gebundenen Antikörper repräsentiert; aus Morgenthaler et al. (2006) S. 113.

\subsection{Statistik}

Für die statistische Analyse wurde das Programm SPSS für Windows in der Version 16.0.2 der Firma SPSS Inc. (Chicago, Illinois, Vereinige Staaten von Amerika) eingesetzt. Aufgrund der nicht normalverteilten Werte wurden die Konzentrationen der Peptide für die Mehrzahl der Analysen logarithmiert.

Mittels des Mann-Whitney-U-Tests zweier unabhängiger Stichproben wurde die asymptotische Signifikanz von Konzentrationsunterschieden berechnet. Dabei kennzeichnete eine asymptotische Signifikanz $<0,05$ signifikante Unterschiede. Zur Analyse der Korrelationen zwischen den Laborparametern und den Ergebnissen aus der Echokardiografie sowie der Symptomatik der Patienten wurde eine bivariate Korrelationsanalyse nach Kendall-Tau-b durchgeführt.

Die diagnostische Relevanz verschiedener Parameter wurde mittels Receiver operating characteristic-Kurven (ROC-Kurven) sowie deren Fläche unter der Kurve (AUC) überprüft. 


\section{Ergebnisse}

\subsection{Deskriptive Statistik des Patientenkollektivs}

\subsubsection{Grundlegende Patientendaten}

In den Tabellen dieses Abschnittes sind die grundlegenden Charakteristika des untersuchten Patientenkollektivs aufgeführt. Insgesamt setzt sich das Kollektiv aus 1687 Patienten zusammen, wovon 841 (49,9\%) Männer und 846 (50,1\%) Frauen waren. In den Tabellen werden zur besseren Übersichtlichkeit folgende Abkürzungen verwendet: Häufigkeit (n), Mittelwert (MW) Standardabweichung (STBW) und Standardfehler (SF).

\begin{tabular}{|l|r|r|c|}
\hline & MW & STBW & SF \\
\hline Alter [Jahre] & 65,98 & 8,43 & 0,21 \\
\hline BMI [kg/m²] & 29,12 & 7,75 & 0,19 \\
\hline Körperoberfläche [m²] & 1,94 & 0,22 & 0,01 \\
\hline Taillenumfang [cm] & 98,43 & 14,01 & 0,34 \\
\hline Hüftumfang [cm] & 105,26 & 11,88 & 0,29 \\
\hline RR systolisch [mmHg] & 146,01 & 21,54 & 0,53 \\
\hline RR diastolisch [mmHg] & 82,92 & 11,75 & 0,29 \\
\hline Herzfrequenz [1/min] & 70,59 & 11,82 & 0,29 \\
\hline
\end{tabular}

Tabelle 2: Die Tabelle zeigt die klinische Charakterisierung des Patientenkollektivs.

\subsubsection{Risikofaktoren im Patientenkollektiv}

In diesem Abschnitt sind Angaben bezüglich der zum Untersuchungszeitpunkt bereits bekannten kardiovaskulären Risikofaktoren und Vorerkrankungen aufgeführt. Dazu gehören das Rauchen, Diabetes mellitus, Hypertonie, Hyperlipidämie, chronisch obstruktive Lungenerkrankungen (COPD) und die koronare Herzkrankheit (KHK). Darüber hinaus finden sich weitere Häufigkeitsangaben zu bereits eventuell erlittenen Myokardinfarkten und der Frage nach Familienmitgliedern, die vor ihrem 60. Lebensjahr einen Myokardinfarkt hatten. Auch weitere vaskuläre Vorerkrankungen in Form einer peripheren arteriellen Verschlusskrankheit (pAVK) und zerebrovaskulären Erkrankungen sind aufgeführt. 


\begin{tabular}{|l|r|r|}
\hline & \multicolumn{1}{|c|}{$\mathrm{n}$} & Prozent [\%] \\
\hline arterielle Hypertonie & 1327 & 78,7 \\
\hline Hyperlipidämie & 669 & 39,7 \\
\hline ehemalige Raucher & 642 & 38,1 \\
\hline Diabetes mellitus & 398 & 23,6 \\
\hline KHK & 326 & 19,3 \\
\hline Myokardinfakt in Familie <60 Jahre & 201 & 11,9 \\
\hline Raucher & 193 & 11,5 \\
\hline Zustand nach Myokardinfarkt & 164 & 9,7 \\
\hline COPD & 118 & 7,0 \\
\hline zerebrovaskuläre Erkrankungen & 110 & 6,5 \\
\hline pAVK & 78 & 4,6 \\
\hline
\end{tabular}

Tabelle 3: Die Tabelle zeigt die Häufigkeitsverteilung der kardiovaskulären Risikofaktoren im Kollektiv absteigend nach ihrer Häufigkeit.

\subsubsection{Symptome der Herzinsuffizienz im Patientenkollektiv}

In diesem Abschnitt finden sich Tabellen, die die Symptomatik der Herzinsuffizienz und ihre Häufigkeitsverteilung im Kollektiv verdeutlichen. Die erste Tabelle zeigt dabei die Ergebnisse des 6-Minuten-Gehtests, die zweite eine Auswahl der anamnestisch und mittels körperlicher Untersuchung erhobenen Symptome der HF.

Der 6-Minuten-Gehtest wurde bei 1503 Patienten durchgeführt. Der MW der zurückgelgten Gehstrecke beträgt 515,88 m bei einer STBW von 109,68 und einem SF von 2,83. 


\begin{tabular}{|l|r|r|}
\hline & \multicolumn{1}{|c|}{$\mathrm{n}$} & Prozent [\%] \\
\hline Nykturie & 944 & 56,0 \\
\hline Belastungsdyspnoe & 470 & 27,8 \\
\hline Müdigkeit/Leistungsschwäche & 379 & 22,5 \\
\hline Ödeme & 317 & 18,8 \\
\hline nächtlicher Husten & 88 & 5,2 \\
\hline paroxysmale nächtliche Dyspnoe & 55 & 3,3 \\
\hline Orthopnoe & 54 & 3,2 \\
\hline Ruhedyspnoe & 39 & 2,3 \\
\hline Pulmonale Rasselgeräusche & 31 & 1,8 \\
\hline Halsvenenstauung & 22 & 1,3 \\
\hline Framingham-Summe $\geq 4$ & 61 & 3,6 \\
\hline
\end{tabular}

Tabelle 4: Aufgeführt ist die Häufigkeitsverteilung der Symptome der Herzinsuffizienz im Gesamtkollektiv. Die Auswahl der Symptome orientierte sich an den Framingham-Kriterien.

\subsubsection{Medikation}

Im Folgenden wird die Häufigkeit der Medikation mit kardiovaskulärer Indikation im Gesamtkollektiv betrachtet.

\begin{tabular}{|l|r|r|}
\hline & $\mathrm{n}$ & Prozent [\%] \\
\hline Betablocker & 742 & 44,4 \\
\hline ACE-Hemmer & 691 & 41,3 \\
\hline Thiazide & 616 & 36,8 \\
\hline Calcium-Antagonisten & 319 & 19,1 \\
\hline AT1-Antagonisten & 267 & 16,0 \\
\hline Schleifendiuretika & 197 & 11,8 \\
\hline Nitrat & 149 & 8,9 \\
\hline andere Diuretika & 83 & 5,0 \\
\hline Herzglykoside & 77 & 4,6 \\
\hline Aldosteron-Antagonisten & 32 & 1,9 \\
\hline
\end{tabular}

Tabelle 5: Die Tabelle zeigt die Häufigkeitsverteilung verschiedener Substanzgruppen im Gesamtkollektiv 


\subsubsection{Echokardiografie}

Die folgende Tabelle zeigt die Parameter der Echokardiografie im Patientenkollektiv. Hierbei handelt es sich um die Daten sämtlicher Patienten, sofern von diesen Daten verfügbar waren. Es werden also nicht isoliert die Patienten mit DD und DHF betrachtet. Unter 1687 untersuchten Patienten wiesen 1552 (92\%) eine LVEF von $\geq 50 \%$ auf, bei 135 (8\%) war eine Reduktion der LVEF auf $<50 \%$ messbar.

\begin{tabular}{|l|r|r|c|}
\hline & MW & STBW & SF \\
\hline LVEF [\%] & 59,87 & 8,34 & 0,20 \\
\hline Dicke interventrikuläres Septum [mm] & 12,15 & 1,91 & 0,05 \\
\hline Dicke Hinterwand [mm] & 11,27 & 1,66 & 0,04 \\
\hline LVEDD [mm] & 49,30 & 6,11 & 0,15 \\
\hline LVMI [g/m²] & 117,39 & 28,30 & 0,69 \\
\hline LAVI [ml/m²] & 24,74 & 9,82 & 0,29 \\
\hline Mitralisdoppler: E-Welle [cm/s] & 72,53 & 19,89 & 0,49 \\
\hline Mitralisdoppler: A-Welle [cm/s] & 79,50 & 19,45 & 0,49 \\
\hline E/A & 0,94 & 0,37 & 0,01 \\
\hline Gewebedoppler medial: e'-Welle [cm/s] & 6,05 & 1,72 & 0,05 \\
\hline E/e' medial & 13,42 & 5,27 & 0,13 \\
\hline pulmonalvenöser Fluss systolisch [cm/s] & 61,70 & 13,67 & 0,34 \\
\hline pulmonalvenöser Fluss diastolisch [cm/s] & 46,43 & 13,74 & 0,34 \\
\hline S/D & 1,42 & 0,43 & 0,01 \\
\hline Dezelerationszeit [ms] & 252,47 & 72,85 & 1,79 \\
\hline IVRT [ms] & 103,81 & 22,29 & 0,55 \\
\hline
\end{tabular}

Tabelle 6: Übersicht über die Ergebnisse der Echokardiografie im Gesamtkollektiv

In den nachstehenden Tabellen ist die Einteilung der Patienten in das Diagnoseschema der diastolischen Dysfunktion nach KNHI TP7 der Universitätsmedizin Göttingen dargestellt. Auch hier wird das gesamte Kollektiv betrachtet, also inklusive der Patienten mit reduzierter LVEF. Die Zusammenfassung der Schweregrade II und III erfolgte deshalb, weil es nur wenige Patienten mit einer DD des Schweregrades III im Kollektiv gab. 62 Patienten konnten durch das Schema nicht klassifiziert werden, so dass die Gesamtzahl der Patienten sich hier auf 1625 beläuft. 
Ergebnisse

\begin{tabular}{|l|c|r|}
\hline & $\mathrm{n}$ & Prozent [\%] \\
\hline LEVF $\geq 50 \%$, keine DD & 279 & 16,5 \\
\hline LEVF $\geq 50 \%$, DD Grad I & 963 & 57,1 \\
\hline LEVF $\geq 50 \%$, DD Grad II-III & 248 & 14,7 \\
\hline LVEF $<50 \%$ & 135 & 8,0 \\
\hline
\end{tabular}

Tabelle 7: Die Tabelle zeigt die Einteilung der Patienten in das Diagnoseschema der diastolischen Dysfunktion nach KNHI TP7 sowie die Zahl der Patienten mit reduzierter LVEF. 


\subsection{Ergebnisse der speziellen Laboranalytik}

\subsubsection{Verteilung der Werte im Kollektiv}

In diesem Abschnitt werden die Ergebnisse der speziellen Laboranalytik dargestellt. Die erste Tabelle gibt einen Überblick über die Verteilung der Serumkonzentrationen dieser Peptide als Messwerte im Gesamtkollektiv. Zur weiteren Illustration der Verteilung folgen Histogramme zu den jeweiligen Parametern. Aufgrund der nicht normalverteilten Werte basieren diese im Gegensatz zur Tabelle auf logarithmierten Werten. Jedes dieser Histogramme zeigt dabei auf der Abszisse den Logarithmus zur Basis 10 (log10) der für das jeweilige Peptid gemessenen Werte, während auf der Ordinate die Häufigkeit (n) in Absolutzahlen ablesbar ist. Zusätzlich ist jedes Histogramm mit einer Normalverteilungskurve versehen. Die Gesamtsumme der Patienten wird hier mit 1625 angegeben, da die 62 durch das Diagnoseschema des KNHI nicht klassifizierbaren Patienten nicht eingerechnet wurden.

\begin{tabular}{|l|l|r|r|r|r|r|}
\hline & & $\begin{array}{c}\text { NT-proBNP } \\
\text { [pg/ml] }\end{array}$ & $\begin{array}{c}\text { MR-proANP } \\
\text { [pmol/l] }\end{array}$ & $\begin{array}{c}\text { MR-proADM } \\
\text { [nmol/l] }\end{array}$ & $\begin{array}{c}\text { CT-proET-1 } \\
\text { [pmol/l] }\end{array}$ & $\begin{array}{c}\text { CT-proAVP } \\
\text { [pmol//] }\end{array}$ \\
\hline LEVF $\geq 50 \%$, keine DD & MW & 120,10 & 89,90 & 0,54 & 53,89 & 4,76 \\
\hline n=279 & STBW & 145,56 & 44,32 & 0,17 & 13,43 & 4,22 \\
\hline LEVF $\geq 50 \%$, DD Grad I & MW & 141,76 & 96,22 & 0,61 & 56,98 & 5,81 \\
\hline n=963 & STBW & 216,78 & 61,51 & 0,21 & 16,83 & 5,92 \\
\hline LEVF $\geq 50 \%$, DD Grad II-III & MW & 228,51 & 120,38 & 0,62 & 58,58 & 5,86 \\
\hline n=248 & STBW & 318,32 & 69,22 & 0,21 & 17,73 & 6,28 \\
\hline LVEF<50\% & MW & 727,58 & 169,19 & 0,74 & 68,88 & 9,22 \\
\hline n=135 & STBW & 1016,12 & 115,22 & 0,32 & 27,76 & 10,06 \\
\hline Insgesamt & MW & 199,95 & 104,88 & 0,61 & 57,68 & 5,92 \\
\hline n=1625 & STBW & 398,05 & 69,75 & 0,22 & 17,98 & 6,27 \\
\hline
\end{tabular}

Tabelle 8: Übersicht über die Verteilung der mittleren Serumkonzentrationen im Gesamtkollektiv bezogen auf die verschiedenen Grade der Dysfunktion. 


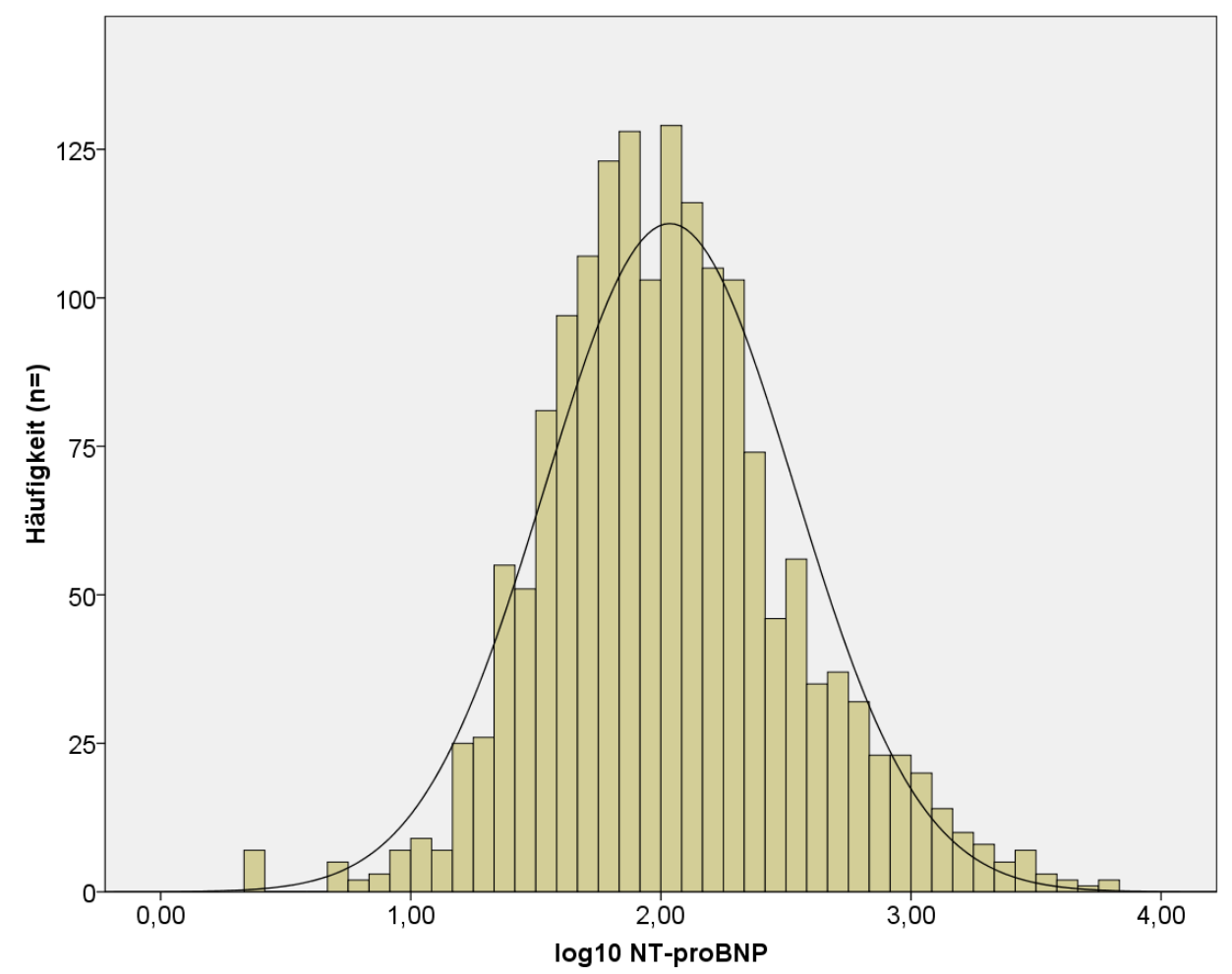

Abbildung 5: Häufigkeitsverteilung des NT-proBNP im Gesamtkollektiv

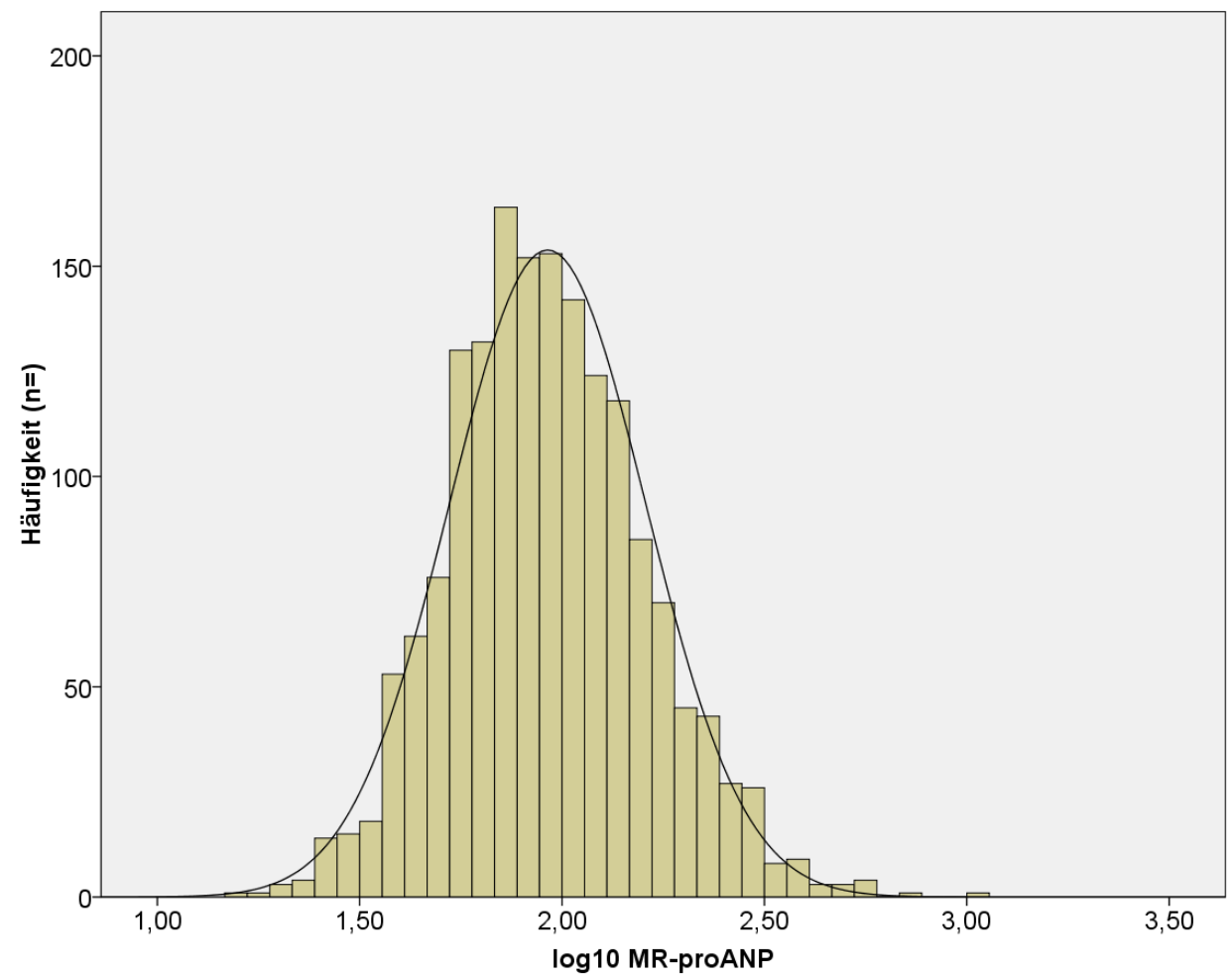

Abbildung 6: Häufigkeitsverteilung des MR-proANP im Gesamtkollektiv 
Ergebnisse

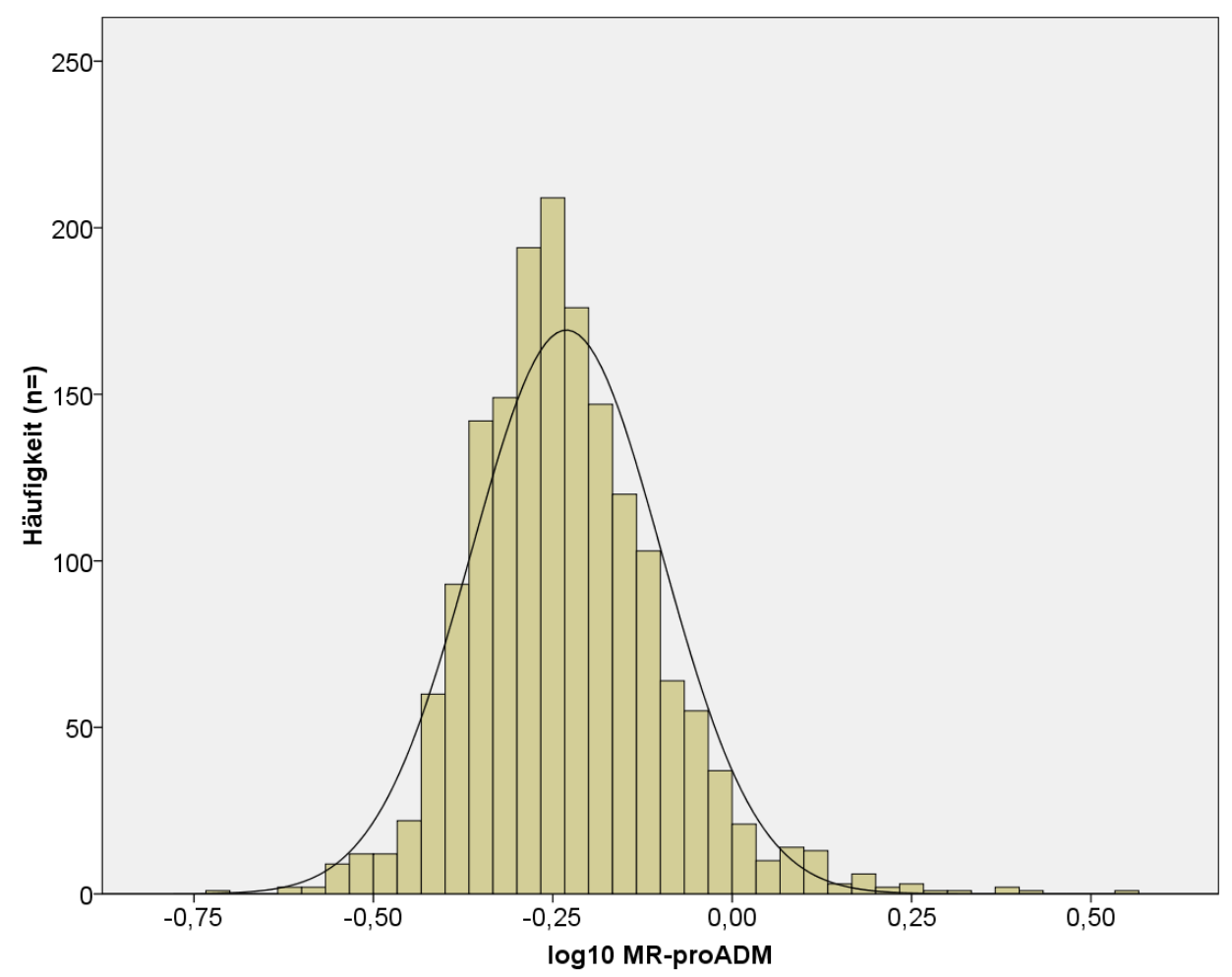

Abbildung 7: Häufigkeitsverteilung des MR-proADM im Gesamtkollektiv

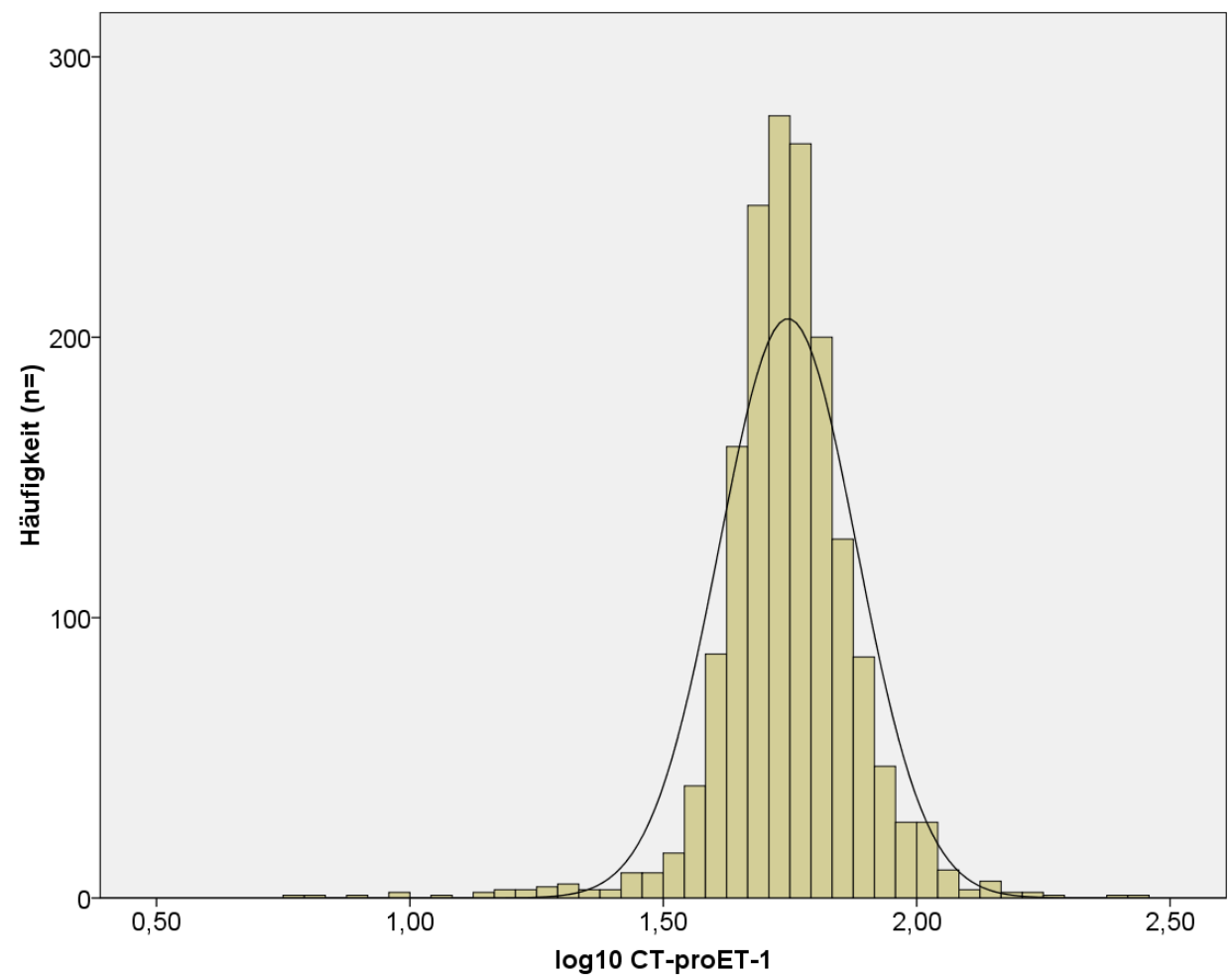

Abbildung 8: Häufigkeitsverteilung des CT-proET-1 im Gesamtkollektiv 
Ergebnisse

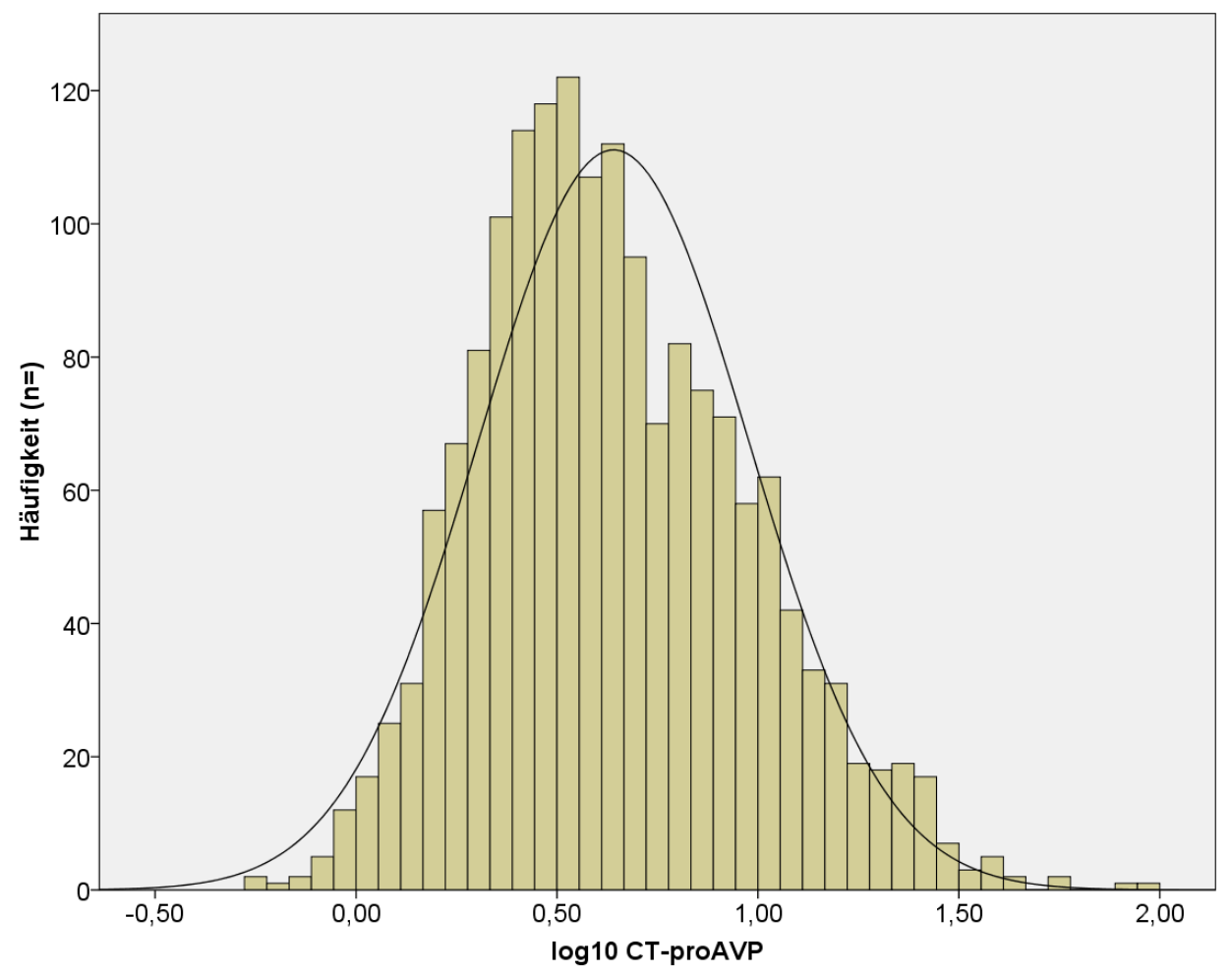

Abbildung 9: Häufigkeitsverteilung des CT-proAVP im Gesamtkollektiv 


\subsubsection{Regulation der Peptide in Abhängigkeit von diastolischer und systolischer Dysfunktion}

Um eine genauere Bewertung der Ergebnisse zu ermöglichen, erfolgte eine Signifikanzanalyse für die Unterschiede in der Serumkonzenzentration der Peptide. Die folgende Tabelle zeigt jeweils einen Vergleich zwischen zwei Erkrankungsstadien in den einzelnen Spalten. Ein Stern $\left({ }^{*}\right)$ kennzeichnet die Fälle, in denen für das in der jeweiligen Zeile stehende Peptid ein signifikanter Unterschied in der Serumkonzentration der genannten Stadien nachgewiesen wurde.

\begin{tabular}{|l|r|r|r|r|r|}
\hline & $\begin{array}{c}\text { NT- } \\
\text { proBNP }\end{array}$ & $\begin{array}{c}\text { MR- } \\
\text { proANP }\end{array}$ & $\begin{array}{c}\text { MR- } \\
\text { proADM }\end{array}$ & $\begin{array}{c}\text { CT- } \\
\text { proET-1 }\end{array}$ & $\begin{array}{c}\text { CT- } \\
\text { proAVP }\end{array}$ \\
\hline $\begin{array}{l}\text { asymptotische Signifikanz } \\
\text { Vergleich keine DD mit DD Grad I }\end{array}$ & $0,031^{*}$ & 0,240 & $0,000^{*}$ & $0,007^{*}$ & $0,003^{*}$ \\
\hline $\begin{array}{l}\text { asymptotische Signifikanz } \\
\text { Vergleich keine DD mit DD Grad II-III }\end{array}$ & $0,000^{*}$ & $0,000^{*}$ & $0,000^{*}$ & $0,006^{*}$ & 0,257 \\
\hline $\begin{array}{l}\text { asymptotische Signifikanz } \\
\text { Vergleich keine DD mit DD Grad I-III }\end{array}$ & $0,001^{*}$ & $0,015^{*}$ & $0,000^{*}$ & $0,003^{*}$ & $0,006^{*}$ \\
\hline $\begin{array}{l}\text { asymptotische Signifikanz } \\
\text { Vergleich keine DD mit LVEF }<50 \%\end{array}$ & $0,000^{*}$ & $0,000^{*}$ & $0,000^{*}$ & $0,000^{*}$ & $0,000^{*}$ \\
\hline $\begin{array}{l}\text { asymptotische Signifikanz } \\
\text { Vergleich DD Grad I mit DD Grad II-III }\end{array}$ & $0,000^{*}$ & $0,000^{*}$ & 0,476 & 0,355 & 0,149 \\
\hline $\begin{array}{l}\text { asymptotische Signifikanz } \\
\text { Vergleich DD Grad I mit LVEF }<50 \%\end{array}$ & $0,000^{*}$ & $0,000^{*}$ & $0,000^{*}$ & $0,000^{*}$ & $0,000^{*}$ \\
\hline $\begin{array}{l}\text { asymptotische Signifikanz } \\
\text { Vergleich DD Grad II-III mit LVEF }<50 \%\end{array}$ & $0,000^{*}$ & $0,000^{*}$ & $0,000^{*}$ & $0,000^{*}$ & $0,000^{*}$ \\
\hline $\begin{array}{l}\text { asymptotische Signifikanz } \\
\text { Vergleich DD Grad I-III mit LVEF }<50 \%\end{array}$ & $0,000^{*}$ & $0,000^{*}$ & $0,000^{*}$ & $0,000^{*}$ & $0,000^{*}$ \\
\hline
\end{tabular}

Tabelle 9: Dargestellt sind die Signifikanzen für die Unterschiede in der Serumkonzentration zwischen den einzelnen Stadien. Signifikante Unterschiede sind mit einem Stern markiert.

Die gezeigten Unterschiede zwischen den einzelnen Stadien sind, wie aus der Tabelle ersichtlich ist, überwiegend signifikant (asymptotische Signifikanz <0,05). Von dieser Regel gibt es einige Ausnahmen. Im Falle der Unterscheidung zwischen DD Grad I und DD Grad IIIII zeigen MR-proADM, CT-proET-1 und CT-proAVP keine signifikanten Unterschiede. Für das letztgenannte Peptid ist auch der Unterschied zwischen LVEF $\geq 50 \%$ sowie der Abwesenheit einer DD und DD Grad II-III nicht signifikant. Im Falle von LVEF $\geq 50 \%$ sowie der Abwesenheit einer DD und DD Grad I ist die Konzentration von CT-proAVP dagegen 
signifikant unterschiedlich. Die letzte Ausnahme findet sich bei der Unterscheidung der Patienten mit LVEF $\geq 50 \%$ und ohne Zeichen einer DD von solchen der DD Grad I anhand von MR-proANP.

Die folgenden Abbildungen stellen die stadienabhängige Erhöhung der Werte der speziellen Laborparameter NT-proBNP, MR-proANP, MR-proADM, CT-proET-1 und CT-proAVP grafisch dar. Jede der Grafiken zeigt auf der Abszisse die Einteilung der DD in die Grade LVEF $\geq 50 \%$ und keine DD, DD Grad I, die zusammengefassten Grade der DD II und III und als letzte Kategorie LVEF $<50 \%$. Die Ordinate zeigt die logarithmierten Werte für den jeweiligen Parameter mit einem 95\%igen Konfidenzintervall (CI). Im Diagramm sind jeweils der Mittelwert und die Standardabweichung der Ergebnisse ablesbar. Signifikante Konzentrationsunterschiede für die jeweiligen Stadien sind nach folgendem Schema gekennzeichnet:

*: $\quad p<0,05$ für Vergleich mit der Gruppe LVEF $\geq 50 \%$, keine DD

\#: $\quad p<0,05$ für Vergleich mit der Gruppe LVEF $\geq 50 \%$, DD Grad I

$\$$ : $\quad p<0,05$ für Vergleich mit der Gruppe LVEF $\geq 50 \%$, DD Grad II-III. 


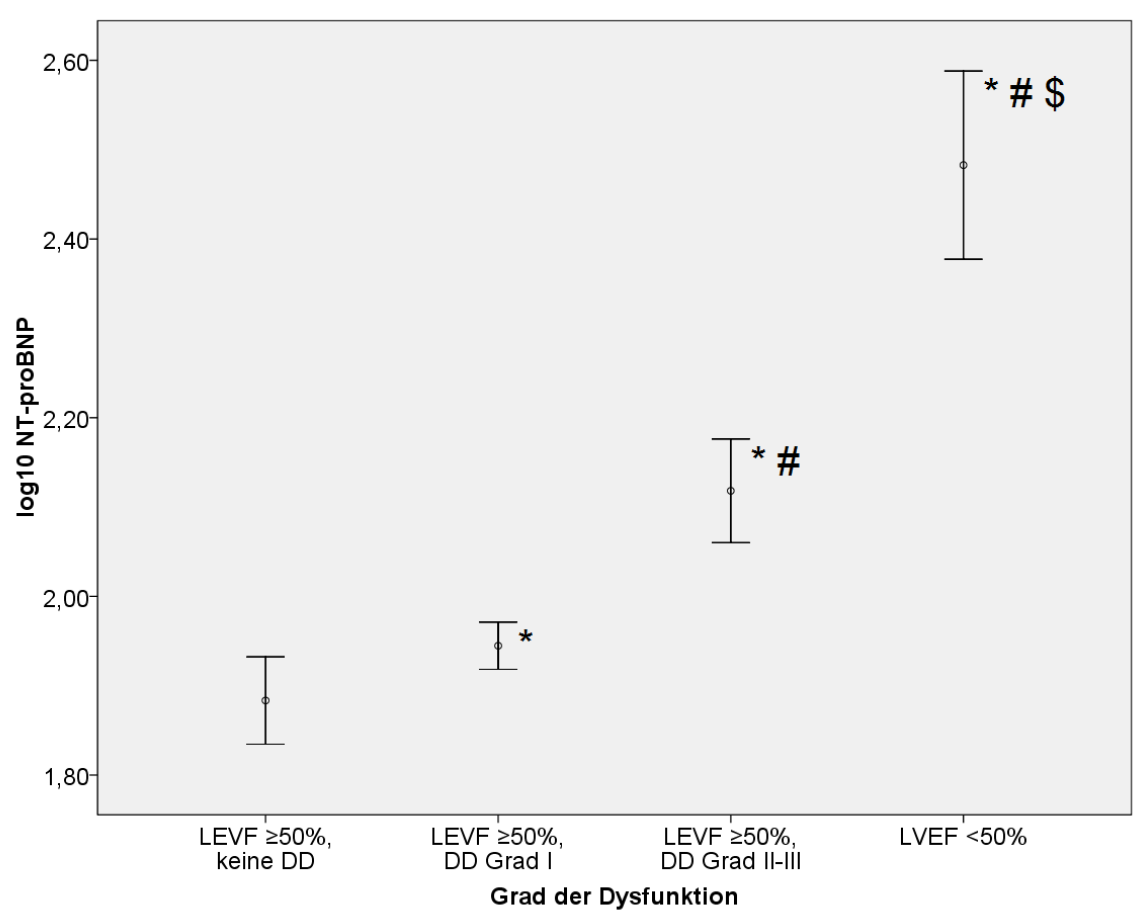

Abbildung 10: Auf der Ordinate sind die logarithmierten Werte für NT-proBNP in Abhängigkeit vom Grad der DD auf der Abszisse aufgetragen. Zum Vergleich finden sich die Ergebnisse der Patienten mit reduzierter LVEF.

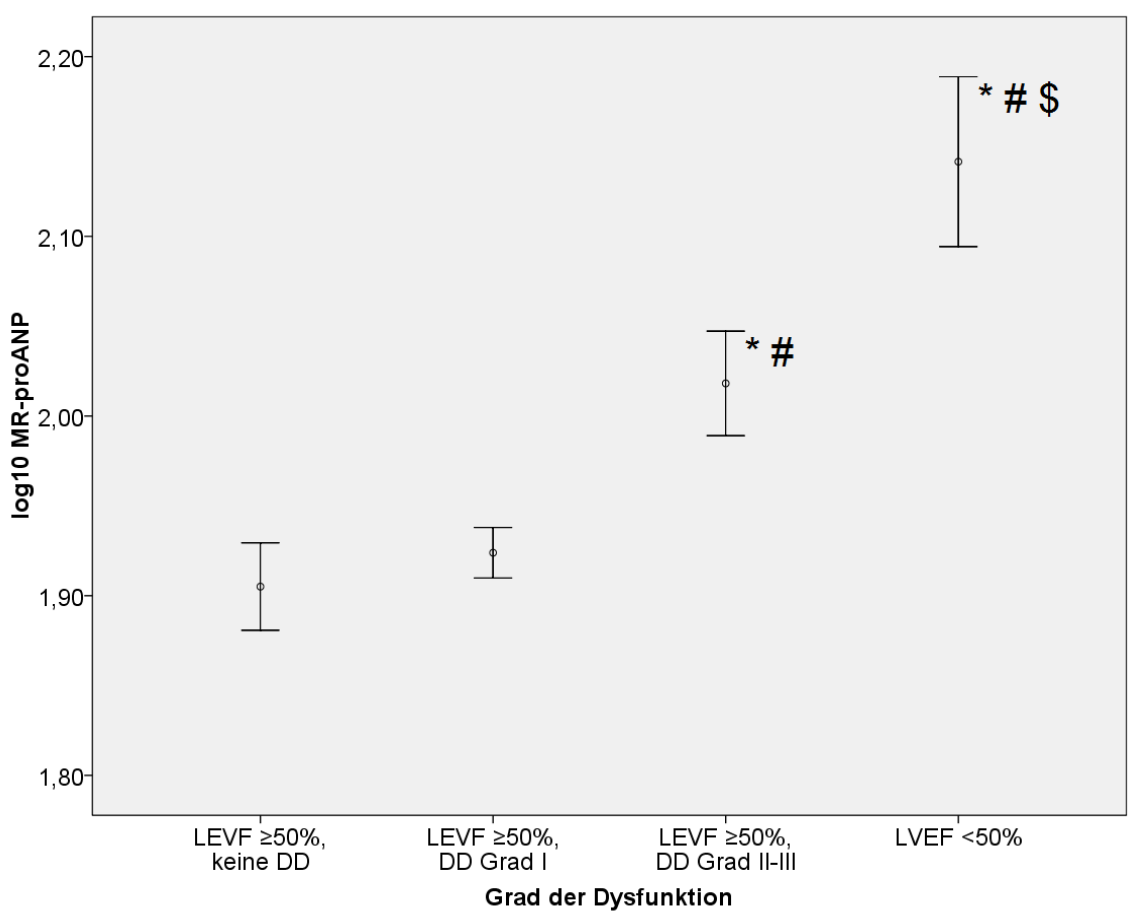

Abbildung 11: Auf der Ordinate sind die logarithmierten Werte für MR-proANP in Abhängigkeit vom Grad der DD auf der Abszisse aufgetragen. Zum Vergleich finden sich die Ergebnisse der Patienten mit reduzierter LVEF. 


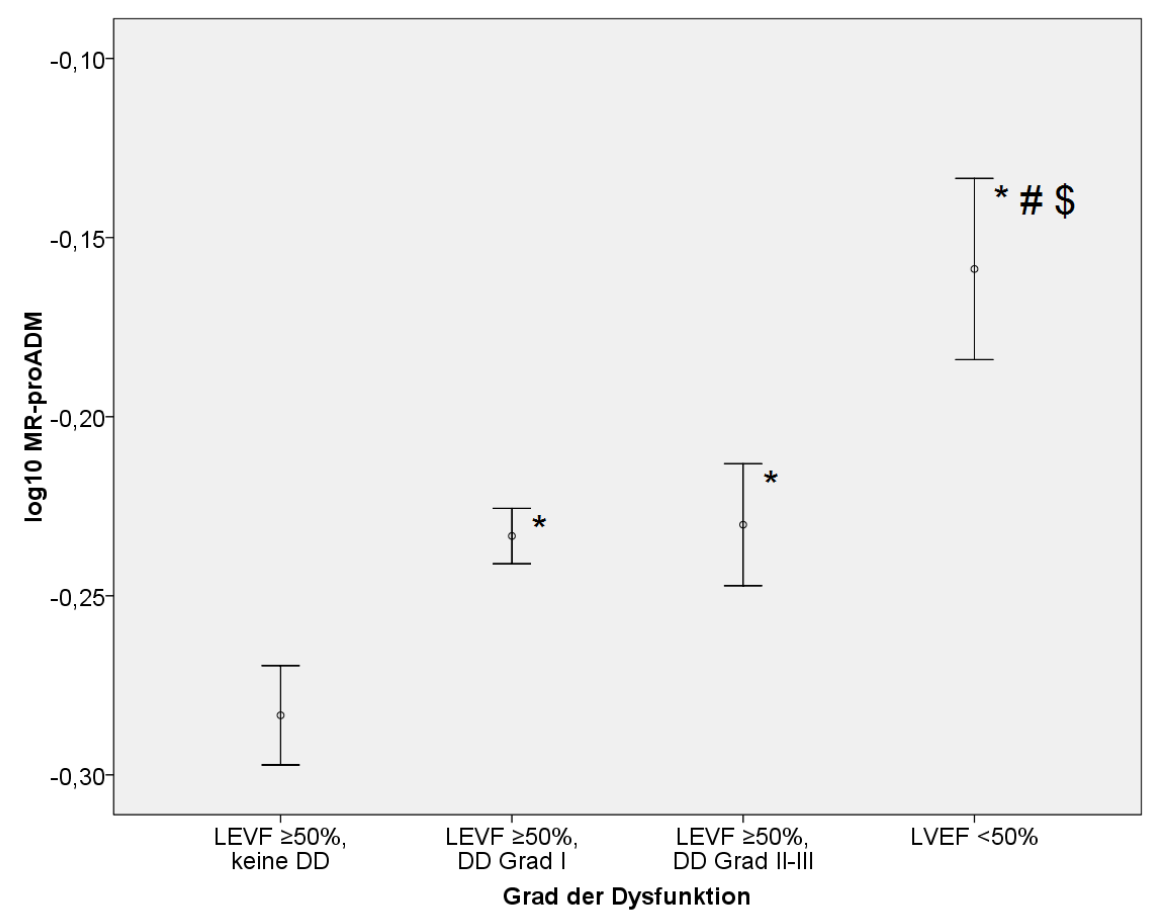

Abbildung 12: Auf der Ordinate sind die logarithmierten Werte für MR-proADM in Abhängigkeit vom Grad der DD auf der Abszisse aufgetragen. Zum Vergleich finden sich die Ergebnisse der Patienten mit reduzierter LVEF.

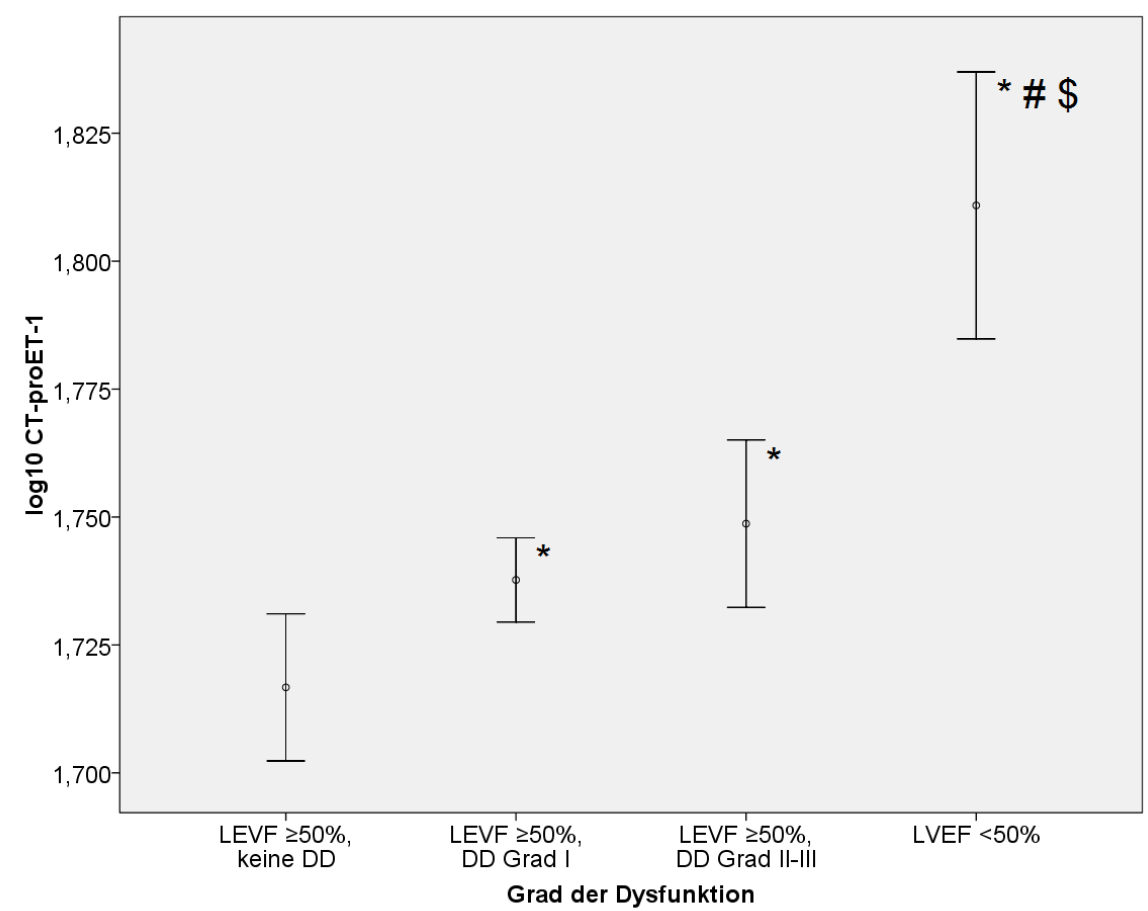

Abbildung 13: Auf der Ordinate sind die logarithmierten Werte für CT-proET-1 in Abhängigkeit vom Grad der DD auf der Abszisse aufgetragen. Zum Vergleich finden sich die Ergebnisse der Patienten mit reduzierter LVEF. 


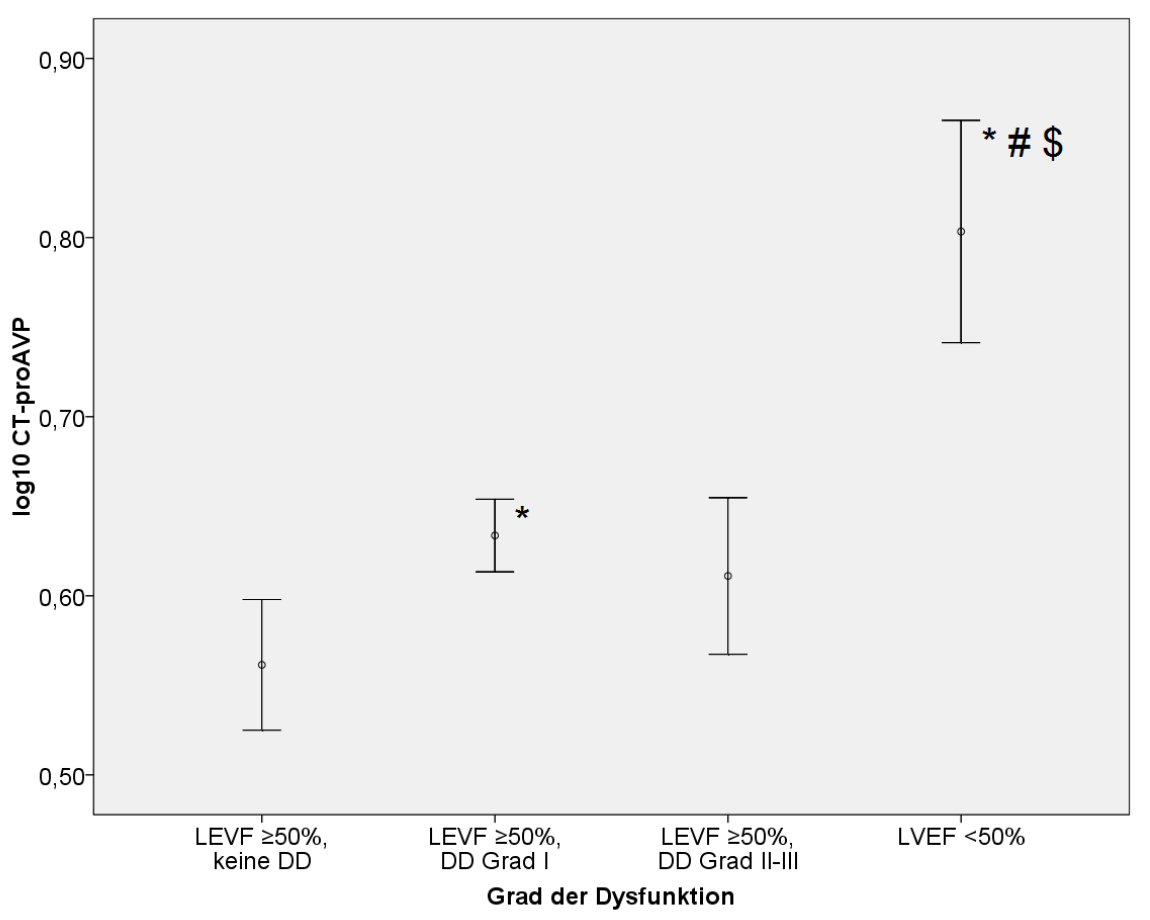

Abbildung 14: Auf der Ordinate sind die logarithmierten Werte für CT-proAVP in Abhängigkeit vom Grad der DD auf der Abszisse aufgetragen. Zum Vergleich finden sich die Ergebnisse der Patienten mit reduzierter LVEF.

Die folgende Tabelle trennt zusätzlich asymptomatische und symptomatische Patienten, wobei als symptomatisch diejenigen Patienten galten, die mindestens eines der Framingham-Kriterien erfüllten. Hier zeigt sich, dass die symptomatischen Patienten unabhängig von der Gruppenzugehörigkeit in den meisten Fällen höhere Werte für die einzelnen Peptide aufwiesen als die asymptomatischen. 
Ergebnisse

\begin{tabular}{|c|c|c|c|c|c|c|c|}
\hline & & & $\begin{array}{c}\log 10 \mathrm{NT}- \\
\text { proBNP } \\
{[\mathrm{pg} / \mathrm{ml}]}\end{array}$ & $\begin{array}{c}\log 10 \mathrm{MR}- \\
\text { proANP } \\
{[\mathrm{pmol} / \mathrm{l}]}\end{array}$ & $\begin{array}{c}\log 10 \mathrm{MR}- \\
\text { proADM } \\
{[\mathrm{nmol} / \mathrm{l}]}\end{array}$ & $\begin{array}{c}\log 10 \mathrm{CT}- \\
\mathrm{proET}-1 \\
{[\mathrm{pmol} / \mathrm{l}]} \\
\end{array}$ & $\begin{array}{c}\log 10 \mathrm{CT}- \\
\text { proAVP } \\
{[\mathrm{pmol} / \mathrm{l}]} \\
\end{array}$ \\
\hline \multirow{6}{*}{$\begin{array}{l}\text { LVEF } \geq 50 \% \\
\text { keine } \mathrm{DD}\end{array}$} & \multirow[t]{2}{*}{ asymptomatisch } & MW & 1,82 & 1,88 & $-0,30$ & 1,71 & 0,54 \\
\hline & & STBW & 0,39 & 0,20 & 0,10 & 0,12 & 0,31 \\
\hline & \multirow[t]{2}{*}{ symptomatisch } & MW & 2,06 & 1,97 & $-0,22$ & 1,75 & 0,62 \\
\hline & & STBW & 0,44 & 0,20 & 0,14 & 0,11 & 0,30 \\
\hline & \multirow[t]{2}{*}{ Gesamt } & MW & 1,88 & 1,91 & $-0,28$ & 1,72 & 0,56 \\
\hline & & STBW & 0,41 & 0,21 & 0,12 & 0,12 & 0,31 \\
\hline \multirow{6}{*}{$\begin{array}{l}\text { LVEF } \geq 50 \% \text {, } \\
\text { DD Grad I }\end{array}$} & \multirow[t]{2}{*}{ asymptomatisch } & MW & 1,89 & 1,90 & $-0,26$ & 1,72 & 0,62 \\
\hline & & STBW & 0,40 & 0,21 & 0,11 & 0,11 & 0,31 \\
\hline & \multirow[t]{2}{*}{ symptomatisch } & MW & 2,03 & 1,95 & $-0,20$ & 1,76 & 0,65 \\
\hline & & STBW & 0,43 & 0,24 & 0,13 & 0,15 & 0,34 \\
\hline & \multirow[t]{2}{*}{ Gesamt } & MW & 1,94 & 1,92 & $-0,23$ & 1,74 & 0,63 \\
\hline & & STBW & 0,42 & 0,22 & 0,12 & 0,130 & 0,32 \\
\hline \multirow{6}{*}{$\begin{array}{l}\text { LVEF } \geq 50 \%, \\
\text { DD Grad II-III }\end{array}$} & \multirow[t]{2}{*}{ asymptomatisch } & MW & 2,03 & 1,97 & $-0,26$ & 1,73 & 0,57 \\
\hline & & STBW & 0,46 & 0,22 & 0,13 & 0,12 & 0,34 \\
\hline & \multirow[t]{2}{*}{ symptomatisch } & MW & 2,23 & 2,08 & $-0,19$ & 1,78 & 0,67 \\
\hline & & STBW & 0,44 & 0,24 & 0,14 & 0,14 & 0,35 \\
\hline & \multirow[t]{2}{*}{ Gesamt } & MW & 2,12 & 2,02 & $-0,23$ & 1,75 & 0,61 \\
\hline & & STBW & 0,46 & 0,23 & 0,14 & 0,13 & 0,35 \\
\hline \multirow[t]{6}{*}{ LVEF <50\% } & \multirow[t]{2}{*}{ asymptomatisch } & MW & 2,35 & 2,10 & $-0,21$ & 1,76 & 0,71 \\
\hline & & STBW & 0,67 & 0,31 & 0,13 & 0,14 & 0,27 \\
\hline & \multirow[t]{2}{*}{ symptomatisch } & MW & 2,57 & 2,18 & $-0,13$ & 1,85 & 0,86 \\
\hline & & STBW & 0,57 & 0,25 & 0,15 & 0,15 & 0,40 \\
\hline & \multirow[t]{2}{*}{ Gesamt } & MW & 2,48 & 2,14 & $-0,16$ & 1,81 & 0,80 \\
\hline & & STBW & 0,62 & 0,28 & 0,15 & 0,15 & 0,36 \\
\hline \multirow[t]{6}{*}{ Insgesamt } & \multirow[t]{2}{*}{ asymptomatisch } & MW & 1,92 & 1,92 & $-0,27$ & 1,72 & 0,60 \\
\hline & & STBW & 0,44 & 0,22 & 0,11 & 0,12 & 0,31 \\
\hline & \multirow[t]{2}{*}{ symptomatisch } & MW & 2,13 & 2,00 & $-0,19$ & 1,77 & 0,68 \\
\hline & & STBW & 0,49 & 0,25 & 0,14 & 0,15 & 0,35 \\
\hline & \multirow[t]{2}{*}{ Gesamt } & MW & 2,01 & 1,95 & $-0,24$ & 1,74 & 0,63 \\
\hline & & STBW & 0,47 & 0,24 & 0,13 & 0,13 & 0,33 \\
\hline
\end{tabular}

Tabelle 10: Serumkonzentrationen der einzelnen Hormone bezogen auf die Art der Pumpfunktionsstörung sowie das Vorliegen von Symptomen. 
Auch für diese Konzentrationsunterschiede zwischen symptomatischen und asymptomatischen Patienten erfolgte eine Signifikanzanalyse. In den Zeilen der Tabelle finden sich die einzelnen Schweregrade, in den Spalten die untersuchten Peptide. Signifikante Unterschiede sind mit einem Stern $\left(^{*}\right)$ markiert.

\begin{tabular}{|c|c|c|c|c|c|}
\hline & $\begin{array}{c}\text { NT- } \\
\text { proBNP }\end{array}$ & $\begin{array}{c}\text { MR- } \\
\text { proANP }\end{array}$ & $\begin{array}{c}\text { MR- } \\
\text { proADM }\end{array}$ & $\begin{array}{c}\text { CT- } \\
\text { proET-1 }\end{array}$ & $\begin{array}{c}\text { CT- } \\
\text { proAVP }\end{array}$ \\
\hline $\begin{array}{l}\text { asymptotische Signifikanz } \\
\text { Vergleich symptomatische und asymptomatische } \\
\text { Patienten mit LVEF } \geq 50 \% \text {, keine DD }\end{array}$ & $0,000^{*}$ & $0,009^{*}$ & $0,000^{*}$ & $0,017^{\star}$ & 0,085 \\
\hline $\begin{array}{l}\text { asymptotische Signifikanz } \\
\text { Vergleich symptomatische und asymptomatische } \\
\text { Patienten mit LVEF } \geq 50 \% \text {, DD Grad I }\end{array}$ & $0,000^{*}$ & $0,001^{*}$ & $0,000^{*}$ & $0,000^{*}$ & 0,440 \\
\hline $\begin{array}{l}\text { asymptotische Signifikanz } \\
\text { Vergleich symptomatische und asymptomatische } \\
\text { Patienten mit LVEF } \geq 50 \% \text {, DD Grad II-III }\end{array}$ & $0,001^{*}$ & $0,001^{*}$ & $0,000^{*}$ & $0,000^{*}$ & $0,026^{*}$ \\
\hline $\begin{array}{l}\text { asymptotische Signifikanz } \\
\text { Vergleich symptomatische und asymptomatische } \\
\text { Patienten mit LVEF } \geq 50 \% \text {, DD Grad I-III }\end{array}$ & $0,000^{*}$ & $0,000^{*}$ & $0,000^{*}$ & $0,000^{*}$ & 0,084 \\
\hline $\begin{array}{l}\text { asymptotische Signifikanz } \\
\text { Vergleich symptomatische und asymptomatische } \\
\text { Patienten mit LVEF }<50 \%\end{array}$ & 0,054 & 0,195 & $0,001^{*}$ & $0,000^{*}$ & $0,011^{*}$ \\
\hline
\end{tabular}

Tabelle 11: Die Tabelle zeigt die Signifikanzen für den Unterschied in der Serumkonzentration der genannten Peptide von symptomatischen und asymptomatischen Patienten in der jeweiligen Gruppe der Dysfunktion. Signifikante Unterschiede sind mit einem Stern $\left(^{*}\right)$ markiert.

In dieser Tabelle wird deutlich, dass symptomatische Patienten in der überwiegenden Zahl der Fälle eine signifikant höhere Konzentration der untersuchten Peptide im Blut aufweisen als asymptomatische Patienten. Die Ausnahme bildet hier zum Einen CT-proAVP, das nur in zwei der untersuchten Fälle signifikante Unterschiede zeigt. Zum Anderen liefern NT-proBNP und MR-proANP keine signifikanten Unterschiede bei der Unterscheidung zwischen symptomatischen und asymptomatischen Patienten mit reduzierter LVEF. Zur weiteren Illustration dieser Sachverhalte finden sich im Folgenden Fehlerbalken zu den jeweiligen Peptiden. Diese zeigen die logarithmierten Serumkonzentrationen für die jeweiligen Grade der Dysfunktion getrennt nach asymptomatischen und symptomatischen Patienten. Auch hier sind signifikante ( $p<0,05)$ Unterschiede zwischen asymptomatischen und symptomatischen Patienten mit einem Stern $\left(^{*}\right)$ gekennzeichnet. 


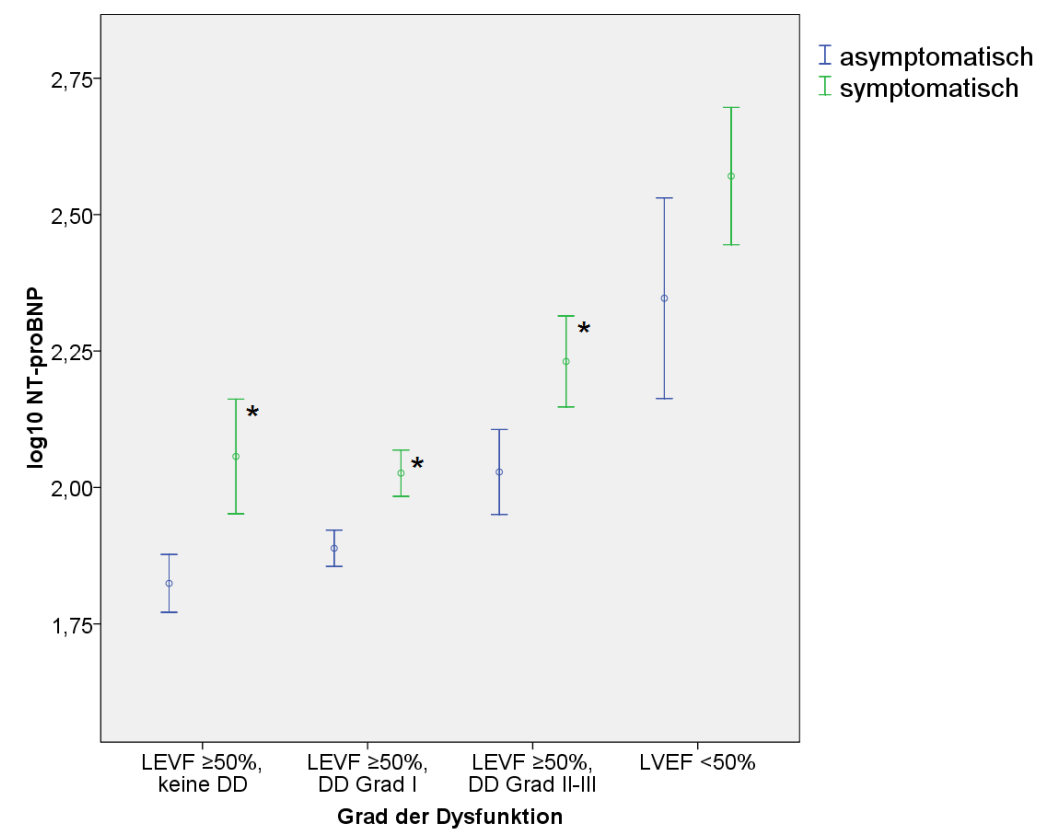

Abbildung 15: Auf der Ordinate sind die Serumkonzentrationen von log10 NT-proBNP für die einzelnen Grade der Dysfunktion (Abszisse) jeweils für symptomatische und asymptomatische Patienten gegenübergestellt. Signifikante Unterschiede zwischen symptomatischen und asymptomatischen Patienten sind mit einem Stern $\left({ }^{*}\right)$ markiert.

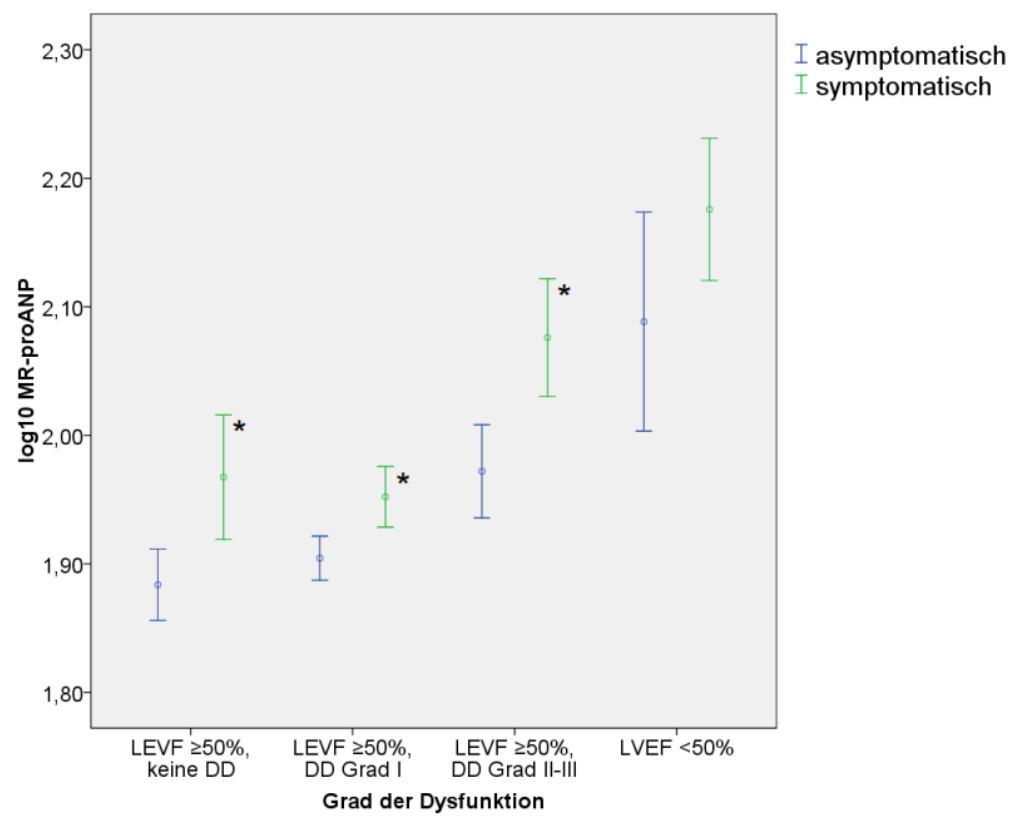

Abbildung 16: Auf der Ordinate sind die Serumkonzentrationen von log10 MR-proANP für die einzelnen Grade der Dysfunktion (Abszisse) jeweils für symptomatische und asymptomatische Patienten gegenübergestellt. Signifikante Unterschiede zwischen symptomatischen und asymptomatischen Patienten sind mit einem Stern $\left(^{*}\right)$ markiert. 


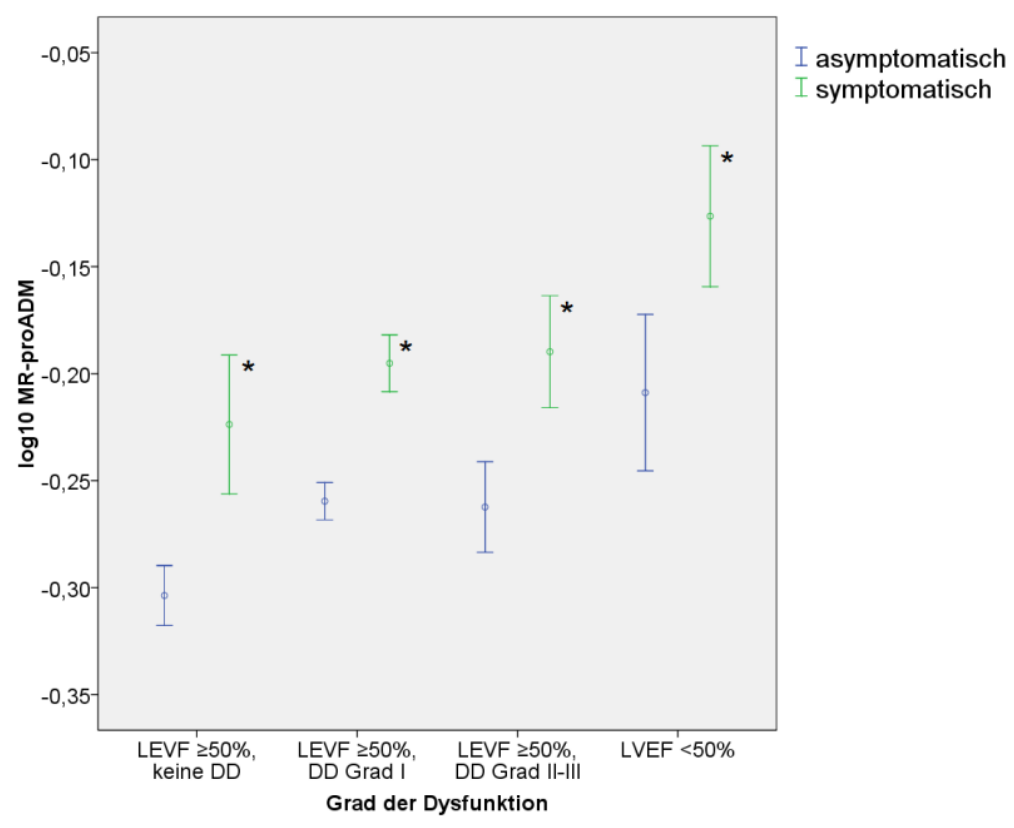

Abbildung 17: Auf der Ordinate sind die Serumkonzentrationen von log10 MR-proADM für die einzelnen Grade der Dysfunktion (Abszisse) jeweils für symptomatische und asymptomatische Patienten gegenübergestellt. Signifikante Unterschiede zwischen symptomatischen und asymptomatischen Patienten sind mit einem Stern $\left({ }^{*}\right)$ markiert.

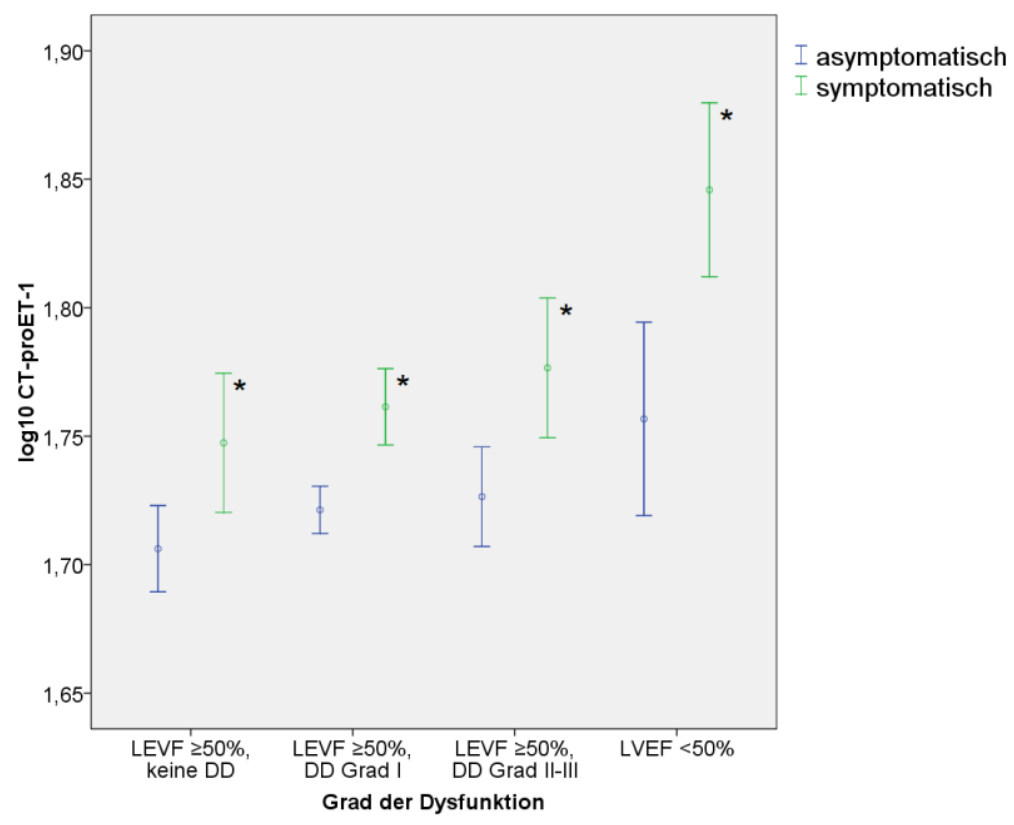

Abbildung 18: Auf der Ordinate sind die Serumkonzentrationen von log10 CT-proET-1 für die einzelnen Grade der Dysfunktion (Abszisse) jeweils für symptomatische und asymptomatische Patienten gegenübergestellt. Signifikante Unterschiede zwischen symptomatischen und asymptomatischen Patienten sind mit einem Stern $\left(^{*}\right)$ markiert. 


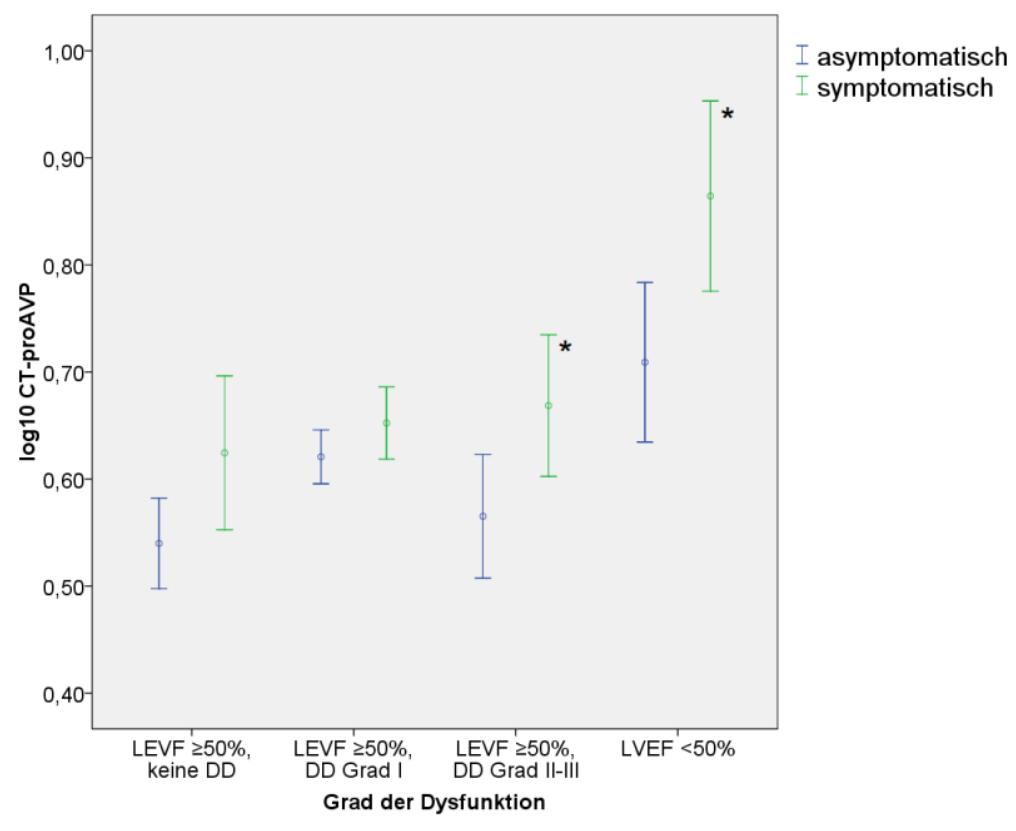

Abbildung 19: Auf der Ordinate sind die Serumkonzentrationen von log10 CT-proAVP für die einzelnen Grade der Dysfunktion (Abszisse) jeweils für symptomatische und asymptomatische Patienten gegenübergestellt. Signifikante Unterschiede zwischen symptomatischen und asymptomatischen Patienten sind mit einem Stern $\left({ }^{*}\right)$ markiert.

Zusammenfassend lässt sich also feststellen, dass ein Anstieg der Serumkonzentration der beschriebenen Werte vor allem beim Übergang von der Abwesenheit einer DD zu Grad I nach KNHI TP7 bei erhaltener LVEF zu beobachten ist. Eine weitere Steigerung beim Fortschreiten zu einer höhergradigen DD ist nicht bei allen Hormonen zu beobachten. Teilweise sind die Verteilungsmuster auch unterschiedlich. Die höchsten Werte zeigten stets die Patienten mit einer eingeschränkten LVEF. Symptomatische Patienten, definiert als Vorliegen mindestens eines Symptoms aus den Framingham-Kriterien, zeigen in den meisten Fällen unabhängig von der Gruppe höhere Werte als asymptomatische Patienten. 


\subsubsection{Zusammenhang zwischen den speziellen Laborparametern und Parametern der linksventrikulären Geometrie, der diastolischen Funktion und der Symptomatik}

Die Tabellen dieses Abschnitts geben eine Übersicht über Korrelationen der einzelnen, teilweise logarithmierten Werte der Laborparameter und Parametern der Echokardiografie und ausgewählten Symptomen der HF. Dabei kennzeichnet ein einzelner Stern $\left(^{*}\right)$ eine zweiseitige Signifikanz auf dem 0,05 Niveau, zwei Sterne $\left(^{* *}\right)$ dagegen eine zweiseitige Signifikanz auf dem 0,01 Niveau.

Aus der ersten Tabelle ist ersichtlich, dass die untersuchten Laborparameter und die Parameter der Echokardiografie fast ausnahmslos signifikant miteinander korrelieren. So finden sich etwa signifikante positive Korrelationen auf dem 0,05 Niveau von E/e' medial und allen Laborparametern mit Ausnahme von CT-proAVP. Ein ähnliches Bild zeigt sich bei der positiven Korrelation zwischen E/A-Verhältnis und den Laborparametern. Hier korreliert auch CT-proAVP mit E/A. Allerdings ist diese Korrelation, wie auch für CT-proET-1 und MRproADM, negativ.

\begin{tabular}{|l|l|c|c|c|c|c|}
\hline \multirow{2}{*}{ E/A } & Korrelationskoeffizient & $\begin{array}{c}\text { log10 NT- } \\
\text { proBNP }\end{array}$ & $\begin{array}{c}\text { log10 MR- } \\
\text { proANP }\end{array}$ & $\begin{array}{c}\text { log10 MR- } \\
\text { proADM }\end{array}$ & $\begin{array}{c}\text { log10 CT- } \\
\text { proET-1 }\end{array}$ & $\begin{array}{c}\text { log10 CT- } \\
\text { proAVP }\end{array}$ \\
\cline { 2 - 7 } & Signifikanz (2-seitig) & $0,036^{*}$ & $0,061^{* *}$ & $-0,080^{* *}$ & $-0,042^{*}$ & $-0,077^{* *}$ \\
\hline \multirow{2}{*}{\begin{tabular}{l}
\multirow{2}{*}{ E/e' } \\
medial
\end{tabular}} & Korrelationskoeffizient & $0,192^{* *}$ & $0,198^{* *}$ & $0,187^{* *}$ & $0,143^{* *}$ & 0,030 \\
\cline { 2 - 7 } & Signifikanz (2-seitig) & 0,000 & 0,000 & 0,000 & 0,000 & 0,064 \\
\hline \multirow{2}{*}{ LAVI } & Korrelationskoeffizient & $0,270^{* *}$ & $0,296^{* *}$ & $0,213^{* *}$ & $0,133^{* *}$ & $0,146^{* *}$ \\
\cline { 2 - 7 } & Signifikanz (2-seitig) & 0,000 & 0,000 & 0,000 & 0,000 & 0,000 \\
\hline \multirow{2}{*}{ LVMI } & Korrelationskoeffizient & $0,144^{* *}$ & $0,131^{* *}$ & $0,102^{* *}$ & $0,068^{* *}$ & $0,181^{* *}$ \\
\cline { 2 - 7 } & Signifikanz (2-seitig) & 0,000 & 0,000 & 0,000 & 0,000 & 0,000 \\
\hline \multirow{2}{*}{ S/D } & Korrelationskoeffizient & $-0,160^{* *}$ & $-0,129^{* *}$ & $-0,021$ & $-0,036^{*}$ & $-0,024$ \\
\cline { 2 - 7 } & Signifikanz (2-seitig) & 0,000 & 0,000 & 0,198 & 0,028 & 0,145 \\
\hline
\end{tabular}

Tabelle 12: Korrelationen zwischen Laborparametern und Echokardiografie sowie der Medikation. Ein einzelner Stern $\left(^{*}\right)$ kennzeichnet eine zweiseitige Signifikanz auf dem 0,05 Niveau, zwei Sterne $\left(^{* *}\right)$ dagegen eine zweiseitige Signifikanz auf dem 0,01 Niveau. 
Die folgende Tabelle verdeutlicht die Korrelationen zwischen den Laborparametern und ausgewählten Symptomen der HF. Hier ist beispielsweise ersichtlich, dass das Vorliegen einer Belastungsdyspnoe auf dem 0,05 Niveau signifikant und positiv mit sämtlichen untersuchten Laborparametern korreliert. Im Gegensatz dazu korrelieren Ruhe-, Belastungsund paroxysmale nächtliche Dyspnoe nicht oder nur in Ausnahmefällen mit den Laborparametern. Im Falle der Ödeme und der Nykturie zeigte sich hingegen fast durchgehend eine positive Korrelation auf 0,05 Niveau.

\begin{tabular}{|l|l|c|c|c|c|c|}
\hline & & $\begin{array}{c}\text { log10 NT- } \\
\text { proBNP }\end{array}$ & $\begin{array}{c}\text { log10 MR- } \\
\text { proANP }\end{array}$ & $\begin{array}{c}\text { log10 MR- } \\
\text { proADM }\end{array}$ & $\begin{array}{c}\text { log10 CT- } \\
\text { proET-1 }\end{array}$ & $\begin{array}{c}\text { log10 CT- } \\
\text { proAVP }\end{array}$ \\
\hline \multirow{2}{*}{$\begin{array}{l}\text { Belastungs- } \\
\text { dyspnoe }\end{array}$} & Korrelationskoeffizient & $0,154^{* *}$ & $0,132^{* *}$ & $0,236^{* *}$ & $0,189^{* *}$ & $0,103^{* *}$ \\
\cline { 2 - 7 } & Signifikanz (2-seitig) & 0,000 & 0,000 & 0,000 & 0,000 & 0,000 \\
\hline \multirow{2}{*}{ Ruhedyspnoe } & Korrelationskoeffizient & 0,015 & 0,001 & $0,041^{*}$ & 0,023 & 0,001 \\
\cline { 2 - 7 } & Signifikanz (2-seitig) & 0,454 & 0,956 & 0,038 & 0,240 & 0,958 \\
\hline \multirow{2}{*}{$\begin{array}{l}\text { nächtliche } \\
\text { Dyspnoe }\end{array}$} & Korrelationskoeffizient & 0,017 & 0,008 & 0,026 & 0,039 & 0,031 \\
\hline \multirow{2}{*}{ Orthopnoe } & Signifikanz (2-seitig) & 0,387 & 0,687 & 0,199 & 0,051 & 0,125 \\
\hline \multirow{2}{*}{ Ödeme } & Korrelationskoeffizient & 0,031 & 0,019 & $0,077^{* *}$ & $0,057^{* *}$ & 0,030 \\
\cline { 2 - 7 } & Signifikanz (2-seitig) & 0,116 & 0,333 & 0,000 & 0,004 & 0,137 \\
\hline \multirow{2}{*}{ Nykturie } & Korrelationskoeffizient & $0,133^{* *}$ & $0,115^{* *}$ & $0,226^{* *}$ & $0,179^{* *}$ & $0,072^{* *}$ \\
\cline { 2 - 7 } & Signifikanz (2-seitig) & 0,000 & 0,000 & 0,000 & 0,000 & 0,000 \\
\cline { 2 - 7 } & Korrelationskoeffizient & $0,151^{* *}$ & $0,146^{* *}$ & $0,167^{* *}$ & $0,129^{* *}$ & $0,052^{* *}$ \\
\cline { 2 - 7 } & Signifikanz (2-seitig) & 0,000 & 0,000 & 0,000 & 0,000 & 0,009 \\
\hline
\end{tabular}

Tabelle 13: Korrelationen zwischen Laborparametern und ausgewählten Symptomen der Herzinsuffizienz. Ein einzelner Stern (*) kennzeichnet eine zweiseitige Signifikanz auf dem 0,05 Niveau, zwei Sterne $\left({ }^{* *}\right)$ dagegen eine zweiseitige Signifikanz auf dem 0,01 Niveau. 
Die letzte Tabelle dieses Abschnittes zeigt die Korrelationen zwischen den Laborparametern und den Framingham-Kriterien. Auch hier zeigt sich bei den verschiedenen Modellen stets eine positive, auf dem 0,05 Niveau signifikante positive Korrelation zwischen den Parametern.

\begin{tabular}{|l|l|c|c|c|c|c|}
\hline & & $\begin{array}{c}\text { log10 NT- } \\
\text { proBNP }\end{array}$ & $\begin{array}{c}\text { log10 MR- } \\
\text { proANP }\end{array}$ & $\begin{array}{c}\text { log10 MR- } \\
\text { proADM }\end{array}$ & $\begin{array}{c}\text { log10 CT- } \\
\text { proET-1 }\end{array}$ & $\begin{array}{c}\text { log10 CT- } \\
\text { proAVP }\end{array}$ \\
\hline \multirow{2}{*}{$\begin{array}{l}\text { Framingham- } \\
\text { Summe }\end{array}$} & Korrelationskoeffizient & $0,177^{* *}$ & $0,145^{* *}$ & $0,256^{* *}$ & $0,208^{* *}$ & $0,096^{* *}$ \\
\cline { 2 - 7 } & Signifikanz (2-seitig) & 0,000 & 0,000 & 0,000 & 0,000 & 0,000 \\
\hline \multirow{2}{*}{$\begin{array}{l}\text { M Major oder 2 } \\
\text { Minor }\end{array}$} & Korrelationskoeffizient & $0,119^{* *}$ & $0,102^{* *}$ & $0,205^{* *}$ & $0,182^{* *}$ & $0,111^{* *}$ \\
\cline { 2 - 7 } & Signifikanz (2-seitig) & 0,000 & 0,000 & 0,000 & 0,000 & 0,000 \\
\hline \multirow{2}{*}{$\begin{array}{l}\text { Major oder 1 } \\
\text { Major + Minor }\end{array}$} & Korrelationskoeffizient & $0,094^{* *}$ & $0,084^{* *}$ & $0,144^{* *}$ & $0,138^{* *}$ & $0,100^{* *}$ \\
\cline { 2 - 7 } & Signifikanz (2-seitig) & 0,000 & 0,000 & 0,000 & 0,000 & 0,000 \\
\hline \multirow{2}{*}{$\begin{array}{l}\text { Framingham- } \\
\text { Summe } \geq 4\end{array}$} & Korrelationskoeffizient & $0,092^{* *}$ & $0,081^{* *}$ & $0,143^{* *}$ & $0,143^{* *}$ & $0,097^{* *}$ \\
\cline { 2 - 7 } & Signifikanz (2-seitig) & 0,000 & 0,000 & 0,000 & 0,000 & 0,000 \\
\hline
\end{tabular}

Tabelle 14: Korrelationen zwischen verschiedenen Darstellungen der Framingham-Kriterien und den Laborparametern. Ein einzelner Stern $\left({ }^{*}\right)$ kennzeichnet eine zweiseitige Signifikanz auf dem 0,05 Niveau, zwei Sterne $\left(^{* \star}\right)$ dagegen eine zweiseitige Signifikanz auf dem 0,01 Niveau.

Zusammenfassend ist festzustellen, dass die untersuchten Laborparameter mit den Parametern der DD in der Echokardiografie fast durchgehend signifikant korrelieren. Betrachtet man die einzelnen Symptome der Herzinsuffizienz und die Modelle der Framingham-Kriterien, ist ebenfalls eine überwiegend signifikante Korrelation ersichtlich. 


\subsubsection{Regressionsanalysen für E/e‘}
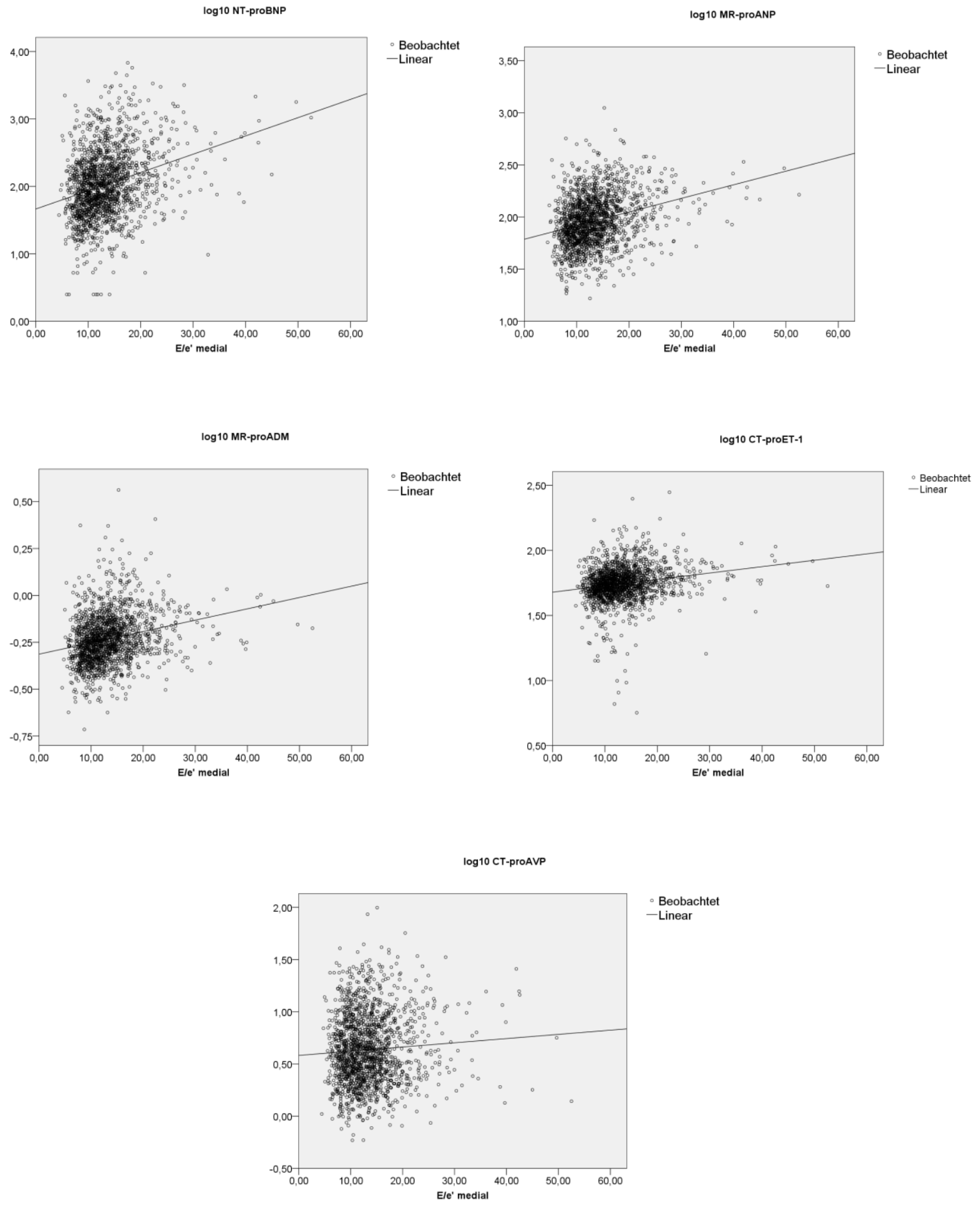

Abbildung 20: Dargestellt sind die Häufigkeiten der Serumkonzentrationen für die einzelnen Laborparameter in Bezug auf E/e'. Die oberste Reihe zeigt log10 NT-proBNP und log10 MRproANP. In der Mitte finden sich die Grafiken für log10 MR-proADM und log10 CT-proET-1, in der untersten Reihe schließlich log10 CT-proAVP. 


\subsubsection{Regressionsanalyse für LAVI}
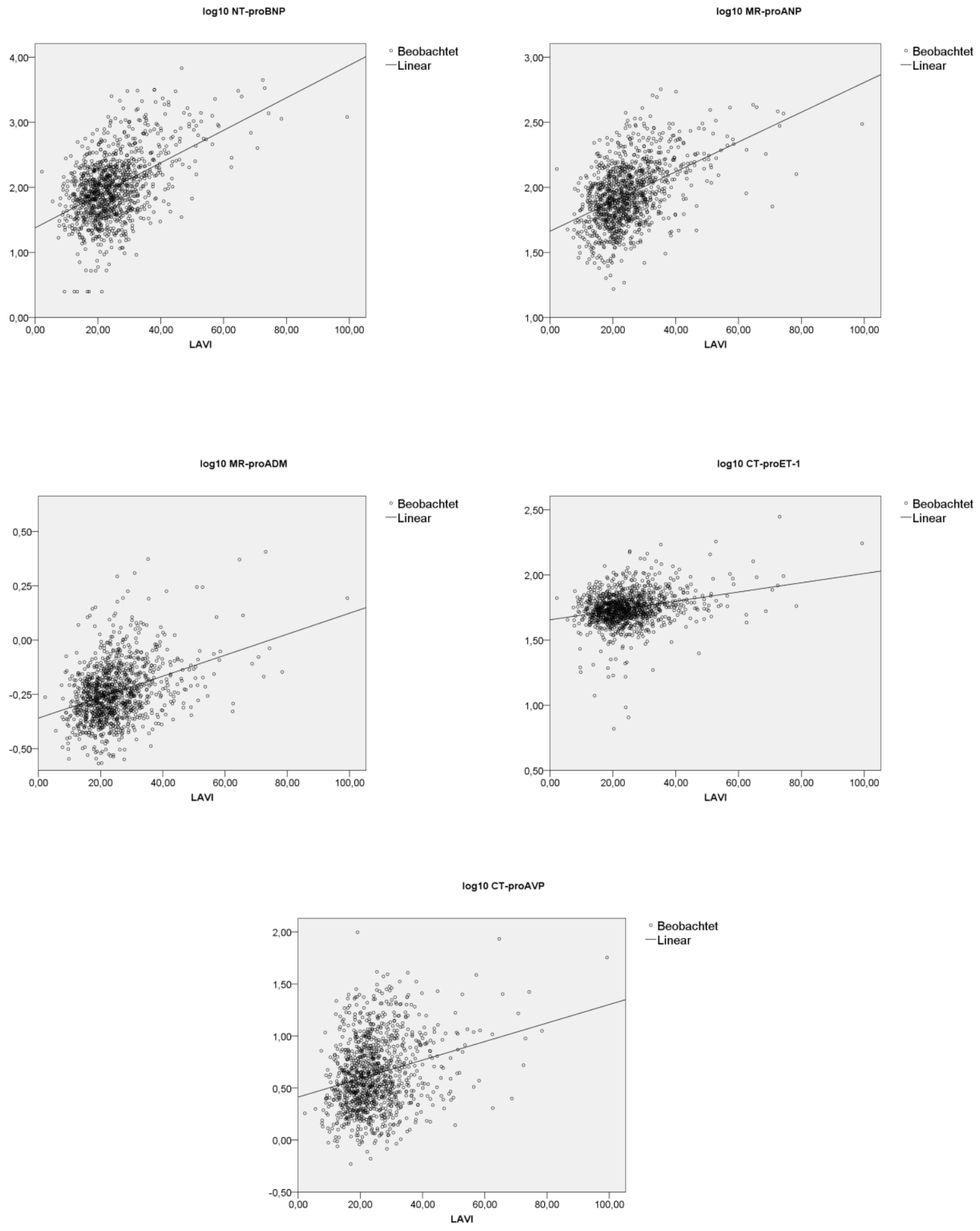

Abbildung 21: Dargestellt sind die Häufigkeiten der Serumkonzentrationen für die einzelnen Laborparameter in Bezug auf LAVI. Die oberste Reihe zeigt log10 NT-proBNP und log10 MR-proANP. In der Mitte finden sich die Grafiken für log10 MR-proADM und $\log 10$ CTproET-1, in der untersten Reihe schließlich log10 CT-proAVP. 


\subsubsection{Regressionsanalyse für Symptome}
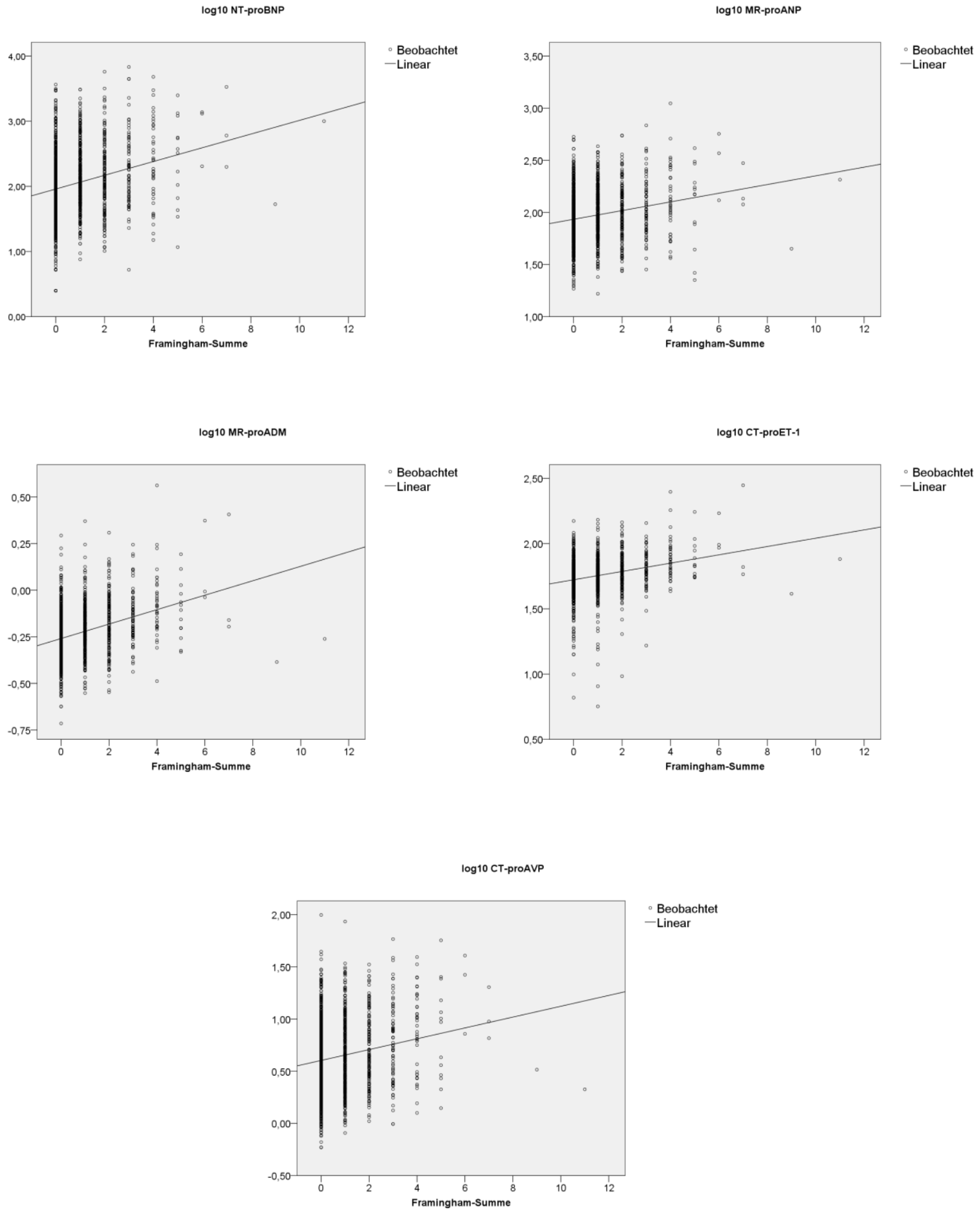

Abbildung 22: Dargestellt sind die Häufigkeiten der Serumkonzentrationen für die einzelnen Laborparameter in Bezug auf die Summe der vorliegenden Framingham-Symptome. Die oberste Reihe zeigt log10 NT-proBNP und log10 MR-proANP. In der Mitte finden sich die Grafiken für log10 MR-proADM und log10 CT-proET-1, in der untersten Reihe schließlich $\log 10$ CT-proAVP. 


\subsubsection{Diskrimination von Anwesenheit und Abwesenheit einer ventrikulären Dysfunktion anhand der Laborparameter}

Dieses Kapitel behandelt die Frage nach der Eignung der einzelnen Laborparameter zur Detektion einer DD oder eingeschränkten LVEF und zur Diskrimination zwischen Vorliegen einer solchen Funktionsstörung des Herzens und deren Abwesenheit. Dies geschieht anhand von Receiver Operating Characteristic-Kurven (ROC-Kurven). Dabei sind jeweils Sensitivität und Spezifität für jeden Messpunkt gegeneinander aufgetragen. In der zugehörigen Tabelle sind die Flächen unter der Kurve (AUC) für jeden Parameter aufgeführt. Ein höherer Wert steht dabei für eine höhere Trennschärfe des Parameters.

Zusammenfassend ergibt sich, dass die untersuchten Peptide auf Grund ihrer niedrigen Trennschärfe nur bedingt zur Unterscheidung zwischen An- und Abwesenheit einer DD geeignet sind. Auch deren Stadien lassen sich nur bedingt unterscheiden. Betrachtet man die Diskrimination zwischen reduzierter und nicht reduzierter LVEF, zeigen die Peptide deutlich bessere Trennschärfen. Meist besitzen NT-proBNP und NT-proANP die höchsten AUC. 


\subsubsection{Diskrimination zwischen Abwesenheit einer DD und Anwesenheit einer diastolischen Dysfunktion Grad I}

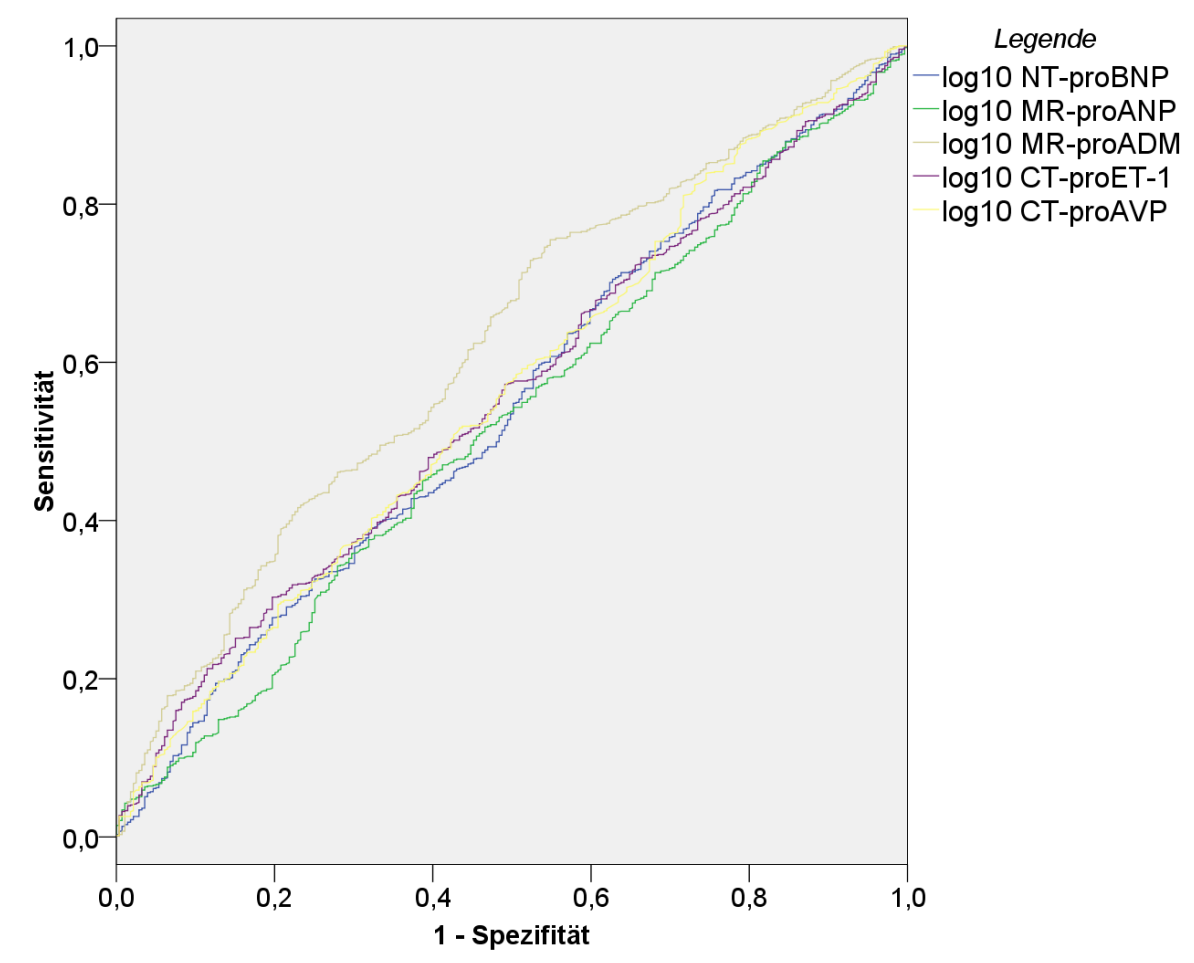

Abbildung 23: ROC-Kurven für die einzelnen Peptide in Bezug auf eine Diskrimination zwischen Abwesenheit einer DD und Anwesenheit einer DD Grad I.

\begin{tabular}{|l|c|}
\hline & AUC \\
\hline $\log 10$ NT-proBNP & 0,54 \\
\hline $\log 10$ MR-proANP & 0,52 \\
\hline $\log 10$ MR-proADM & 0,62 \\
\hline $\log 10$ CT-proET-1 & 0,55 \\
\hline $\log 10$ CT-proAVP & 0,56 \\
\hline
\end{tabular}

Tabelle 15: Fläche unter der Kurve (AUC) für die Diskrimination zwischen Abwesenheit einer DD und Anwesenheit einer DD Grad I.

Im Falle der Diskrimination zwischen dem Vorliegen einer DD Grad I und der Abwesenheit einer solchen zeigt sich, dass die AUC der einzelnen Hormone nur wenig über der Fläche einer Zufallsentscheidung $(0,5)$ liegen. Den höchsten gemessenen Wert weist hier das MRproADM auf $(0,62)$. Das heißt, dass die Parameter zur Unterscheidung der beiden Zustände eine nur bedingte Eignung zeigen. 


\subsubsection{Diskrimination zwischen Vorliegen einer diastolischen Dysfunktion Grad I und II-III}

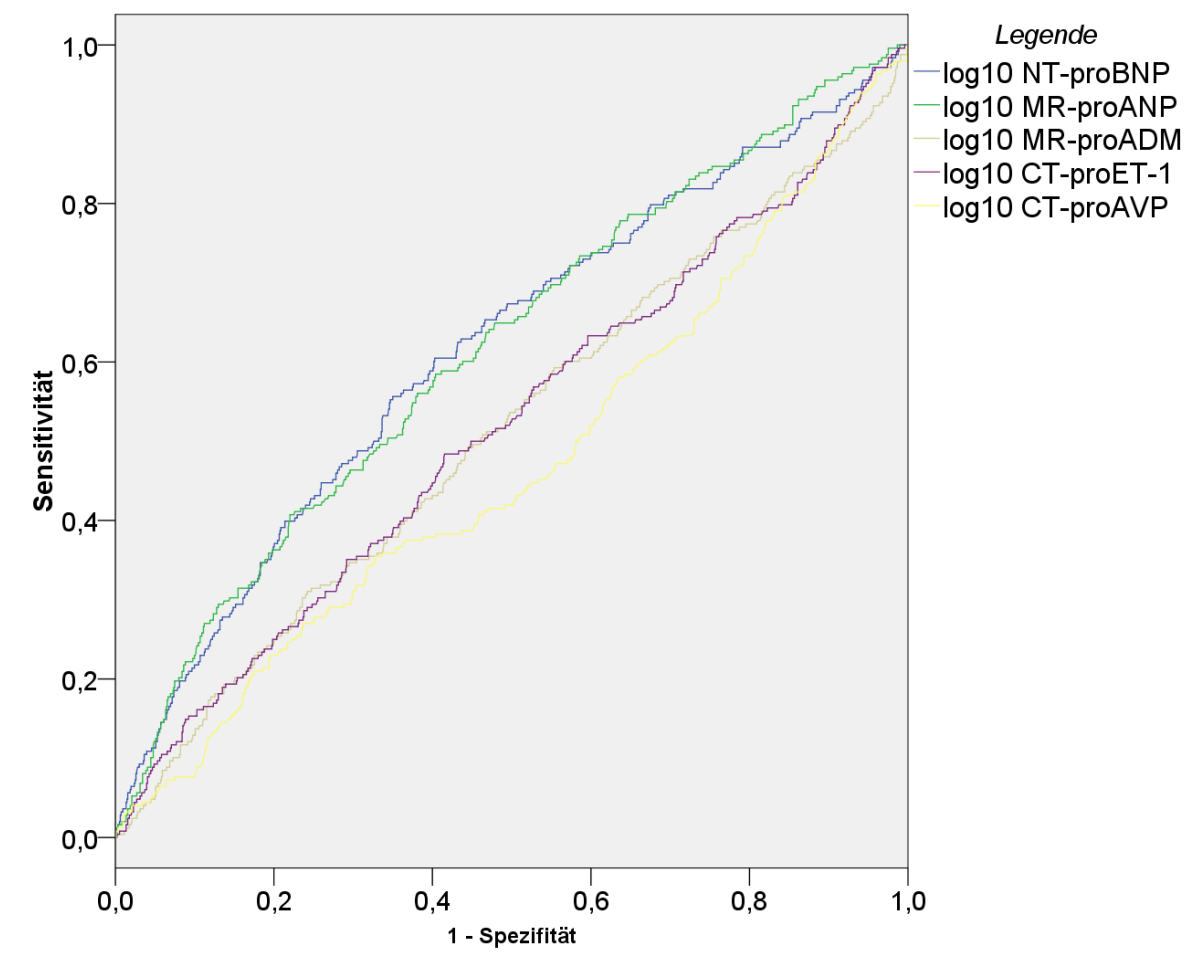

Abbildung 24: ROC-Kurven für die einzelnen Peptide in Bezug auf eine Diskrimination zwischen DD Grad I und II-III.

\begin{tabular}{|l|c|}
\hline & AUC \\
\hline $\log 10$ NT-proBNP & 0,62 \\
\hline $\log 10$ MR-proANP & 0,62 \\
\hline $\log 10$ MR-proADM & 0,52 \\
\hline $\log 10$ CT-proET-1 & 0,52 \\
\hline $\log 10$ CT-proAVP & 0,47 \\
\hline
\end{tabular}

Tabelle 16: Fläche unter der Kurve (AUC) für die Diskrimination zwischen einer DD Grad I und einer DD Grad II-III.

Ähnlich wie im vorigen Fall liegen die höchsten AUC von NT-proBNP und NT-proANP bei 0,6. Im Falle von CT-proAVP $(0,47)$ liegt die Kurve unter der einer Zufallsentscheidung $(0,5)$. Deshalb eignen sich die genannten Parameter ebenfalls nur bedingt zur Unterscheidung der beiden Schweregrade der DD Grad I und Grad II-III. 


\subsubsection{Diskrimination zwischen Abwesenheit einer diastolischen Dysfunktion und Vorliegen einer diastolischen Dysfunktion jeglichen Grades}

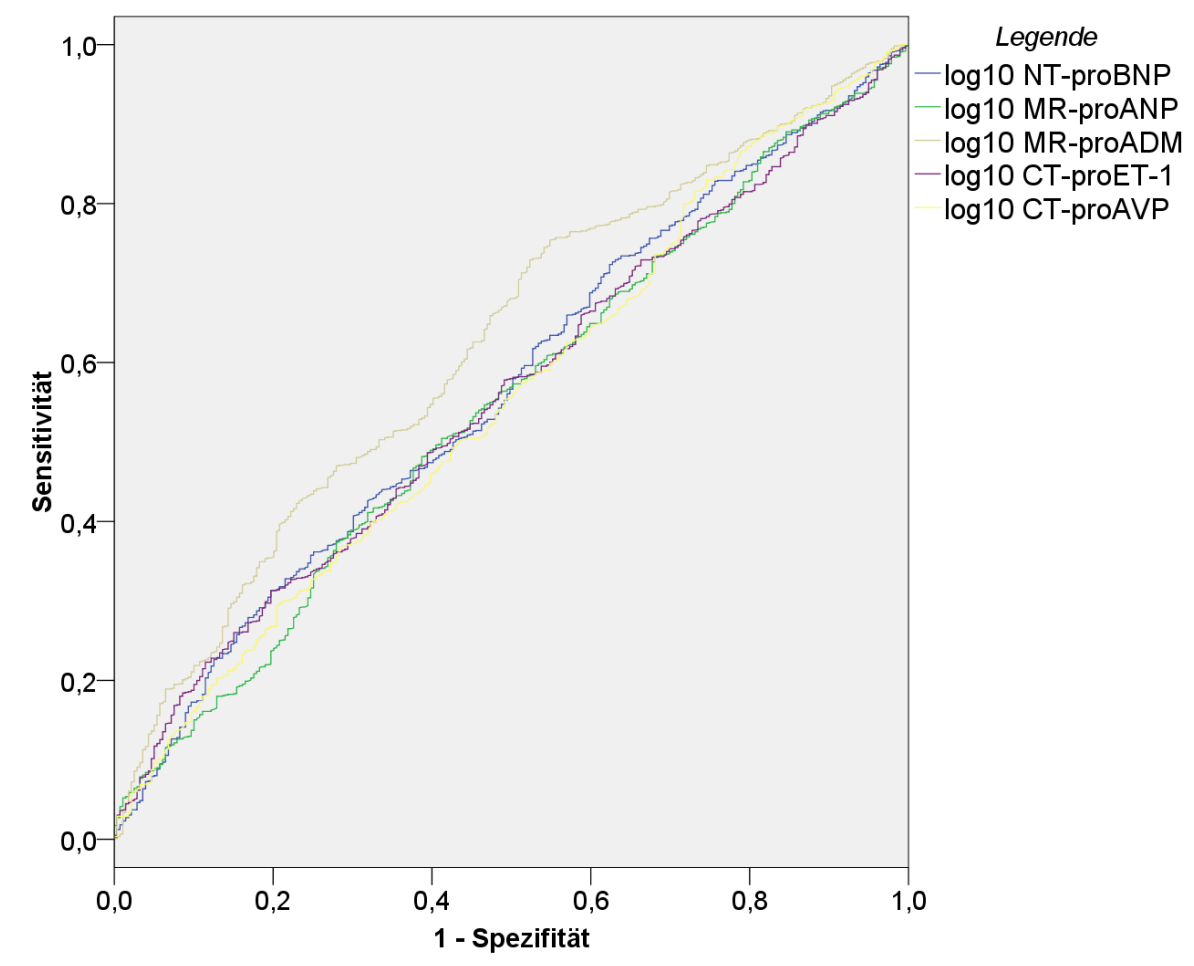

Abbildung 25: ROC-Kurven für die einzelnen Peptide in Bezug auf eine Diskrimination zwischen DD Grad 0 und DD jeglichen Grades.

\begin{tabular}{|l|c|}
\hline & AUC \\
\hline $\log 10$ NT-proBNP & 0,57 \\
\hline $\log 10$ MR-proANP & 0,55 \\
\hline $\log 10$ MR-proADM & 0,62 \\
\hline $\log 10$ CT-proET-1 & 0,56 \\
\hline $\log 10$ CT-proAVP & 0,55 \\
\hline
\end{tabular}

Tabelle 17: Fläche unter der Kurve (AUC) für die Diskrimination zwischen An- Abwesenheit einer DD jeglichen Grades.

Bei der Unterscheidung zwischen der Abwesenheit einer DD und dem Vorliegen einer solchen unabhängig vom Schweregrad sind die AUC, wie in den Entscheidungen zuvor, relativ niedrig. Anders als in den vorherigen Betrachtungen besitzt hier allerdings MRproADM mit 0,62 die höchste AUC und damit die höchste Trennschärfe. 


\subsubsection{Diskrimination zwischen eingeschränkter und nicht eingeschränkter linksventrikulärer Ejektionsfraktion}

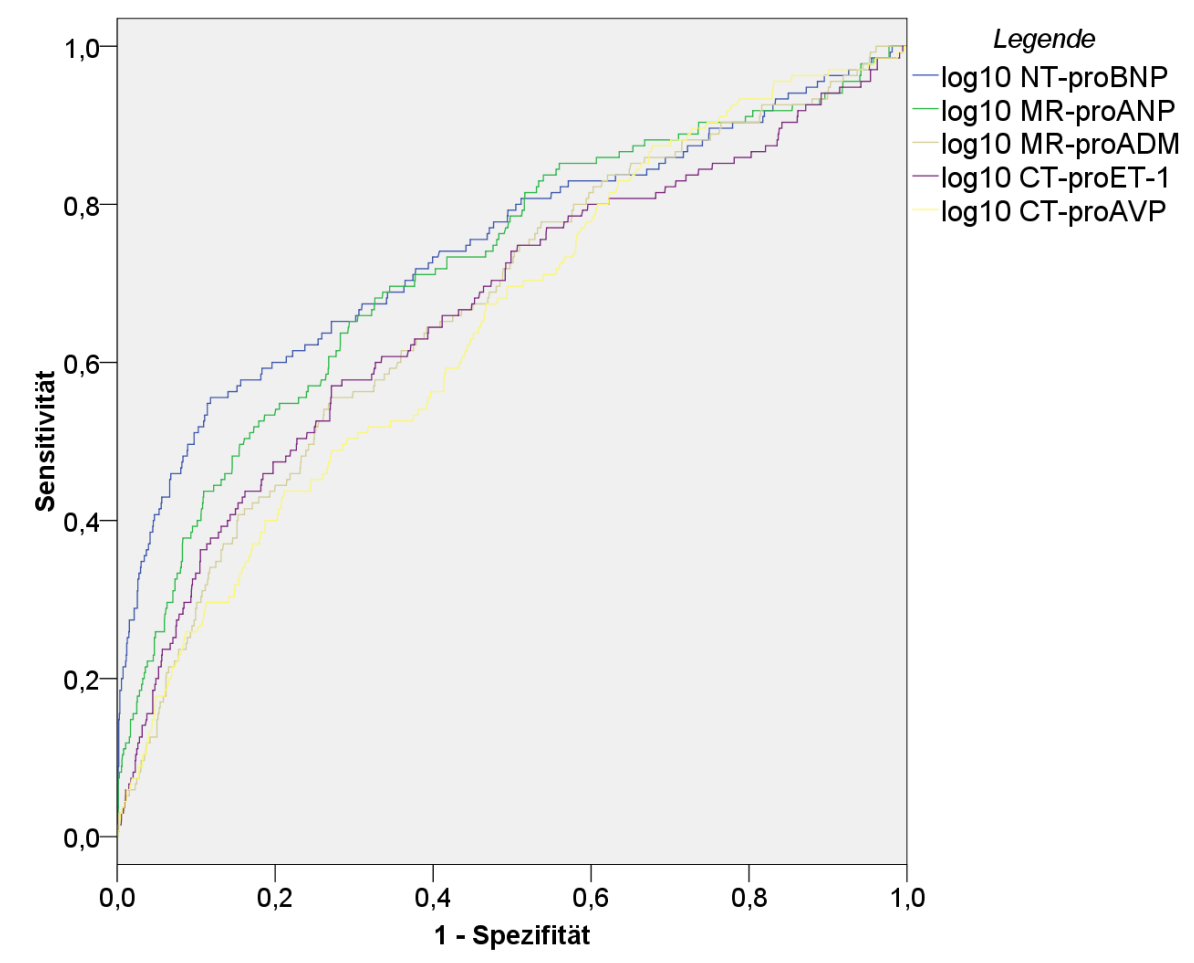

Abbildung 26: ROC-Kurven für die einzelnen Peptide in Bezug auf eine Diskrimination zwischen Patienten mit LVEF $\geq 50 \%$ und Patienten mit LVEF $<50 \%$.

\begin{tabular}{|l|c|}
\hline & AUC \\
\hline $\log 10$ NT-proBNP & 0,75 \\
\hline $\log 10$ MR-proANP & 0,72 \\
\hline $\log 10$ MR-proADM & 0,67 \\
\hline $\log 10$ CT-proET-1 & 0,67 \\
\hline $\log 10$ CT-proAVP & 0,65 \\
\hline
\end{tabular}

Tabelle 18: Fläche unter der Kurve (AUC) für die Diskrimination zwischen Patienten mit LVEF $\geq 50 \%$ und Patienten mit LVEF $<50 \%$.

Bei der Unterscheidung zwischen Vorliegen einer reduzierten LVEF von $<50 \%$ und dem Vorliegen einer nicht reduzierten LVEF $>50 \%$ zeigen die Parameter eine bessere Diskriminationsfähigkeit als es bei der DD der Fall war. Vor allem NT-proBNP und MRproANP zeigen relativ hohe AUC von über 0,7. Auch die AUC der anderen Parameter sind höher als bei der Diskrimination der DD. 


\section{Diskussion}

Neben der systolischen Dysfunktion (SD) ist auch die diastolische Dysfunktion (DD), pathophysiologisches Korrelat der diastolischen Herzinsuffizienz (DHF), bereits im asymptomatischen Stadium mit einer reduzierten Prognose assoziiert. Für die DD gibt es keine einheitlichen Diagnoserichtlinien sondern verschiedene, hauptsächlich auf der Echokardiografie basierende Schemata. Diese sind untereinander nur bedingt vergleichbar und im klinischen Alltag nicht immer praktikabel einsetzbar.

Wünschenswert wäre es, einen serologischen Marker zu finden, dessen Konzentration im Blut sich mit Auftreten der Erkrankung reproduzierbar verändert und der somit einen Surrogatparameter zur Diagnosefindung der DD darstellen könnte. Dies würde helfen, an einer DD oder DHF erkrankte Patienten von nicht Erkrankten zu unterscheiden. Hilfreich wäre auch der Nachweis einer Korrelation zwischen dem Schweregrad der Erkrankung sowie deren Symptomatik und der Konzentration eines solchen Markers. Dadurch käme dieser auch als Verlaufsparameter in Frage, um eine Progression der Erkrankung abzuschätzen und den Erfolg einer Therapie zu überwachen. Im Idealfall wäre dieser Marker zur primären Detektion einer DD oder DHF fähig und könnte somit die bisher uneinheitliche Diagnosefindung, etwa durch die Echokardiografie, vereinfachen und unterstützen.

Bisher haben nur wenige Studien den Stellenwert der neurohumoralen Aktivierung bezüglich ihrer diagnostischen Fähigkeiten untersucht. Auch die Eignung der Parameter zur Verlaufkontrolle und Therapieüberwachung ist weitgehend unklar. Zu diesem Zweck wurden in dieser Arbeit die Hormone bzw. Hormonfragmente NT-proBNP, MR-proANP, CT-pro-ET-1, CT-proAVP und MR-proADM auf ihre Tauglichkeit als Serummarker der DD hin untersucht. Teilweise haben sich diese Marker, wie in der Einleitung beschrieben, bereits bei der Detektion der SD und Herzinsuffizienz (SHF) als hilfreich erwiesen. Im Folgenden sollen die Ergebnisse der vorliegenden Arbeit bewertet und in den bisherigen Wissensstand der Forschung zu diesem Thema eingeordnet werden.

\subsection{Studiendesign und Patientenkollektiv}

In der dieser Arbeit zu Grunde liegenden prospektiven und multizentrischen Kohortenstudie „Prävalenz und Verlauf der diastolischen Dysfunktion und der diastolischen Herzinsuffizienz“ (Diast-CHF) des Teilprojektes 7 (TP7) Diastolische Dysfunktion des Kompetenznetzes Herzinsuffizienz (KNHI) wurden 1687 Patienten untersucht. Die Rekrutierung erfolgte über Praxis-EDV von Hausärzten beziehungsweise den Basisdatensatz der Abteilung Allgemeinmedizin der Universitätsmedizin Göttingen. Bedingung war das Vorliegen 
mindestens eines Risikofaktors für die Entwicklung einer DD oder eine bereits von ärztlicher Seite gestellte Diagnose einer HF. Somit untersuchte die Studie ein Risikokollektiv, das nicht vorselektiert war. Dies entspricht der Situation im klinischen Alltag, in der bei einem Patienten beispielsweise der Verdacht auf das Vorliegen einer DD oder DHF geäußert wurde und eine diagnostische Bestätigung erwünscht ist. Tschöpe et al. (2005) untersuchten die Eignung von NT-proBNP als alleiniges diagnostisches Mittel der DD. In dieser Untersuchung wurde im Gegensatz zur vorliegenden Arbeit ein vorselektiertes Kollektiv von Patienten mit bereits bekannter DD einer gesunden Kontrollgruppe gegenübergestellt. Somit war zwar ein Vergleich zwischen gesunden und erkrankten Probanden im etwa gleichen Verhältnis möglich, allerdings kann deshalb nur bedingt Rückschluss auf die Fähigkeiten zur Detektion einer nur vermeintlich vorliegenden DD gezogen werden. Einen anderen Ansatz verfolgten Redfield et al. (2004) in ihrer Studie zur Eignung von BNP als Surrogatparameter zur Detektion einer DD oder SD. Hier wurden die Patienten zufällig aus dem Rochester Epidemiology Project ausgewählt, einem Register zur Erfassung der Inzidenz von Erkrankungen bei Bewohnern im amerikanischen Bundesstaat Minnesota. Somit wurden in diesem Falle sowohl Vorerkrankungen als auch Risikofaktoren der Probanden nicht als Rekrutierungskriterium betrachtet.

In der vorliegenden Arbeit wurden 1687 Patienten untersucht, dabei waren Männer mit 49.9\% und Frauen mit 50,1\% annähernd gleich vertreten. Bei Tschöpe et al. (2005) findet sich ein leichtes Überwiegen des männlichen Geschlechts mit $55 \%$ bei einer wesentlich geringeren Patientenzahl von 118 inklusive 50 Kontrollprobanden mit regulärer diastolischer Funktion, bei Redfield et al. (2004) sind Männer mit 48\% leicht in der Unterzahl. Hier betrug die Gesamtzahl der untersuchten Fälle 2042. Eine klare Geschlechtspräferenz ist somit in keiner Arbeit zu finden, was die unklare Situation in der Literatur diesbezüglich widerspiegelt. Bezüglich des BMl fällt auf, dass die Patienten von Tschöpe et al. (2005) mit einem Mittelwert von $26,1 \mathrm{~kg} / \mathrm{m}^{2}$ deutlich niedrigere Werte als im Falle der beiden anderen Studien aufweisen. Die Daten von Redfield et al. (2004) und Diast-CHF sind höher und mit 28,4 $\mathrm{kg} / \mathrm{m}^{2}$ beziehungsweise $29,12 \mathrm{~kg} / \mathrm{m}^{2}$ in etwa vergleichbar. Dies könnte unter anderem daran liegen, dass das Kollektiv von Tschöpe et al. (2005) mit einem Mittelwert von 49 Jahren deutlich jünger war. Sowohl Redfield et al. (2004) mit 62 Jahren, als auch Diast-CHF mit 65,98 Jahren haben ein im Mittelwert deutlich älteres Kollektiv untersucht und sind vom Alter her vergleichbar. Außerdem dürfte die Art der Rekrutierung ein weiterer einflussreicher Faktor sein. Im Gesamtkollektiv von Tschöpe et al. (2005) sind gesunde Kontrollprobanden enthalten, über deren kardiovaskuläre Risikofaktoren keine Angaben gemacht werden. Übergewicht stellt allerdings einen wesentlichen Risikofaktor von kardiovaskulären Erkrankungen im Allgemeinen und der DD im Speziellen dar (Fischer et al. 2003). Bezüglich 
Herzfrequenz und Blutdruckwerten liefern weder Redfield et al. (2004), noch Tschöpe et al. (2005) Werte. Grewal et al. (2008) untersuchten 181 Patienten mit LVEF >40\% und NYHA IIIV aus einer echokardiografischen Substudie von CHARM. Die Patienten wurden dann mittels Doppler-Echokardiografie den Gruppen normale, milde oder moderate bis schwere DD zugeordnet. Das mittlere Alter war mit 65 Jahren mit dem von Diast-CHF vergleichbar. Die Mittelwerte für Herzfrequenz $(68 / \mathrm{min})$, systolischer $(134,5 \mathrm{mmHg})$ und diastolischer Blutdruck $(77 \mathrm{mmHg}$ ) lagen alle etwas unter den Werten von Diast-CHF mit 70,59/min, 146,01 und 82,92 mmHg. Auf die Herzfrequenz könnte sich die bei Grewal et al. (2008) deutlich häufigere Medikation mit Betablockern ausgewirkt haben, 64\% stehen hier 44,4\% bei Diast-CHF gegenüber. Die Blutdruckwerte könnten ebenfalls durch die Medikation beeinflusst sein, allerdings ergibt sich hier kein klares Bild. Bei Diast-CHF überwiegen ACEHemmer mit 41,3\% gegenüber 19\% bei Grewal et al. (2008) deutlich. Auf der anderen Seite war die Verordnung von Diuretika mit $67 \%$ bei Grewal et al. (2008) etwas häufiger als bei Diast-CHF mit insgesamt 53,6\%. In diesem Zusammenhang ist noch zu betonen, dass Grewal et al. (2008) nur Patienten ab NYHA II einschlossen und somit ein ausschließlich symptomatisches Kollektiv untersuchten. Dies ist eine mögliche Erklärung für die Unterschiede in der Medikation der beiden Kollektive.

Die arterielle Hypertonie war im Falle von Diast-CHF mit 78,7\% der am häufigsten vorhandene Risikofaktor. Bei Tschöpe et al. (2005) war der Anteil der Hypertoniker mit 37\% deutlich geringer. Im Kollektiv der DD war der Anteil mit 43\% nur wenig höher. Im Falle des Diabetes mellitus zeigte Diast-CHF mit 23,6\% eine höhere Fallzahl als Tschöpe et al. (2005) mit $9 \%$ im Gesamtkollektiv und 13\% in der Gruppe der DD. Vermutlich ist das Alter ein beeinflussender Faktor dieser Sachverhalte. Allerdings finden sich auch bei Redfield et al. (2004), deren Kollektiv bezüglich des Alters mit dem Kollektiv von Diast-CHF vergleichbar ist, deutlich geringere Fallzahlen für arterielle Hypertonie (29,5\%) und Diabetes mellitus (7,5\%). Der Grund dafür ist wahrscheinlich hauptsächlich in der Art der Rekrutierung zu suchen. Einschlusskriterium für Diast-CHF war, dass zum Zeitpunkt der Rekrutierung bereits mindestens ein Risikofaktor vorlag. Redfield et al. (2004) dagegen wählten ihre Patienten zufällig aus einem Krankenregister aus. Bemerkenswert ist außerdem, dass hier ein gesondertes Hochrisikokollektiv aufgestellt wurde, in dem Patienten $\geq 65$ Jahre mit entweder einem arteriellen Hypertonus oder KHK erfasst wurden. Die hier anzutreffende Zahl von 78,9\% Hypertonikern ist mit Diast-CHF vergleichbar.

Wie bereits erwähnt, waren Betablocker in Diast-CHF die am häufigsten verordnete Substanzgruppe mit kardiovaskulärer Indikation. Bei 44,4\% der Patienten fand sich ein solcher Wirkstoff in der Vormedikation. Im Gesamtkollektiv von Redfield et al. (2004) nahmen dagegen nur $14,5 \%$ der Patienten einen Betablocker ein. Für die ACE-Hemmer ergibt sich 
ein ähnliches Bild, 9,0\% der Patienten von Redfield et al. (2004) stehen 41,3\% der Patienten von Diast-CHF gegenüber. Die Verordnungshäufigkeit von Diuretika wird von Redfield et al. (2004) allgemein mit 17\% angegeben, während bei Diast-CHF eine genaue Aufschlüsselung nach Substanzuntergruppen zu finden ist. Allein Thiazide erhielten hier allerdings $36,8 \%$ der Patienten. Dabei kommt vermutlich erneut die Art der Rekrutierung zum Tragen. Sämtliche Patienten in Diast-CHF zeigten kardiovaskuläre Auffälligkeiten. Redfield et al. (2004) dagegen rekrutierten ihre Patienten aus einem Krankenregister auf Zufallsbasis und somit nicht nur kardiovaskulär Erkrankte. Die deutlich höhere Häufigkeit der Betablocker im Hochrisikokollektiv von Redfield et al. (2004) stützt die Theorie. Hier sind die Werte zumindest für Diuretika (42,5\%) und Betablocker (37,4\%) mit Diast-CHF vergleichbar. Weitere Angaben zur Verordnungshäufigkeit finden sich bei Redfield et al. (2004) nicht, bei Tschöpe et al. (2005) wurde die Medikation mit bestimmten Substanzgruppen 48 Stunden vor der Untersuchung abgesetzt und es finden sich keine Angaben zur Vormedikation des Kollektivs.

Die Nykturie stellte in Diast-CHF das häufigste Symptom einer manifesten HF dar, 56\% der untersuchten Patienten wiesen diese Beschwerden auf. Das zweithäufigste Symptom im Kollektiv war die Belastungsdyspnoe mit 27,8\%, gefolgt von der Müdigkeit und Leistungsschwäche mit 22,5\%. Maisel et al. (2002) untersuchten Patienten, die unter Dyspnoe litten. Bei 47\% wurde die Diagnose HF gestellt. Die häufigsten Symptome waren im Gesamtkollektiv die Unterarten der Dyspnoe. Ein Vergleich mit Diast-CHF erscheint hier nicht sinnvoll, da in erstgenannter Studie Dyspnoe das Einschlusskriterium darstellte. Unterschenkelödeme wiesen bei Maisel et al. (2002) 42\% der Patienten auf. Diese Zahl ist deutlich höher als die im Rahmen von Diast-CHF ermittelten 18,8\%. Auch eine Halsvenenstauung konnten Maisel et al. (2002) bei $22 \%$ und damit wesentlich mehr Patienten als Diast-CHF ermitteln (1,3\%). Eine möglich Erklärung für diese Unterschiede besteht darin, dass Maisel et al. (2002) anhand eines Symptoms der Herzinsuffizienz rekrutierten, während Diast-CHF einen kardiovaskulären Risikofaktor als Rekrutierungsgrundlage verwendete. Somit könnten in ersterer Studie mehr Patienten erfasst worden sein, die eine höhergradigere und somit möglicherweise von ausgeprägteren Symptomen begleitete HF aufwiesen. Weder bei Tschöpe et al. (2005), noch bei Redfield et al (2004) finden sich Angaben zur Häufigkeit der Symptome in ihrem Kollektiv. Deshalb ist ein Vergleich mit Diast-CHF nicht möglich.

Im 6-Minuten-Gehtest lag der Mittelwert der zurückgelegten Strecke im Falle von Diast-CHF bei 515,88 m. Weder Tschöpe et al. (2005) noch Redfield et al. (2004) liefern Angaben zu einer etwaigen Durchführung dieses Tests in ihrem Kollektiv. Verglichen mit anderen Arbeiten zur systolischen HF ist der Wert aus Diast-CHF höher. Demers et al. (2001) 
beispielsweise untersuchten Patienten mit einer LVEF $<40 \%$. In diesem Kollektiv lag der Mittelwert bei $381 \mathrm{~m}$. Dieses Ergebnis ist nur teilweise mit dem aus Diast-CHF vergleichbar, da mit der SHF eine andere Form der HF untersucht wurde. Außerdem waren bei Demers et al. (2001) Patienten ausgeschlossen, deren Gehstrecke über 500m lag. Ein ähnliches Kollektiv untersuchten Frankenstein et al. (2007), hier wurden Patienten mit LVEF $\leq 40 \%$ eingeschlossen, eine Obergrenze für die Gehstrecke bestand nicht. Mit $459 \mathrm{~m}$ liegt der Mittelwert hier zwischen den beiden zuvor genannten Kollektiven und ist ebenfalls aufgrund der Untersuchung einer SHF nur bedingt mit Diast-CHF vergleichbar.

Die bezüglich der echokardiografischen Klassifikation der DD zahlenmäßig größte Gruppe in Diast-CHF wird von den Patienten mit einer LVEF $\geq 50 \%$ und DD Grad I gebildet. $57,1 \%$ der Probanden finden sich hier. Patienten mit DD Grad III waren nur in sehr geringer Zahl vertreten, so dass die Schweregrade II und III zusammengefasst wurden und zusammen $14,7 \%$ des Kollektivs repräsentieren. Diese Ergebnisse entsprechen dem allgemeinen Wissensstand, nach dem vor allem Patienten mit DD niedrigeren Grades beobachtet werden. Auch bei Tschöpe et al. (2005) fanden sich unter 68 Patienten mit DD 52, bei denen eine verzögerte Relaxation vorlag. Im pseudonormalen und restriktiven Stadium finden sich dagegen nur 10 bzw. 8 Patienten. Bei Redfield et al. (2004) wurde eine nicht direkt vergleichbare Unterteilung in milde (365 Patienten) und mittle bis schwere DD (137 Patienten) angewendet. Allerdings ist auch hier ein Überwiegen der leichtgradigen DD zu erkennen. Dies liegt vermutlich unter anderem in der schlechten Prognose begründet, die mit einem Fortschreiten der Erkrankung zur manifesten HF assoziiert ist (Tribouilloy et al. 2008).

Zusammenfassend ist festzuhalten, dass bezüglich der genannten Studien unterschiedliche Schwerpunkte bei der Fragestellung und damit auch bei der Rekrutierung gesetzt wurden. Während Tschöpe et al. (2005) ein hoch vorselektiertes und voruntersuchtes Kollektiv betrachteten und einem gesunden Kontrollkollektiv gegenüberstellten, wählten Redfield et al. (2004) ihre Patienten zufällig aus. Diast-CHF wählte ein Risikokollektiv mit Patienten ab 50 Jahren aus und stellt somit eine epidemiologische Studie dar. Die anamnestischen und klinischen Parameter sind somit nur bedingt vergleichbar, allerdings finden sich auch Parallelen, vor allem zwischen Diast-CHF und dem Hochrisikokollektiv von Redfield et al. (2004).

\subsection{Echokardiografie}

In Diast-CHF kam ein Schema zum Einsatz, das an der Universitätsmedizin Göttingen (UMG) etabliert wurde (Wachter et al. 2007). Die Einteilung der Patienten geschieht hier, abgesehen von der LVEF, sowohl anhand des E/A-Verhältnisses, als auch anhand des 
Verhältnisses von E/e'. Weitere diagnostisch relevante Werte dieses Schemas stellen das Verhältnis von S/D und das E/A-Verhältnis unter Valsalva-Manöver dar. Tschöpe et al. (2005) dagegen setzten zwar ebenfalls einen Gewebedoppler ein, beurteilten allerdings anstatt des E/e'- das $E^{\prime} / A^{\prime}-$ Verhältnis, wobei $A^{\prime}$ die spätdiastolische Mitralanulusgeschwindigkeit darstellt. Zusätzlich wurde neben dem S/D-Verhältnis die Dezelerationszeit (DT) zur Stadieneinteilung hinzugezogen. Redfield et al. (2004) verwendeten ein Schema, das mit dem von Diast-CHF angewendeten vergleichbar ist (Redfield et al. 2003). Auch hier kam das E/e'-Verhältnis zum Einsatz und es fand eine Unterteilung des restriktiven Stadiums in reversibel und irreversibel anhand des ValvalvaManövers statt. Bezüglich der Zahlenwerte ergeben sich allerdings leichte Unterschiede. So definieren Redfield et al. (2003) das Stadium der verzögerten Relaxation mit E/A $\leq 0,75$, während in Diast-CHF hier $<1$ als Grenzwert verwendet wurde. In ersterem Schema werden außerdem noch S/D und E/e' herangezogen, Diast-CHF dagegen sieht das Stadium der verzögerten Relaxation mit $E / A<1$ als hinreichend definiert an. Für die Stadien der Pseudonormalität und der Restriktion ergeben sich ebenfalls unterschiedliche Grenzwerte für das E/A-Verhältnis, die Grenzwerte für E/e‘ sind dagegen identisch.

Der Mittelwert der LVEF lag bei Diast-CHF bei 59,87\%, was einen geringeren Wert darstellt als die durch Tschöpe et al. (2005) ermittelten 67\%. Hier wirkt sich wahrscheinlich die Tatsache aus, dass in Diast-CHF 8,0\% der Patienten eine LVEF von $<50 \%$ aufwiesen und nicht ausgeschlossen wurden, wie es bei Tschöpe et al. (2005) der Fall war. In Redfield et al. (2004) finden sich keine Angaben zur mittleren LVEF, allerdings zeigten mit 6,0\% vergleichbar viele Patienten eine LVEF $\leq 50 \%$.

Der LVEDD ist zwischen Diast-CHF mit im Mittelwert 49,30 mm und Tschöpe et al. (2005) mit $50 \mathrm{~mm}$ in der Gesamtpopulation und $51 \mathrm{~mm}$ in der Untergruppe der DD gut vergleichbar. Beim LVMI zeigten sich deutlichere Unterschiede, Diast-CHF lieferte 117,39 g/m², während das Gesamtkollektiv von Tschöpe et al. (2005) einen Mittelwert von $107 \mathrm{~g} / \mathrm{m}^{2}$ und die Untergruppe der DD von $114 \mathrm{~g} / \mathrm{m}^{2}$ aufwies. Im Falle des LAVI liegt der Mittelwert für DiastCHF mit 24,74 ml/m² wiederum höher als bei Tschöpe et al. mit $18,8 \mathrm{ml} / \mathrm{m}^{2} \mathrm{im}$ gesamten Kollektiv. Der Mittelwert der Untergruppe der DD liegt auch im Falle des LAVI mit $21 \mathrm{ml} / \mathrm{m}^{2}$ höher und damit näher am Wert aus Diast-CHF.

Das mittlere E/A-Verhältnis im Gesamtkollektiv von Tschöpe et al. (2005) lag bei 1,2, während in der Untergruppe ein Mittelwert von 0,9 angegeben wird. Letzterer ist ungefähr mit dem des Gesamtkollektivs von Diast-CHF vergleichbar, hier lag der Mittelwert bei 0,94. Auch die Mittelwerte des S/D-Verhältnisses des Gesamtkollektivs von Diast-CHF $(1,42)$ und des DD-Unterkollektivs von Tschöpe et al. (2005) $(1,3)$ liegen nahe beieinander. Für die Dezelerationszeit liefert Diast-CHF mit 252,47 ms einen deutlich höheren Mittelwert als der 
bei Tschöpe et al. (2005) für das DD-Unterkollektiv berichtete Mittelwert von 198 ms. Im Gegensatz dazu lag in dieser Studie der Mittelwert für die IVRT mit 113 ms höher als im Falle von Diast-CHF (103,81 ms). Dies ist unerwartet, da sich beide Zeiten eigentlich analog zueinander verhalten müssten.

Bezüglich e' finden sich weder bei Tschöpe et al. (2005), noch bei Redfield et al. (2004) Angaben. Ceyhan et al. (2008) untersuchten ein Kollektiv aus 40 Patienten mit arteriellem Hypertonus. Der Mittelwert des Alters lag mit 52 Jahren deutlich unter dem Wert von DiastCHF. Trotz der Tatsache, dass Patienten mit manifester HF bei Ceyhan et al. (2008) ausgeschlossen wurden, lag der Mittelwert für e' in dieser Studie mit 6,4 ms nahe dem aus Diast-CHF mit 6,05 ms. Dies ist vermutlich dadurch zu erklären, dass in Diast-CHF ebenfalls viele Patienten ohne manifeste HF eingeschlossen wurden. Der Einfluss der Patienten mit manifester HF erklärt möglicherweise auch, dass der Mittelwert in Diast-CHF noch etwas niedriger liegt. Allerdings ist zu beachten, dass die beiden Kollektive aufgrund ihrer stark unterschiedlichen Größe und den unterschiedlichen Krankheitsgeschichten nur bedingt vergleichbar sind.

Betrachtet man die echokardiografische Klassifikation der Dysfunktion in den einzelnen Studien, so ergibt sich ein in groben Zügen gesehen einheitliches Bild. Zahlen zur SD finden sich aufgrund des Studiendesigns bei Tschöpe et al. (2005) nicht. Redfield et al. (2004) und Diast-CHF liefern mit 6,0\% beziehungsweise 8,0\% Anteil der Patienten mit LVEF $<50 \%$ trotz der unterschiedlichen Rekrutierungsverfahren vergleichbare Werte. Bei den einzelnen Graden der DD überwiegt stets das mildeste Stadium. Bei Diast-CHF wiesen bezogen auf das Gesamtkollektiv 57,1\% eine DD Grad I auf, Tschöpe et al. (2005) berichten von 43,3\% Patienten mit verzögerter Relaxation. In der von Redfield et al. (2004) veröffentlichten Studie schließlich klassifizierte man 17,9\% der Patienten als zum Stadium der milden DD gehörend.

Bezüglich der höheren Stadien wiesen in Diast-CHF 14,7\% der Patienten eine DD des Grades II-III auf. Tschöpe et al. (2005) kamen zu einem ähnlichen Ergebnis, 15\% wiesen ein pseudonormales oder restriktives Füllungsmuster auf. Redfield et al. (2004) kamen auch hier wieder zu einem niedrigeren Ergebnis als die beiden anderen Studien, 6,7\% der Fälle wurden als mittlere bis schwere DD klassifiziert. Auffällig ist somit, dass trotz der erwähnten Unterschiede in der Rekrutierung Diast-CHF und Tschöpe et al. (2005) zu ähnlichen Gruppengrößen kommen. Bei Redfield et al. (2004) dagegen fanden sich niedrigere Zahlen. Dies liegt wahrscheinlich darin begründet, dass die Probanden hier zufällig und unabhängig von Risikofaktoren oder Erkrankungen ausgewählt wurden. In allen Studien ist jedoch ein Überwiegen der milderen Stadien zu erkennen. Mögliche Ursache ist die höhere Mortalität, mit der eine DD vor allem höheren Grades einhergeht, unabhängig von Alter, Geschlecht und LVEF (Redfield et al. 2003). 
Insgesamt ergeben sich also in den genannten Studien im Wesentlichen vergleichbare Werte. Die Größen der einzelnen Gruppen der Dysfunktion beispielsweise ähneln sich. Allerdings sind einige Werte auch widersprüchlich. Die Unterschiede lassen sich am ehesten, aber nicht in jedem Fall, durch die unterschiedlichen Rekrutierungsmuster und zugrunde liegende Diagnoseschemata erklären.

\subsection{Diskussion der Laboranalytik}

Die Analyse der Peptidkonzentrationen im Serum gestattet im Wesentlichen folgende Kernaussagen. Es findet sich zunächst eine Erhöhung dieser Werte bei Vorliegen einer DD, die in der überwiegenden Zahl der Fälle auch stadienabhängig ist. Weiterhin ergibt sich eine signifikant höhere Serumkonzentration bei Patienten, die Symptome einer HF zeigen gegenüber solchen, die eine asymptomatische Dysfunktion aufweisen. Außerdem besteht ein signifikanter Zusammenhang zwischen den Parametern, die den Schweregrad der DD charakterisieren, und der Konzentration der Peptide. Schließlich wurden Fähigkeiten der Peptide zur Detektion der einzelnen Schweregrade der DD und zur Detektion der SD untersucht. Für diese Aufgabe waren die Peptide jedoch nicht geeignet.

\subsubsection{Erhöhung der Werte bei Vorliegen einer Dysfunktion und Stadienabhängigkeit}

Ein wesentliches Ergebnis der vorliegenden Arbeit ist die Tatsache, dass die untersuchten Peptide jedes für sich beim Vorliegen einer DD bereits des Grades I und auch bei Vorliegen einer SD im Mittelwert erhöht sind. Mit Ausnahme von MR-proANP ist diese Erhöhung auch signifikant und findet sich auch unabhängig von einer eventuell bestehenden Symptomatik des Patienten. Außerdem zeigen die Ergebnisse einen signifikanten Unterschied in der Serumkonzentration von Patienten ohne DD und mit einer LVEF $>50 \%$ und solchen mit einer DD jeglichen Grades. Weiterhin fällt auf, dass die Peptide in zwei Gruppen aufgeteilt werden können, wovon eine zu Beginn der Erkrankung beim Übergang von der Abwesenheit einer DD zur Manifestation einer DD Grad I ihren stärksten und signifikanten Anstieg aufweist. Zu dieser Gruppe gehören MR-proADM, CT-proET-1 und CT-proAVP. Der Unterschied in der Serumkonzentration dieser Peptide ist beim Vergleich von Patienten mit einer DD Grad I und Patienten mit DD Grad II-III nicht mehr signifikant. Die andere Gruppe dagegen, bestehend aus NT-proBNP und MR-proANP, steigt zunächst vergleichsweise gering und für MRproANP nicht signifikant an, beim Übergang der DD Grad I zur DD Grad II-III jedoch findet sich ein deutlicherer und auch in beiden Fällen signifikanter Anstieg. Somit liegt die Vermutung nahe, dass die erstgenannte Gruppe der Hormone zur Detektion einer frühen DD 
besser geeignet ist als die letztgenannte. Diese wiederum könnte bei der Detektion einer höhergradigen DD oder der Verlaufskontrolle von Vorteil sein. Die beobachteten Ergebnisse lassen somit auch den Schluss zu, dass die Hormone der ersten Gruppe einen pathophysiologischen Faktor zur Entwicklung einer Dysfunktion darstellen, während die Hormone der zweiten Gruppe eine Art Gegenregulation des Körpers darstellen könnten, der im Verlauf der Krankheit auf eine zunehmende Druckbelastung des Herzens hin reagiert. Allein durch den vasokonstriktorischen Effekt von ET-1 und Vasopressin ist dieser mögliche pathophysiologische Aspekt allerdings nicht zu begründen, denn Adrenomedullin zeigt ein ähnliches Verteilungsmuster im Verlauf der DD, wirkt aber vasodilatatorisch. Es sind weitere Studien nötig, um diese Vermutungen zu bestätigen oder zu widerlegen.

\subsubsection{NT-proBNP}

NT-proBNP ist ein Peptid, dessen Veränderungen im Rahmen der DD bereits vergleichsweise oft Gegenstand klinischer Studien war. Tschöpe et al. (2005) beispielsweise wiesen bei ihren Patienten mit verzögerter Relaxation eine Erhöhung mit im Mittelwert 151,6 $\mathrm{pg} / \mathrm{ml}$ gegenüber der Kontrollgruppe mit $51,89 \mathrm{pg} / \mathrm{ml}$ nach. Bei Patienten mit pseudonormalem und restriktivem Füllungsmuster war eine weitere Steigerung auf 308,1 $\mathrm{pg} / \mathrm{ml}$ beziehungsweise 2307,1 pg/ml nachweisbar. Patienten mit reduzierter LVEF wurden in dieser Studie nicht untersucht. In Diast-CHF findet sich bereits bei den Patienten ohne Zeichen einer DD und LVEF >50\% ein Mittelwert von 120,10 pg/ml. Bei DD Grad I liegt der Mittelwert bei $141,76 \mathrm{pg} / \mathrm{ml}$, Patienten mit Schweregrad II-III schließlich wiesen einen Mittelwert von $228,51 \mathrm{pg} / \mathrm{ml}$ auf. Vergleicht man diese Zahlen, so fällt auf, dass die Patienten ohne DD und SD in Diast-CHF eine im Mittelwert deutlich höhere Serumkonzentration von NT-proBNP aufweisen als die Kontrollpatienten in der Studie von Tschöpe et al. (2005). NTproBNP beziehungsweise das biologisch aktive BNP zeigt eine positive Korrelation mit dem Alter sowohl von gesunden (Wang et al. 2002) als auch von Patienten mit kardiovaskulären Erkrankungen (Redfield et al. 2004). Somit ist dieser Unterschied möglicherweise durch das im Mittel höhere Alter des Kollektivs von Diast-CHF zu erklären. Auch eine Tendenz zu höheren Werten bei Frauen wird bei Redfield et al. (2004) beobachtet, weshalb auch das leichte Überwiegen des männlichen Geschlechts bei Tschöpe et al. (2005) hier einen Einfluss haben könnte. Die Erhöhung der NT-proBNP-Serumkonzentration bei kardiovaskulär Vorerkrankten könnte auch den im Vergleich zu Tschöpe et al. (2005) geringeren, aber dennoch signifikanten Anstieg beim Übergang von der Abwesenheit einer DD zu Grad I bei Diast-CHF erklären. In letzterer Studie war das Vorliegen mindestens eines kardiovaskulären Risikofaktors Rekrutierungskriterium. Zwar finden sich auch in der Kontrollgruppe von Tschöpe et al. (2005) Patienten mit entsprechenden Risikofaktoren, 
allerdings sind, wie bereits erwähnt, auch in der Gruppe der DD weniger Patienten mit solchen zu finden, als es bei Diast-CHF der Fall ist. Schließlich kann auch durch eine medikamentöse Behandlung mit Diuretika, Digitalis und ACE-Hemmern die Serumkonzentration von NT-proBNP verändert werden (Falcão et al. 2004). Im Falle von Tschöpe et al. (2005) wurden Diuretika, Betablocker, Kalziumantagonisten, sowie ACEHemmer und AT1-Antagonisten 48 Stunden vor der Untersuchung pausiert. Der Einfluss dieser Maßnahme ist allerdings schwer abschätzbar.

Betrachtet man die Mittelwerte von Patienten mit höhergradiger DD, so kehrt sich der geschilderte Trend um. Dem Mittelwert von 228,51 pg/ml aus Diast-CHF für die Gruppe der Schweregrade II-III stehen bei Tschöpe et al. (2005) 308,1 pg/ml für die Gruppe des pseudonormalen und $2307,1 \mathrm{pg} / \mathrm{ml}$ für die Gruppe des restriktiven Füllungsmusters gegenüber. Dazu ist zunächst anzumerken, dass in Diast-CHF prozentual gesehen nur wenige Patienten mit DD Grad III vertreten waren, weshalb die Schweregrade II und III zusammengefasst wurden. Auch bei Tschöpe et al. (2005) zeigten nur 6 von 68 Patienten ein restriktives Füllungsmuster. Ein möglicher Grund für diese Unterschiede ist, dass bei Tschöpe et al. (2005) einen hoher Anteil der Patienten symptomatisch waren, 58 von 68 aus der Gruppe der DD wiesen eine NYHA der Klasse II-III auf. Entsprechend berichten Tschöpe et al. (2005) auch von einer positiven Korrelation der Werte mit der NYHA-Klasse. Außerdem könnte der weit überwiegende Anteil der Patienten mit DD Grad II in Diast-CHF diejenigen des Schweregrades III maskieren. Wie bereits erwähnt, sind diese Schweregrade in DiastCHF zusammengefasst. Eine erhöhte Wandspannung des Ventrikels wirkt als Stimulus für eine vermehrte Ausschüttung von NT-proBNP und könnte somit ebenfalls auf die gemessenen Werte Einfluss genommen haben. Mit steigendem Grad der Dysfunktion ist von einer steigenden Wandspannung des Ventrikels auszugehen. Da nur vergleichsweise wenige Patienten mit höhergradiger DD in Diast-CHF vertreten waren, ist der Einfluss dieses Effektes hier vermutlich geringer als im Falle von Tschöpe et al. (2005). Auch ein erhöhter LVEDD kommt als auslösender Faktor für erhöhte Serumkonzentrationen von NT-proBNP in Betracht. Allerdings sind zumindest die Mittelwerte dieses Parameters in Diast-CHF und Tschöpe et al. (2005) vergleichbar, so dass der Effekt hier vermutlich von untergeordneter Bedeutung ist. Ein Einfluss der Messmethode ist dagegen unwahrscheinlich, da in beiden Arbeiten der Elecsys ${ }^{\circledR}$ proBNP Test der Firma Roche (Mannheim, Deutschland) zum Einsatz kam. Redfield et al. (2004) wiesen eine ebenfalls stadienabhängige Erhöhung für BNP in ihrem Kollektiv nach. Allerdings sind hier keine Messwerte angegeben, so dass ein direkter Vergleich der Kollektive nicht möglich ist.

Den höchsten Mittelwert für NT-proBNP in Diast-CHF wiesen letztendlich Patienten mit einer LVEF $<50 \%$ auf. Dieser lag bei $727,58 \mathrm{pg} / \mathrm{ml}$ und damit deutlich höher als im Falle der DD. 
Dies ist ein ähnliches Ergebnis wie im Falle von Redfield et al. (2004). Auch hier wird von einer Erhöhung der Werte bei Erniedrigung der LVEF berichtet, zumindest bei älteren Patienten und bei Männern. Bei Tschöpe et al. (2005) stellte eine LVEF $<50 \%$ ein Ausschlusskriterium dar, so dass hier keine Aussage über Parallelen oder Widersprüche der einzelnen Studien getroffen werden kann.

\subsubsection{MR-proANP}

Im Falle von MR-proANP findet sich ebenfalls eine Erhöhung der Serumkonzentration bei Patienten mit DD Grad I (96,22 pmol/l) gegenüber solchen ohne Zeichen einer DD und mit einer LVEF >50\% (89,90 pmol/l). Allerdings ist diese Erhöhung im Vergleich zu den anderen untersuchten Peptiden nicht signifikant. Betrachtet man die Schweregrade II-III, so erhöhen sich diese Ergebnisse weiter auf einen Mittelwert von 120,38 pmol/l. Dies stellt einen signifikanten Anstieg sowohl in Bezug auf eine DD Grad 0, also auch auf eine DD Grad I dar. Die höchsten Werte wurden erneut bei Vorliegen einer eingeschränkten LVEF beobachtet. Der Mittelwert liegt hier bei 169,19 pmol/l. Auch dies ist ein signifikanter Anstieg gegenüber den anderen untersuchten Ausprägungen der Dysfunktion. Eine mögliche Erklärung für die Tatsache, dass der Anstieg beim Übergang von Grad 0 zu Grad I nicht signifikant ist, liegt im Syntheseort von ANP begründet. Es wird im gesunden Herzen fast ausschließlich in den Kardiomyozyten des Atriums sezerniert. Zu dem Zeitpunkt, in dem sich eine DD noch in einem frühen Stadium befindet, ist die atriale Funktion wahrscheinlich noch überwiegend im Normalzustand und es liegt keine massive Erhöhung des LAVI vor. Im Verlauf der Erkrankung verändern sich diese Parameter dagegen deutlich und die Unterschiede in der Serumkonzentration von ANP werden signifikant. Außerdem wird ANP bei Vorliegen einer Hypertrophie des Ventrikels, wie sie im späteren Verlauf der DD häufig auftritt, zusätzlich zum Atrium auch im Ventrikel sezerniert, was zusätzlich Einfluss auf die Serumkonzentration und damit die Signifikanzen haben dürfte.

Im Gegensatz zu BNP und NT-proBNP gibt es wenige Studien, die ANP und sein Fragment MR-proANP zum Gegenstand haben. Insbesondere in Bezug auf die DD gibt es keine Untersuchungen. Gegenhuber et al. (2006) untersuchten 251 Patienten mit Dyspnoe als Hauptsymptom. Bei 137 von innen wurde eine akut dekompensierte HF als Hauptursache der Beschwerden angesehen. Diese Patienten wiesen mit $338 \mathrm{pmol} / \mathrm{l}$ einen signifikant höheren Mittelwert für MR-proANP auf als es die übrigen Patienten mit $98 \mathrm{pmol} / \mathrm{l}$ taten. Verglichen mit den Mittelwerten aus Diast-CHF sind diese Werte deutlich höher. Eine mögliche Ursache ist der wesentlich höhere Anteil von Patienten mit reduzierter LVEF bei Gegenhuber et al. (2006). Diese Studie basiert auf einem Kollektiv von Mueller et al. (2005), in dem Patienten mit systolischer Dysfunktion deutlich häufiger vertreten waren als solche 
mit DD. Das Verhältnis war 116 zu 21. Bezüglich der Medikation finden sich bei Gegenhuber et al. (2006) keine Angaben, auch diese ist aber als Einflussfaktor denkbar.

\subsubsection{MR-proADM}

Wie im Falle der zuvor genannten Hormone zeigte auch MR-proADM bei Diast-CHF einen Anstieg der Mittelwerte mit steigendem Schweregrad der DD. Bei den Patienten ohne Anzeichen einer DD oder SD lag der Mittelwert bei 0,54 nmol// und stieg bei Schweregrad I der DD auf 0,61 nmol/I an. Allerdings ist der Anstieg zwischen Grad I und Grad II-III weniger stark ausgeprägt, bei letzterer Gruppe lag der Mittelwert bei 0,62 nmol/. Dies stellt einen nicht signifikanten Anstieg dar. Ein erneuter stärkerer und auch signifikanter Anstieg findet sich bei den Patienten mit reduzierter $\operatorname{LVEF}(0,74 \mathrm{nmol} / \mathrm{l})$.

Eine mögliche Erklärung dafür, dass MR-proADM lediglich zu Beginn der Entität DD einen signifikanten Anstieg zeigt, liegt in der Wirkungsweise von ADM begründet. Es erhöht durch Senkung des systemischen Blutdrucks und eine Dilatation der Koronarien die Auswurfleistung des Herzens (Ishimitsu et al. 2006). Als auslösende Faktoren für die Sezernierung von ADM gelten dementsprechend Hypertonie und KHK, die Risikofaktoren für die Entwicklung einer DD darstellen. Möglicherweise treten also stark erhöhte Konzentrationen lediglich zu einem frühen Zeitpunkt in der Entwicklung einer DD auf. Betrachtet man dagegen die SD, so scheint sich diese Entwicklung umzukehren. Hier wird von steigenden Serumkonzentrationen des ADM bei sinkender LVEF berichtet (Jougasaki et al. 2001). Möglicherweise wirkt hier eine Hypervolämie, wie sie im Rahmen einer SD auftritt, als auslösender Faktor (Cheung et al. 2004).

Speziell in Bezug auf die DD gibt es kaum Voruntersuchungen für ADM. Yu et al. (2001) untersuchten 77 Patienten mit einem mittleren Alter von 66,3 Jahren der NYHA-Klassen IIIV. 31 der Patienten wiesen eine isolierte DD auf. Als Diagnoseschema kam eine Kombination aus E/A-Verhältnis, Dezelerationszeit und S/D-Verhältnis zum Einsatz. Ein Gewebedoppler wurde nicht durchgeführt. 77\% der untersuchten Patienten gehörten der NYHA-Klasse II an. Zwar wurde bei Yu et al. (2001) Adrenomedullin selbst und nicht, wie im Falle von Diast-CHF, dessen Fragment MR-proADM gemessen. Allerdings dürtten die Ergebnisse zumindest bezüglich der Qualität untereinander vergleichbar sein, da die Freisetzung des MR-proADM vermutlich stöchiometrisch erfolgt (Morgenthaler et al. 2005). Ein Vergleich bezüglich der Quantität der Werte ist somit aber nicht möglich. Auch bei Yu et al. (2001) fand sich eine signifikante Erhöhung der Adrenomedullinkonzentration bei Patienten mit DD oder reduzierter LVEF gegenüber den gesunden Kontrollpatienten. Die höchsten Werte zeigten Patienten mit SD und restriktivem Füllungsmuster, gefolgt von 
Patienten mit SD ohne Restriktion und solchen mit DD. Ein signifikanter Unterschied zwischen den beiden Letztgenannten war nicht feststellbar. Letzterer Punkt ist zwar nicht direkt mit Diast-CHF vergleichbar, da hier keine eigene Gruppe für Patienten mit reduzierter LVEF aufgestellt wurde. Dennoch wurde bei Diast-CHF ein signifikanter Unterschied zwischen den Serumkonzentrationen von Patienten mit DD und SD festgestellt. Möglicherweise liegt dies darin begründet, dass unterschiedliche Diagnoseschemata verwendet wurden. So kam bei Yu et al. (2001) beispielsweise kein Gewebedoppler zum Einsatz. Der genaue Grund für diese Unterschiede bleibt letztendlich unklar, auch die in anderen Studien berichtete negative Korrelation der ADM- oder MR-proADM-Spiegel mit der LVEF konnten Yu et al. (2001) nicht bestätigen. Es werden weitere Studien nötig sein, um die Rolle von ADM in der Entwicklung und im Verlauf von DD und SD zu klären.

\subsubsection{CT-proET-1}

Die Ergebnisse von Diast-CHF weisen auch für CT-proET-1 eine signifikante Erhöhung der Mittelwerte bereits beim Übergang von Stadium 0 zum Stadium I der DD nach. Der Anstieg beim Übergang von Stadium I zu Stadium II-III dagegen ist zwar vorhanden, aber nicht signifikant.

Die hier beobachteten Konzentrationsunterschiede sind mit denen des zuvor diskutierten MR-proADM vergleichbar. Betrachtet man die Wirkungsweise der beiden Hormone ADM und ET-1, so fällt auf, das ET-1 dem ADM entgegengesetzte Effekte hat. Es ist mit Hypertension und Vasokonstriktion, auch an den Koronarien, assoziiert (Hemsén et al. 1990). Dementsprechend könnte es eine pathogenetische Rolle bei der Entwicklung der DD darstellen, während MR-proADM den oder einen Gegenspieler des ET-1 repräsentiert. Entsprechend wird auch von einer supprimierenden Wirkung des ADM auf die Sezernierung ET-1 berichtet (Cheung et al. 2004). Beide Peptide waren in Diast-CHF vor allem in den frühen Erkrankungsstadien erhöht. Somit könnte ET-1 ursächlich an Veränderungen beteiligt sein, die zur Entwicklung einer DD führen können, während ADM die Gegenregulation darstellt. Im späteren Verlauf der Erkrankungen sind nur noch geringe Steigerungen der Serumkonzentration zu verzeichnen, was anzeigen könnte, dass diese ursprünglich auslösenden Faktoren in den Hintergrund treten. Diese Theorie wird durch die Erkenntnis gestützt, dass ET-1 die Synthese von ANP und BNP fördert, selbst aber wiederrum durch die Substanzen supprimiert wird (Hanehira et al. 1997). In Diast-CHF wurden für NT-proBNP und MR-proANP vor allem in den schwereren Stadien der DD erhöhte Werte nachgewiesen. Somit könnte ein Anstieg von ET-1 in den früheren Stadien eine verstärkte Sezernierung von ANP und BNP im Verlauf bewirken, die dann wiederrum über eine negative Rückkopplung 
die Bildung von ET-1 dämpfen, was sich in Diast-CHF in nur noch leichten Veränderungen der CT-proET-1 Spiegel in den höheren Stadien geäußert haben könnte.

In Diast-CHF wurde zum ersten Mal gezeigt, dass CT-proET-1 mit dem Auftreten einer DD in erhöhten Serumkonzentrationen im Blut nachweisbar ist, auch wenn der Anstieg zwischen den Gruppen nur teilweise signifikant ist. Für die DD im Speziellen ist der Einfluss von ET-1 bisher kaum untersucht. Ein direkter Vergleich mit anderen Studien ist hier somit nicht möglich. Trotz des starken vasokonstriktorischen Effektes und dem berichteten positiven Rückkopplungsmechanismus auf die Aldosteronsynthese (Cozza et al. 1989), dessen Wirkung mit der Entwicklung einer DD in Verbindung gebracht wird, fällt der Anstieg beim Übergang von Stadium 0 der DD zum Stadium I vergleichsweise gering aus. Der Grund dafür bleibt unklar, allerdings scheint die Rolle von ET-1 bei der Entwicklung einer kardialen Dysfunktion oder manifesten HF noch nicht vollständig verstanden. Beispielsweise konnte auch eine Studie zur Therapie der akuten HF mit dem ET-1-Rezeptorantagonisten Tezosentan keine Verbesserung von Symptomatik oder Folgen der akuten HF nachweisen (McMurray et al. 2007).

\subsubsection{CT-proAVP}

Ähnlich wie MR-proADM und CT-proET-1 konnte auch für CT-proAVP ein signifikanter Anstieg in erster Linie beim Übergang von DD Grad 0 zur DD Grad I nachgewiesen werden. Hier ist der Anstieg vergleichsweise stark ausgeprägt. Bei der Gruppe der DD Grad II-III jedoch findet sich ein Abfall der Werte in etwa auf das Niveau der DD Grad 0. Dies erscheint zunächst verwunderlich. Eine mögliche Erklärung ist die bereits geäußerte Theorie, dass die untersuchten Hormone zu unterschiedlichen Zeiten und Krankheitsstadien ihre Maximalkonzentrationen zeigen. Vasopressin wurde dabei zur Gruppe der früh ansteigenden Hormone gezählt. Möglicherweise ist es sogar nur in dieser Phase in erhöhter Konzentration im Blut vorhanden. Die vorliegenden Ergebnisse lassen diesen Schluss zu. Hier könnte ein anderer Mechanismus Ursache der Erhöhung sein.

Stoiser et al. (2006) untersuchten Patienten mit fortgeschrittener HF der NYHA-Klassen IIIIV. Der in dieser Studie berichtete Mittelwert für CT-proAVP, in dieser Studie Copeptin genannt, lag bei 19,7 pmol/l und damit deutlich höher als die in Diast-CHF ermittelten Werte. Wahrscheinlich ist dies unter anderem auf die Tatsache zurückzuführen, dass bei Stoiser et al. (2006) ausschließlich Patienten mit NYHA III-IV und einer manifesten HF untersucht wurden. Damit würde bestätigt, dass die Serumkonzentration von CT-proAVP im Verlauf der Erkrankung ansteigt. $\mathrm{Da}$ in beiden Untersuchungen die Labormaterialien der Firma 
B.R.A.H.M.S. AG (Hennigsdorf, Deutschland) (Morgenthaler et al. 2006) zum Einsatz kamen, ist die Laboranalytik als Grund für diese Unterschiede unwahrscheinlich.

Es fällt also auf, dass die untersuchten Hormone sich in zwei verschiedene Gruppen zusammenfassen lassen. Die Serumkonzentrationen der Peptide aus der ersten Gruppe, bestehend aus CT-proET-1, MR-proADM und CT-pro-AVP, scheinen vor allem in der Frühphase beziehungsweise bei Auftreten der Erkrankung DD anzusteigen und später eine untergeordnete Rolle zu spielen. Dagegen steigen NT-proBNP und MR-proANP als Vertreter der zweiten Gruppe zwar auch zu Beginn leicht an, im Verlauf der Erkrankung ist der Anstieg aber deutlich betont. Ursache dafür könnten unterschiedliche pathophysiologische Rollen der Peptide sein. Nicht für alle Peptide gibt es mit Diast-CHF vergleichbare Voruntersuchungen. Sind diese allerdings vorhanden, so ist dort ebenfalls eine Erhöhung der Serumkonzentrationen der beschriebenen Peptide ersichtlich. Meist liegen die Werte allerdings höher als in Diast-CHF, vermutlich weil in den zum Vergleich herangezogenen Studien ein im Krankheitsverlauf fortgeschrittenes Kollektiv untersucht wurde.

\subsubsection{Erhöhung der Parameter in Gegenwart einer Symptomatik der Herzinsuffizienz}

Grundsätzlich fällt bei der Betrachtung der Ergebnisse eine positive Korrelation zwischen dem Auftreten von Symptomen einer Herzinsuffizienz, definiert durch Vorliegen von mindestens einem Framingham-Kriterium nach Ho et al. (1993), und den Serumkonzentrationen der einzelnen Peptide auf. Die Tendenz zu einem Anstieg der Werte in Gegenwart von Symptomen ist bei allen Hormonen vorhanden, allerdings in unterschiedlicher Ausprägung. Während MR-proADM und CT-proET-1 in jedem der untersuchten Fälle einen signifikanten Unterschied boten und NT-proBNP und MR-proANP dies, mit Ausnahme der Patienten mit reduzierter LVEF, ebenso taten, liefert CT-proAVP ein anderes Bild. Hier ist lediglich für die DD Grad II-III und die reduzierte LVEF ein signifikanter Unterschied zwischen symptomatischen und asymptomatischen Patienten erkennbar.

Das Ausmaß einer neurohumoralen Aktivierung scheint somit generell mit der Ausprägung von Symptomen assoziiert zu sein. Tschöpe et al. (2005) untersuchten, abgesehen von der Kontrollgruppe, ausschließlich symptomatische Patienten, so dass ein direkter Vergleich hier nicht möglich ist. Sie berichten aber auch innerhalb dieses Kollektivs von einer positiven Korrelation von NT-proBNP mit der Ausprägung von Symptomen der HF in Form der NYHAKlasse. Maisel et al. (2002) unterteilten inr Kollektiv von Patienten mit Dyspnoe nach der Ätiologie dieser Beschwerden. Diejenigen Patienten, bei denen die Dyspnoe auf eine HF zurückzuführen war, zeigten signifikant höhere Serumkonzentrationen von BNP als es 
diejenigen taten, bei denen der Symptomatik eine andere Ursache zu Grunde lag. Francis et al. (1990) wiesen einen ähnlichen Effekt für Vasopressin nach. Auch in dieser Studie stieg die Serumkonzentration bei symptomatischen Patienten mit LVEF $\leq 35 \%$ bei Vorliegen einer manifesten HF gegenüber der isolierten Dysfunktion an. Allerdings war auch in diesem Stadium bereits eine neuroendokrine Aktivierung nachweisbar. Die höchsten Werte wurden bei Patienten gemessen, deren Symptomatik eine Therapie mit Diuretika erforderlich machte. Zu einem anderen Schluss kamen Yu et al (2001) bezüglich Adrenomedullin. Hier konnte keine signifikante Korrelation der Adrenomedullinkonzentration mit der NYHA-Klasse nachgewiesen werden.

Somit stellt die geschilderte Laboranalytik im Rahmen von Diast-CHF die erste umfassende Untersuchung zu den Zusammenhängen zwischen Symptomatik und der neurohumoralen Aktivierung im Rahmen der DD dar. Die wesentliche Erkenntnis ist, dass das Auftreten unabhängig von der Gegenwart einer DD oder SD mit einer neurohumoralen Aktivierung assoziiert ist. In der überwiegenden Zahl der Fälle unterscheiden sich die Serumkozentrationen der neurohumoralen Peptide beziehungsweise deren Fragmenten von symptomatischen und asymptomatischen Patienten der HF somit signifikant voneinander.

\subsubsection{Korrelationen der Laborwerte mit echokardiografischen und klinischen Parametern}

Die DD und ihr Verlauf ist zum Einen nach Stadien, zum Anderen aber auch anhand sich kontinuierlich verändernder echokardiografischer Parameter einteilbar. Dazu gehören beispielsweise das Verhältnis von E/e' oder der LAVI. Dabei stellt sich die Frage des Verhältnisses dieser Parameter der DD zur neurohumoralen Aktivierung. Betrachtet man diesbezüglich die Ergebnisse aus Diast-CHF, so findet sich insgesamt gesehen fast ausschließlich eine signifikante Korrelation der echokardiografischen Parameter der DD und den untersuchten Peptiden. In den meisten Fällen liegt die Signifikanz dabei auf dem 0,01 Niveau, teilweise auch auf dem 0,05 Niveau. Für das E/A-Verhältnis ist die Korrelation mit MR-proADM, CT-proET-1 und CT-proAVP negativ. Beim S/D-Verhältnis findet sich durchgängig eine negative Korrelation. Sämtliche Korrelationskoeffizienten sind unter 0,3 und damit vergleichsweise niedrig.

Für die teilweise negative Korrelation des E/A-Verhältnisses gibt es verschiedene Erklärungsmöglichkeiten. Zum Einen verändert es sich im Rahmen der DD und ihrer Stadien in beide Richtungen, was die Interpretation der Korrelation erschwert. Andererseits sind mit MR-proADM, CT-proET-1 und CT-proAVP die Hormone betroffen, für die ein Anstieg vor allem in der Frühphase nachgewiesen wurde. Da definitionsgemäß das E/A-Verhältnis hier 
erniedrigt ist, könnte sich dieser Effekt dabei erneut auswirken. Tschöpe et al. (2005) konnten dagegen keine signifikante Korrelation zwischen E/A-Verhältnis und NT-proBNP

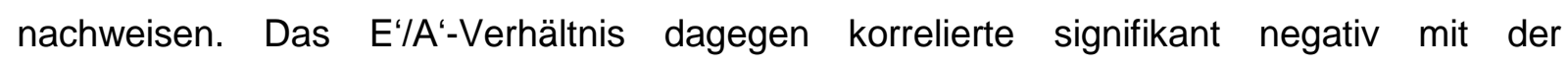
Serumkonzentration von NT-proBNP. Zu den übrigen echokardiografischen Parametern LVMI und dem S/D-Verhältnis war keine Korrelation feststellbar. Möglicherweise hat das wesentlich größere Kollektiv von Diast-CHF Einfluss auf die Signifikanz der Korrelationen. Ceyhan et al. (2008) führten eine Studie zur Korrelation von NT-proBNP zu echokardiografischen Parametern der DD bei 40 hypertensiven Patienten durch. Analog zu Diast-CHF wird hier von einer signifikanten positiven Korrelation von NT-proBNP mit dem E/e'-Verhältnis berichtet. Zwar wurde in dieser Studie der LAVI nicht untersucht, der linksatriale Durchmesser dagegen wurde bestimmt und zeigte, ebenso wie der LVMI, eine signifikante positive Korrelation. Dies deckt sich ebenfalls mit den Ergebnissen aus DiastCHF. Folglich gehen die Dilatation des linken Vorhofs und die Hypertrophie des linken Ventrikels mit einer gesteigerten neurohumoralen Aktivierung einher. Beim E/A-Verhältnis dagegen fanden auch Ceyhan et al. (2008) keine signifikante Korrelation.

Die negative Korrelation zwischen MR-proADM und dem E/A-Verhältnis aus Diast-CHF steht im Widerspruch zu den Ergebnissen von Yu et al. (2001), die von einer positiven signifikanten Korrelation berichten. Der Grund dafür bleibt unklar, der Korrelationskoeffizient aus Diast-CHF ist allerdings wesentlich schwächer (-0,08 gegenüber 0,33 für das Gesamtkollektiv). Im Unterkollektiv der DD von Yu et al. (2001) wiederum findet sich ebenfalls eine negative Korrelation, was sich mit Diast-CHF deckt. Die Korrelation ist aber nicht signifikant. Hierbei ist zu beachten, dass das E/A-Verhältnis sich beim Durchlaufen der Stadien einer DD definitionsgemäß in verschiedene Richtungen verändert. Bei normaler diastolischer Funktion gilt laut Schema des KNHI E/A $\geq 1$. Während der Grad I mit E/A $<1$ als hinreichend definiert gilt, sind die Schweregrade ab II unter anderem erneut durch ein erhöhtes E/A-Verhältnis definiert. Dieser Sachverhalt erschwert die Aufstellung einer Korrelationsrechnung und könnte dieses uneinheitliche Bild bewirken. Kontinuierlich

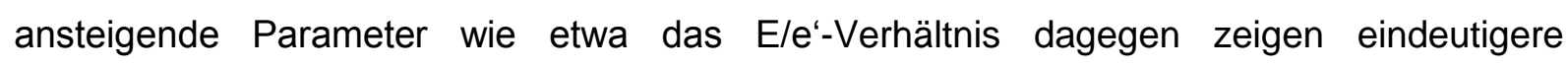
Korrelationen.

Das S/D-Verhältnis zeigt in Diast-CHF eine durchgehend signifikante Korrelation mit den einzelnen Peptiden. Dass diese Korrelation negativ ist, ist wahrscheinlich darauf zurückzuführen, dass das S/D-Verhältnis im Laufe der Erkrankung DD mit dem Maße der atrialen Belastung durch zunehmenden Anteil des diastolischen Flusses absinkt. Für die übrigen Hormonfragmente gibt es bisher kaum Untersuchungen zu den einzelnen Parametern der DD, so dass ein Vergleich hier entfallen muss. 
Bei den Korrelationen der Symptome einer manifesten HF mit den untersuchten Peptiden ergibt sich im Gegensatz zu den Parametern der Echokardiografie ein weniger einheitliches Bild. Zwar ist durchgehend eine positive und signifikante Korrelation der Belastungsdyspnoe ersichtlich. Die übrigen Ausprägungen der Dyspnoe korrelieren nur vereinzelt mit den Laborparametern. Möglicherweise wirkt sich hier die Art der Erhebung der Daten aus. Die Patienten wurden zum Vorliegen der Symptomatik befragt, wodurch eine genaue Klassifikation möglicherweise nicht immer vorgenommen werden konnte. Außerdem untersuchte Diast-CHF ein vergleichsweise wenig symptomatisches Kollektiv, weswegen Patienten mit Orthopnoe und Ruhedyspnoe nur in geringer Zahl vertreten waren. Lediglich $3,2 \%$ beziehungsweise 2,3\% beklagten diese Symptome. Bei den Ödemen und der Nykturie dagegen ist erneut eine durchgehend auf dem 0,05 Niveau signifikante positive Korrelation nachweisbar, wenn auch mit geringem Korrelationskoeffizient. Zumindest die Ödeme stellen ein relativ einfach zu objektivierendes Symptom dar, deshalb ist hier eine höhere Genauigkeit bei der Erfassung anzunehmen. In der Frage der Objektivität tritt ein weiterer Vorteil der laborchemischen Methodik hervor. Die Parameter könnten im Idealfall als objektives, weil nicht vom Untersucher abhängiges, Kriterium für die Diagnosefindung und auch Verlaufskontrolle einer symptomatischen HF herangezogen werden, da sie die entsprechende Symptomatik und deren Verlauf widerspiegeln. Eine Korrelationsberechnung zwischen bestimmten Symptomen und Hormonen der neurohumoralen Aktivierung findet sich kaum in der Literatur, meist wird diese Korrelation lediglich auf die NYHA-Klasse bezogen. Ein Vergleich der Ergebnisse aus Diast-CHF ist somit an dieser Stelle nicht möglich.

Es fällt also auf, dass in Diast-CHF verglichen mit der bestehenden Literatur relativ viele Korrelationen zwischen echokardiografischen Parametern der diastolischen Funktion beziehungsweise Symptomatik der HF auf der einen und der neurohumoralen Aktivierung auf der anderen Seite, nachweisbar sind. Dieses Bild ist allerdings nicht immer einheitlich, vor allem in Bezug auf die einzelnen Symptome. Grundsätzlich scheint aber eine erhöhte neurohumorale Aktivität mit dem Auftreten von Symptomen und pathologischen Veränderungen in der Echokardiografie im Sinne einer DD und SD und auch im Sinne einer manifesten HF assoziiert zu sein.

\subsubsection{Fähigkeit zur Detektion einer kardialen Dysfunktion der einzelnen Parameter}

Im Idealfall wären ein oder mehrere der untersuchten Peptide zur Detektion einer kardialen Dysfunktion in der Lage. Somit hätte der Untersucher ein vergleichsweise einfaches diagnostisches Mittel an der Hand und könnte somit eine echokardiografische oder invasive 
Untersuchung ergänzen oder auf sie verzichten. Um die einzelnen Peptide auf ihre Diskriminationsfähigkeit hin zu prüfen, wurden ROC-Kurven zu den verschiedenen Stadien der Erkrankungen erstellt. Insgesamt ergibt sich dabei ein uneinheitliches Bild. Zwar liegen die AUC fast ausnahmslos über 0,5, allerdings sind die AUC im Allgemeinen vergleichsweise niedrig und ist gibt kein Hormon, das für sämtliche Stadien die höchste oder eine der höchsten AUC zeigt. Bei der Diskrimination zwischen DD Grad 0 und DD Grad I etwa weist MR-proADM mit 0,62 die höchste AUC auf. Ebenso bei der Detektion einer DD jeglichen Grades, auch hier liegt die AUC bei 0,62. Bei der Diskrimination einer DD Grad I von einer DD der Schweregrade II-II dagegen sind NT-proBNP und MR-proANP im Vorteil. Hier sind die AUC insgesamt gesehen am niedrigsten, für CT-proAVP sogar unter 0,5. Die höchsten AUC wurden für die Detektion der reduzierten LVEF ermittelt, hier waren erneut NT-proBNP und MR-proANP am besten geeignet. Auch die AUC der anderen Peptide lagen vergleichsweise hoch.

Diese Ergebnisse stützen die zuvor bereits geäußerte Theorie, dass die untersuchten Peptide für unterschiedliche Stadien der DD unterschiedlich gut geeignet sind. Die Hormone der Gruppe 1 weisen bei der Detektion einer DD Grad I allesamt höhere AUC auf, als es die Hormone der Gruppe 2 tun. Der Grund dafür könnte möglicherweise in unterschiedlichen pathophysiologischen Funktionen dieser Hormone zu suchen sein. Wie bereits erwähnt, werden etwa ET-1 und ADM mit der Entwicklung beziehungsweise Gegenregulation einer Hypertonie in Verbindung gebracht. ET-1 fördert weiterhin die Sezernierung von ANP und BNP, die über negative Rückkopplung die Produktion von ET-1 hemmen.

Andererseits stehen die Ergebnisse aber auch im Widerspruch zu Tschöpe et al. (2005), hier zeigte NT-proBNP eine AUC von 0,83 bezüglich der Detektion einer DD. Dieser Wert lag über dem der Echokardiografie mit Gewebedoppler $(0,81)$ und nur knapp unter dem des LVEDP (0,84). Diese Diskrepanz zur Studie Diast-CHF, in welcher NT-proBNP eine AUC von 0,57 für die Detektion einer DD jeglichen Grades zeigte, liegt in der unterschiedlichen Zusammensetzung der Kollektive und in unterschiedlichen Untersuchungsverfahren begründet. Tschöpe et al. (2005) wählten ausschließlich symptomatische Patienten willkürlich aus, bei denen eine DD bereits vordiagnostiziert war. Dies entspricht nicht der klinischen Alltagssituation, in der ein noch nicht vordiagnostizierter Patient auf das Vorliegen einer DD untersucht werden soll. Diast-CHF dagegen hatte zum Ziel, einen serologischen Surrogatparameter der DD zu finden und wählte zu diesem Zweck nicht voruntersuchte Patienten mit mindestens einem kardiovaskulären Risikofaktor aus. Dies entspricht eher dem Szenario des klinischen Alltags, in dem bei einem Patienten der Verdacht auf eine DD oder DHF geäußert wurde und dieser mit relativ geringem Aufwand bestätigt oder verworfen werden soll. Redfield et al. (2004) verfolgten einen im Gegensatz zu Tschöpe et al. (2005) 
mit Diast-CHF vergleichbaren Ansatz und untersuchten ein ebenfalls nicht vorselektiertes Kollektiv aus zufällig aus einem Krankenregister ausgewählten Patienten. Ähnlich wie in Diast-CHF kam man zu dem Ergebnis, dass BNP nur bedingt als alleiniges diagnostisches Mittel einer DD geeignet ist. Vor allem für die Detektion einer DD jeglichen Grades war die AUC mit 0,52 bis 0,68 relativ niedrig und mit der AUC von NT-proBNP aus Diast-CHF vergleichbar $(0,57)$. Etwas höher lag die AUC zur Detektion einer mittleren bis schweren DD. In Diast-CHF wies NT-proBNP eine AUC von 0,62 für die Diskrimination zwischen einer DD des Grades I und einer DD des Grades II-III auf. Auch hier scheint NT-proBNP also für die Detektion einer höhergradigen DD zwar besser, aber nicht optimal geeignet.

Außerdem wurde auf unterschiedliche Methoden Bezug genommen. Tschöpe et al. (2005) verwendeten invasive Methoden als Referenz, während sich Diast-CHF auf den Gewebedoppler beruft. In der Literatur wird für dieses Verfahren eine hohe Genauigkeit berichtet, etwa von Kasner et al. (2007). Zwar gilt die invasive Diagnostik offenbar weiterhin als Goldstandard, allerdings ist dieses Verfahren für den klinischen Alltag nur wenig praktikabel. Es ist unwahrscheinlich, dass die Widersprüche der beiden Studien durch Unterschiede in der Laboranalytik verursacht wurden, da in beiden Arbeiten dasselbe Kit zur Analyse der Proben zum Einsatz kam.

Ein weiterer einflussreicher Faktor ist womöglich der klinische Status der Patienten. Wie bereits bei der Diskussion der Kollektive erwähnt, untersuchten Tschöpe et al. (2005) ausschließlich symptomatische Patienten. Somit könnte es sich vorwiegend um Patienten handeln, deren Erkrankung wesentlich weiter fortgeschritten ist als im Falle von Diast-CHF. Diese Theorie wird dadurch gestützt, dass symptomatische Patienten sämtlicher Stadien der DD stets signifikant höhere Werte für NT-proBNP aufwiesen, als es asymptomatische Patienten desselben Stadiums taten. Auch Redfield et al. (2004) kamen zu dem Ergebnis, dass die AUC von BNP für die Detektion einer höhergradigen DD höher ist als für die Detektion jeglicher Form der DD.

Möglicherweise nahmen auch das Alter und das Geschlecht Einfluss auf die ROC-Analyse. Wie bereits beschrieben, verändern diese Faktoren die Konzentration von NT-proBNP im Blut. Allerdings kamen Redfield et al. (2004) zu dem Schluss, dass die AUC für Männer und Frauen, sowie bei älteren und jüngeren Patienten, ähnlich war. Dennoch berichten sie von AUC von 0,74 für Männer und 0,73 für Frauen für die Detektion einer mittleren bis schweren DD. Die Gründe für diese Unterschiede bleiben unklar.

Zu den übrigen Hormonfragmenten gibt es in der Literatur keinerlei ROC-Analysen bezüglich DD oder DHF. Lediglich für Patienten mit reduzierter LVEF oder SHF sind einige Studien vertreten, von denen eine beispielhaft Erwähnung finden soll. Elmas et al. (2007) ermittelten 
für MR-proADM eine AUC 0,64 in Bezug auf die Detektion einer LVEF <50\%, ein Wert, der etwas unter dem aus Diast-CHF $(0,67)$ liegt. Diast-CHF ist somit die erste Studie, in deren Rahmen eine umfangreiche Analyse der Diskriminationsfähigkeiten der genannten Peptide in Bezug auf die einzelnen Stadien der DD durchgeführt wurde.

Somit lässt sich abschließend feststellen, dass die beschriebenen Hormonfragmente allein nicht zur Detektion einer DD oder reduzierten LVEF geeignet sind. Die AUC sind vergleichsweise niedrig und keines der Peptide ist in jedem Stadium der Erkrankung den anderen in seiner Diskriminationsfähigkeit überlegen. Dies steht zum Teil im Widerspruch zur bisher vorhandenen Literatur, etwa von Tschöpe et al. (2005) und lässt sich teilweise auf unterschiedliche Rekrutierungswege und Referenzmethoden zurückführen. Redfield et al. (2004) allerdings kamen zu einem ähnlichen Schluss für BNP, das sie als suboptimales diagnostisches Mittel für die asymptomatische DD bezeichnen. Es werden weitere Studien nötig sein, um die Ursache für diese Diskrepanzen zu ermitteln.

\subsection{Limitierungen der Arbeit}

Die vorliegende Untersuchung ist nach dem derzeitigen Wissensstand die erste, die eine detaillierte Prüfung der genannten Peptide auf ihre Eignung als Surrogatparameter der DD durchführt. Dabei wurde ein mit 1687 Patienten vergleichsweise großes Kollektiv untersucht. Lediglich für NT-proBNP beziehungsweise BNP existieren entsprechende Voruntersuchungen.

Invasive Methoden gelten weiterhin als Mittel zum definitiven Nachweis einer DD (Zile et al. 2004). Ein Vergleich der Laborparameter mit dieser Diagnosemethode fehlt in der vorliegenden Arbeit. Allerdings erfährt die Echokardiografie zumindest in Kombination mit einem Gewebedoppler, wie er in Diast-CHF durchgeführt wurde, zunehmende Akzeptanz. Außerdem wird der Methode eine enge Korrelation mit den linksventrikulären Füllungsdrucken bestätigt (Paulus et al. 2007). Für die Echokardiografie existiert aber kein einheitliches und endgültiges Diagnoseschema. Das in Diast-CHF verwendete Schema wurde bereits publiziert (Wachter et al. 2007) und unterscheidet sich in einigen Punkten von den zuvor veröffentlichten. Somit sind die Ergebnisse nur bedingt vergleichbar, was beim jetzigen Stand der Forschung jedoch nicht zu vermeiden ist. Invasive Methoden sind außerdem weder im klinischen Alltag praktikabel, noch im Rahmen einer größeren klinischen Studie wie Diast-CHF in ethisch und finanziell vertretbarem Maße an allen Patienten durchführbar. 
Tschöpe et al. (2005) pausierten in ihrem Kollektiv sämtliche Medikation mit Einfluss auf die Hämodynamik 48 Stunden vor der Untersuchung. Zwar mag dieser Schritt eventuell genauere Ergebnisse liefern, allerdings war es das Ziel von Diast-CHF, dem Untersucher ein nicht nur diagnostisches, sondern auch für die Verlaufskontrolle geignetes Mittel für den klinischen Alltag an die Hand zu geben. Dort ist es nicht vertretbar und auch nicht praktikabel, vor einer Untersuchung die Medikation abzusetzen.

Ein weiterer limitierender Faktor ist die Tatsache, dass nicht bei allen Patienten aus DiastCHF primär der Verdacht auf eine DD oder DHF geäußert wurde. Die Rekrutierung erfolgte nicht wegen charakteristischer Symptome einer HF oder des bereits geäußerten Verdachts auf eine DD. Andererseits kann dieser Punkt auch als Stärke von Diast-CHF angesehen werden, da man so ein nicht vorselektiertes Kollektiv untersuchte und ein realistisches Szenario des klinischen Alltags erhielt, in dem der Verdacht auf eine DD oder DHF mit laborchemischen Methoden bestätigt oder ausgeschlossen werden soll. 


\section{Zusammenfassung}

Die diastolische Dysfunktion (DD) und die diastolische Herzinsuffizienz (DHF) sind Erkrankungen von hoher Prävalenz und Mortalität. Je nach Quelle leiden über $50 \%$ der Patienten mit einer Herzinsuffizienz (HF) unter einer isolierten DD oder DHF. Deren Diagnose ist aufgrund des Fehlens einheitlicher Diagnoserichtlinien erschwert. Aus diesem und auch aus Kostengründen wären ein oder mehrere serologische Surrogatparameter wünschenswert, die im Idealfall das Vorliegen einer solchen Erkrankung und auch ihren Verlauf anzeigen könnten. Untersucht wurden die serologisch stabilen Fragmente der Synthese der neurohumoral aktiven Hormone BNP (NT-proBNP), ANP (MR-proANP), Adrenomedullin (MR-proADM), Endothelin-1 (CT-proET-1) und Vasopressin (CT-proAVP).

Zu diesem Zweck wurden in der prospektiven und multizentrischen Kohortenstudie DiastCHF des Kompetenznetzes Herzinsuffizienz 1687 Patienten mit mindestens einem kardiovaskulären Risikofaktor oder bereits ärztlich gestellter Diagnose einer HF ausgewählt. Untersucht wurden Männer und Frauen im Alter von 50 bis 85 Jahren. Männer und Frauen waren im Kollektiv annähernd gleich stark vertreten. Auch Patienten mit reduzierter linksventrikulärer Ejektionsfraktion (LVEF) wurden untersucht, allerdings fand eine klare Trennung zwischen Patienten mit einer LVEF $\geq 50 \%$ und mit einer LVEF $<50 \%$ statt. Für die echokardiografische Diagnose der DD kam ein bereits publiziertes Schema zum Einsatz, die spezielle Laboranalytik wurde von der Firma B.R.A.H.M.S. AG (Hennigsdorf, Deutschland) durchgeführt. Auch diese Methoden wurden bereits veröffentlicht.

Das mittlere Alter der Patienten betrug 65,98 Jahre, der Mittelwert des BMI lag bei 29,12 $\mathrm{kg} / \mathrm{m}^{2}$. Der häufigste Risikofaktor war mit $78,7 \%$ die arterielle Hypertonie. Der Mittelwert des E/A- und des E/e'-Verhältnisses betrug 0,94 beziehungsweise 13,42. Die Stadien der DD waren im Kollektiv wie folgt vertreten: LVEF $\geq 50 \%$ und keine DD: 16,5\%, DD Grad I und LVEF $\geq 50 \%$ : 57,1\%, DD Grad II-III und LVEF $\geq 50 \%$ : 14,7\%, LVEF <50\%: 8,0\%, nicht klassifizierbar: 3,7\%. Mit steigendem Grad der DD stieg auch die mittlere Serumkonzentration der untersuchten Peptide. NT-proBNP: 120,10 pg/ml (Grad 0), 141,76 pg/ml (Grad I), 228,51 pg/ml (Grad II-III), 727,58 pg/ml (LVEF <50\%). MR-proANP: 89,90 pmol/l, 96,22 pmol//, 120,38 pmol/l, 169,19 pmol/l. MR-proADM: 0,54 nmol/l, 0,61 nmol/l, 0,62 nmol/l, 0,74 nmol/l. CT-pro-ET-1: 53,89 pmol/l, 56,98 pmol//, 58,58 pmol/l, 68,88 pmol/l. CT-proAVP: 4,76 pmol/l, 5,81 pmol/l, 5,86 pmol/l, 9,22 pmol/l. Die Signifikanzanalyse zeigte überwiegend signifikante Anstiege beim Vergleich eines niedrigeren Stadiums mit einem höheren Stadium der DD. Mit Ausnahme von CT-proAVP wiesen sämtliche Peptide bei symptomatischen Patienten mit DD signifikant höhere Werte auf als bei asymptomatischen. Sämtliche Hormone, abgesehen von CT-proAVP, korrelierten signifikant positiv mit dem E/e'Verhältnis. Mit dem E/A-Verhältnis korrelierten NT-proBNP und MR-proANP signifikant 
positiv, während MR-proADM, CT-proET-1 und CT-proAVP signifikant negativ korrelierten. In der überwiegenden Zahl der Fälle korrelierten die genannten Peptide außerdem signifikant positiv mit dem Auftreten von Symptomen der manifesten HF in Form von Belastungsdyspnoe, peripheren Ödemen und Nykturie. Die ROC-Analyse zur Detektion der einzelnen Grade der DD und der reduzierten LVEF lieferte ein uneinheitliches Bild. Während MR-proADM bei der Detektion einer DD Grad I und einer DD jeglichen Grades mit jeweils 0,62 die höchste AUC aufwies, war NT-proBNP bei der Detektion der Patienten mit reduzierter LVEF mit einer AUC von 0,75 den übrigen Parametern überlegen. Bei der Diskrimination einer DD des Grades II oder III von einer solchen des Grades I zeigten NTproBNP und MR-proANP mit jeweils 0,62 die höchsten AUC.

Diese Studie untersucht als erste die Veränderungen der genannten Peptide im Rahmen und im Verlauf einer DD sowie die Eignung dieser als Surrogatparameter der DD in einem großen und nicht vorselektierten Kollektiv. Dabei ergeben sich im Wesentlichen fünf Kernaussagen: Zunächst wurde eine zumeist signifikante Erhöhung der Serumkonzentrationen bei Vorliegen einer DD gezeigt, die teilweise auch stadienabhängig ist. Außerdem waren signifikant erhöhte Spiegel der Peptide mit dem Auftreten von Symptomen der manifesten HF assoziiert. Es fanden sich signifikante Korrelationen der Laborwerte mit echokardiografischen Parametern der DD. Zur Detektion einer DD waren die genannten Hormonfragmente allerdings aufgrund der relativ niedrigen AUC nicht geeignet. 


\section{Abkürzungsverzeichnis}

$\mathrm{T}$

A

$A_{\text {Valsalva }}$

$A^{\prime}$

ACE

$\mathrm{ADH}$

ADM

ALT

ANP

AST

AT1

AUC

AVP

bigET-1

$\mathrm{BMI}$

BNP

${ }^{\circ} \mathrm{C}$

Cl

CK

CK-MB

$\mathrm{cm}$

COPD

CRP

CT-proAVP

CT-proET-1

D

DD

DHF

DT

E

$e^{6}$

EDTA

EDV

EKG
Konstante der linksventrikulären Relaxation

Einstromgeschwindigkeit nach der Vorhofkontraktion

Einstromgeschwindigkeit nach der Vorhofkontraktion unter ValsalvaManöver

spätdiastolische Mitralanulusgeschwindigkeit

Angiotensin-converting-Enzym

antidiuretisches Hormon

Adrenomedullin

Alaninaminotransferase

atriales natriuretisches Peptid

Aspartataminotransferase

Angiotensin-Il-Rezeptor Typ 1

Fläche unter der Kurve

Vasopressin

bigEndothelin- 1

body mass index

brain natriuretic peptide

Grad Celsius

Konfidenzintervall

Kreatinkinase

Kreatinkinase Muscle-Brain

Zentimeter

chronisch-obstruktive Lungenerkrankungen

C-reaktives Protein

C-terminaler Teil des proVasopressin

C-terminales Fragment von proEndothelin-1

diastolischer pulmonalvenöser Fluss

diastolische Dysfunktion

diastolische Herzinsuffizienz

Dezelerationszeit

frühdiastolische Einstromgeschwindigkeit

frühdiastolische Mitralanulusgeschwindigkeit

Ethylendiamintetraessigsäure

elektronische Datenverarbeitung

Elektrokardiogramm 


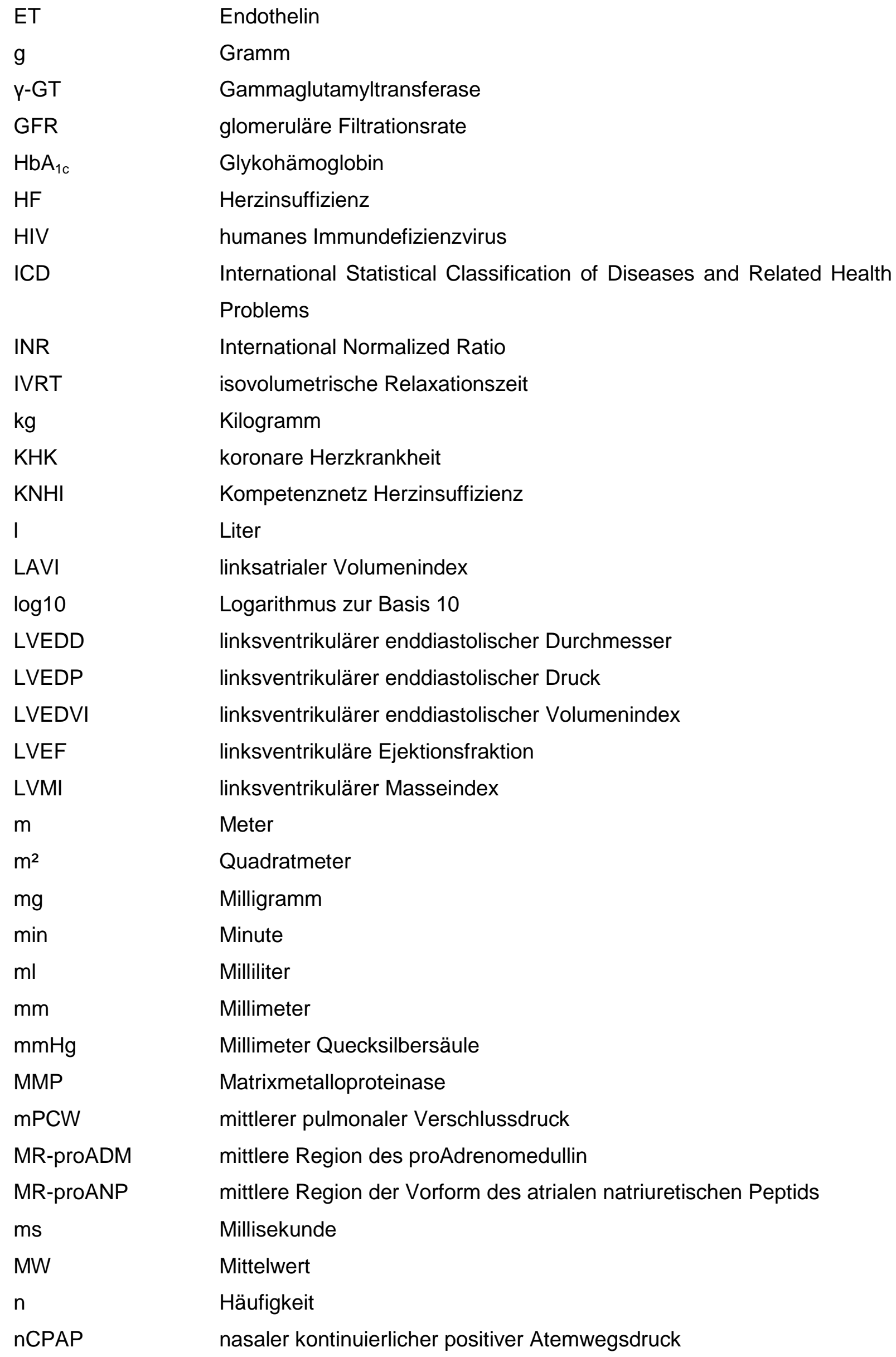




\begin{tabular}{|c|c|}
\hline nmol & Nanomol \\
\hline \multirow[t]{2}{*}{ NT-proANP } & N-terminales Fragment der Vorform des atrialen natriuretischen \\
\hline & Peptids \\
\hline NT-proBNP & N-terminales Fragment der Vorform des brain natriuretic peptide \\
\hline NYHA & New York Heart Association \\
\hline OSAS & obstruktives Schlafapnoesyndrom \\
\hline pAVK & periphere arterielle Verschlusskrankheit \\
\hline $\mathrm{pg}$ & Pikogramm \\
\hline pmol & Pikomol \\
\hline präproET-1 & präproEndothelin-1 \\
\hline proADM & proAdrenomedullin \\
\hline proANP & Vorform des atrialen natriuretischen Peptids \\
\hline proBNP & Vorform des brain natriuretic peptide \\
\hline proET-1 & proEndothelin-1 \\
\hline RAAS & Renin-Angiotensin-Aldosteron-System \\
\hline ROC & Receiver Operating Characteristic \\
\hline s & Sekunde \\
\hline S & systolischer pulmonalvenöser Fluss \\
\hline SD & systolische Dysfunktion \\
\hline SF & Standardfehler \\
\hline SHF & systolische Herzinsuffizienz \\
\hline STBW & Standardabweichung \\
\hline TIA & transitorische ischämische Attacke \\
\hline TIMP & Inhibitor der Matrixmetalloproteinasen \\
\hline TP7 & Teilprojekt 7 des Kompetenznetzes Herzinsuffizienz \\
\hline TSH & Thyroidea-stimulierendes Hormon \\
\hline UMG & Universitätsmedizin Göttingen \\
\hline $\mathrm{VO}_{2 \max }$ & maximale Sauerstoffaufnahme \\
\hline
\end{tabular}




\section{Literaturverzeichnis}

Ahmed SH, Clark LL, Pennington WR, Webb CS, Bonnema DD, Leonardi AH, McClure CD, Spinale FG, Zile MR (2006): Matrix metalloproteinases/tissue inhibitors of metalloproteinases: relationship between changes in proteolytic determinants of matrix composition and structural, functional, and clinical manifestations of hypertensive heart disease.

Circulation 113, 2089-96

Arbab-Zadeh A, Dijk E, Prasad A, Fu Q, Torres P, Zhang R, Thomas JD, Palmer D, Levine BD (2004): Effect of aging and physical activity on left ventricular compliance.

Circulation $\underline{110}, 1799-805$

Arias MA, García-Río F, Alonso-Fernández A, Mediano O, Martínez I, Villamor J (2005): Obstructive sleep apnea syndrome affects left ventricular diastolic function: effects of nasal continuous positive airway pressure in men.

Circulation $\underline{112}, 375-83$

Bergler-Klein J, Klaar U, Heger M, Rosenhek R, Gabriel H, Binder T, Pacher R, Maurer G, Baumgartner $\mathrm{H}$ (2006): Big endothelin-1 is not a predictor in aortic stenosis, but is related to arterial blood pressure.

Int J Cardiol $\underline{113}, 174-80$

Bhatia RS, Tu JV, Lee DS, Austin PC, Fang J, Haouzi A, Gong Y, Liu PP (2006): Outcome of heart failure with preserved ejection fraction in a population-based study.

N Engl J Med $\underline{355}, 260-9$

Bittner V, Weiner DH, Yusuf S, Rogers WJ, Mclntyre KM, Bangdiwala SI, Kronenberg MW, Kostis JB, Kohn RM, Guillotte M (1993): Prediction of mortality and morbidity with a 6-minute walk test in patients with left ventricular dysfunction. SOLVD Investigators.

JAMA $\underline{270}, 1702-7$

Buckley MG, Marcus NJ, Yacoub MH (1999): Cardiac peptide stability, aprotinin and room temperature: importance for assessing cardiac function in clinical practice.

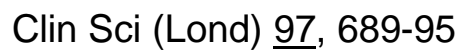


Burnett JC Jr, Kao PC, Hu DC, Heser DW, Heublein D, Granger JP, Opgenorth TJ, Reeder GS (1986): Atrial natriuretic peptide elevation in congestive heart failure in the human.

Science $\underline{231}, 1145-7$

Bursi F, Weston SA, Redfield MM, Jacobsen SJ, Pakhomov S, Nkomo VT, Meverden RA, Roger VL (2006): Systolic and diastolic heart failure in the community.

JAMA $\underline{296}, 2209-16$

Ceyhan C, Unal S, Yenisey C, Tekten T, Ceyhan FB (2008): The role of N terminal pro-brain natriuretic peptide in the evaluation of left ventricular diastolic dysfunction: correlation with echocardiographic indexes in hypertensive patients.

Int J Cardiovasc Imaging 24, 253-9

Cheung BM, Li CY, Wong LY (2004): Adrenomedullin: its role in the cardiovascular system. Semin Vasc Med 4 , 129-34

Cozza EN, Gomez-Sanchez CE, Foecking MF, Chiou S (1989): Endothelin binding to cultured calf adrenal zona glomerulosa cells and stimulation of aldosterone secretion.

J Clin Invest $\underline{84}, 1032-5$

de Bold AJ, Borenstein HB, Veress AT, Sonnenberg H (1981): A rapid and potent natriuretic response to intravenous injection of atrial myocardial extract in rats.

Life Sci $\underline{28}, 89-94$

de Bree FM, Burbach JP (1998): Structure-function relationships of the vasopressin prohormone domains.

Cell Mol Neurobiol $\underline{18}, 173-91$

Demers C, McKelvie RS, Negassa A, Yusuf S, RESOLVD Pilot Study Investigators (2001): Reliability, validity, and responsiveness of the six-minute walk test in patients with heart failure.

Am Heart J 142, 698-703

Dempsey PJ, McCallum ZT, Kent KM, Cooper T (1971): Direct myocardial effects of angiotensin II.

Am J Physiol 220, 477-81 
Elmas E, Lang S, Dempfle CE, Kälsch T, Papassotiriou J, Morgenthaler NG, Borggrefe M, Brueckmann M (2007): Diagnostic performance of mid-regional pro-adrenomedullin as an analyte for the exclusion of left ventricular dysfunction.

Int J Cardiol $\underline{128}, 107-11$

Emori T, Hirata Y, Imai T, Eguchi S, Kanno K, Marumo F (1993): Cellular mechanism of natriuretic peptides-induced inhibition of endothelin-1 biosynthesis in rat endothelial cells.

Endocrinology 133, 2474-80

Falcão LM, Pinto F, Ravara L, van Zwieten PA (2004): BNP and ANP as diagnostic and predictive markers in heart failure with left ventricular systolic dysfunction.

J Renin Angiotensin Aldosterone Syst $\underline{5}, 121-9$

Fischer M, Baessler A, Hense HW, Hengstenberg C, Muscholl M, Holmer S, Döring A, Broeckel U, Riegger G, Schunkert H. (2003): Prevalence of left ventricular diastolic dysfunction in the community. Results from a Doppler echocardiographic-based survey of a population sample.

Eur Heart J $\underline{24}, 320-8$

Francis GS, Benedict C, Johnstone DE, Kirlin PC, Nicklas J, Liang CS, Kubo SH, RudinToretsky E, Yusuf S (1990): Comparison of neuroendocrine activation in patients with left ventricular dysfunction with and without congestive heart failure. A substudy of the Studies of Left Ventricular Dysfunction (SOLVD).

Circulation $\underline{82}, 1724-9$

Frankenstein L, Remppis A, Graham J, Schellberg D, Sigg C, Nelles M, Katus HA, Zugck C (2007): Gender and age related predictive value of walk test in heart failure: Do anthropometrics matter in clinical practice?

Int J Cardiol 127, 331-6

Garcia MJ, Thomas JD, Klein AL (1998): New Doppler echocardiographic applications for the study of diastolic function.

J Am Coll Cardiol 32, 865-75 
Gegenhuber A, Struck J, Poelz W, Pacher R, Morgenthaler NG, Bergmann A, Haltmayer M, Mueller T (2006): Midregional pro-A-type natriuretic peptide measurements for diagnosis of acute destabilized heart failure in short-of-breath patients: comparison with B-type natriuretic peptide (BNP) and amino-terminal proBNP.

Clin Chem $\underline{52}, 827-31$

Gegenhuber A, Struck J, Dieplinger B, Poelz W, Pacher R, Morgenthaler NG, Bergmann A, Haltmayer M, Mueller T (2007): Comparative evaluation of B-type natriuretic peptide, midregional pro-A-type natriuretic peptide, mid-regional pro-adrenomedullin, and Copeptin to predict 1-year mortality in patients with acute destabilized heart failure.

$\mathrm{J}$ Card Fail $\underline{13}$, 42-9

Grewal J, McKelvie R, Lonn E, Tait P, Carlsson J, Gianni M, Jarnert C, Persson H (2008): BNP and NT-proBNP predict echocardiographic severity of diastolic dysfunction.

Eur J Heart Fail 므, 252-9

Guyatt GH, Sullivan MJ, Thompson PJ, Fallen EL, Pugsley SO, Taylor DW, Berman LB (1985): The 6-minute walk: a new measure of exercise capacity in patients with chronic heart failure.

Can Med Assoc J 132, 919-23

Hanehira T, Kohno M, Yoshikawa J (1997): Endothelin production in cultured vascular smooth muscle cells--modulation by the atrial, brain, and C-type natriuretic peptide system. Metabolism 느, 487-93

Hemsén A, Franco-Cereceda A, Matran R, Rudehill A, Lundberg JM (1990): Occurrence, specific binding sites and functional effects of endothelin in human cardiopulmonary tissue.

Eur J Pharmacol 191, 319-28

Ho KK, Pinsky JL, Kannel WB, Levy D (1993): The epidemiology of heart failure: the Framingham Study.

J Am Coll Cardiol 22 (4 Suppl A), 6A-13A

Ichiki Y, Kitamura K, Kangawa K, Kawamoto M, Matsuo H, Eto T (1994): Distribution and characterization of immunoreactive adrenomedullin in human tissue and plasma.

FEBS Lett $\underline{338}, 6-10$ 
Iglarz M, Schiffrin EL (2003): Role of endothelin-1 in hypertension.

Curr Hypertens Rep $\underline{5}, 144-8$

Inoue A, Yanagisawa M, Kimura S, Kasuya Y, Miyauchi T, Goto K, Masaki T (1989): The human endothelin family: three structurally and pharmacologically distinct isopeptides predicted by three separate genes.

Proc Natl Acad Sci U S A $\underline{86}$, 2863-7

Irzmański R, Banach M, Piechota M, Kowalski J, Barylski M, Cierniewski C, Pawlicki L (2007): Atrial and brain natriuretic peptide and endothelin-1 concentration in patients with idiopathic arterial hypertension: the dependence on the selected morphological parameters.

Clin Exp Hypertens 29, 149-64

Ishimitsu T, Ono H, Minami J, Matsuoka H (2006): Pathophysiologic and therapeutic implications of adrenomedullin in cardiovascular disorders.

Pharmacol Ther $\underline{111}, 909-27$

Jalil JE, Doering CW, Janicki JS, Pick R, Shroff SG, Weber KT (1989): Fibrillar collagen and myocardial stiffness in the intact hypertrophied rat left ventricle.

Circ Res $\underline{64}, 1041-50$

Jougasaki M, Grantham JA, Redfield MM, Burnett JC Jr (2001): Regulation of cardiac adrenomedullin in heart failure.

Peptides $\underline{22}, 1841-50$

Kaneko Y, Floras JS, Usui K, Plante J, Tkacova R, Kubo T, Ando S, Bradley TD (2003): Cardiovascular effects of continuous positive airway pressure in patients with heart failure and obstructive sleep apnea.

N Engl J Med $\underline{348}, 1233-41$

Karl J, Borgya A, Gallusser A, Huber E, Krueger K, Rollinger W, Schenk J (1999): Development of a novel, N-terminal-proBNP (NT-proBNP) assay with a low detection limit. Scand J Clin Lab Invest Suppl 230, 177-81 
Kasner M, Westermann D, Steendijk P, Gaub R, Wilkenshoff U, Weitmann K, Hoffmann W, Poller W, Schultheiss HP, Pauschinger M (2007): Utility of Doppler echocardiography and tissue Doppler imaging in the estimation of diastolic function in heart failure with normal ejection fraction: a comparative Doppler-conductance catheterization study.

Circulation $\underline{116}$, 637-47

Katz AM, Zile MR (2006): New molecular mechanism in diastolic heart failure.

Circulation $\underline{113}, 1922-5$

Khan SQ, Dhillon O, Struck J, Quinn P, Morgenthaler NG, Squire IB, Davies JE, Bergmann A, Ng LL (2007): C-terminal pro-endothelin-1 offers additional prognostic information in patients after acute myocardial infarction: Leicester Acute Myocardial Infarction Peptide (LAMP) Study.

Am Heart J 154, 736-42

Kitamura K, Kangawa K, Kawamoto M, Ichiki Y, Nakamura S, Matsuo H, Eto T (1993): Adrenomedullin: a novel hypotensive peptide isolated from human pheochromocytoma.

Biochem Biophys Res Commun 192, 553-60

Klapholz M, Maurer M, Lowe AM, Messineo F, Meisner JS, Mitchell J, Kalman J, Phillips RA, Steingart R, Brown EJ Jr (2004): Hospitalization for heart failure in the presence of a normal left ventricular ejection fraction: results of the New York Heart Failure Registry.

J Am Coll Cardiol $\underline{43}, 1432-8$

Kobayashi K, Kitamura K, Etoh T, Nagatomo Y, Takenaga M, Ishikawa T, Imamura T, Koiwaya Y, Eto T (1996): Increased plasma adrenomedullin levels in chronic congestive heart failure.

Am Heart J $\underline{131}, 994-8$

Lerman A, Gibbons RJ, Rodeheffer RJ, Bailey KR, McKinley LJ, Heublein DM, Burnett JC Jr (1993): Circulating N-terminal atrial natriuretic peptide as a marker for symptomless leftventricular dysfunction.

Lancet $\underline{341}, 1105-9$

Levey AS, Greene T, Kusek JW, Beck GJ, MDRD Study Group (2000): A simplified equation to predict glomerular filtration rate from serum creatinine.

J Am Soc Nephrol 11, A0828 
Lubien E, DeMaria A, Krishnaswamy P, Clopton P, Koon J, Kazanegra R, Gardetto N, Wanner E, Maisel AS (2002): Utility of B-natriuretic peptide in detecting diastolic dysfunction: comparison with Doppler velocity recordings.

Circulation 105, 595-601

Maeda S, Jesmin S, lemitsu M, Otsuki T, Matsuo T, Ohkawara K, Nakata Y, Tanaka K, Goto K, Miyauchi T (2006): Weight loss reduces plasma endothelin-1 concentration in obese men. Exp Biol Med (Maywood) 231, 1044-7

Maisel AS, Krishnaswamy P, Nowak RM, McCord J, Hollander JE, Duc P, Omland T, Storrow AB, Abraham WT, Wu AH (2002): Rapid measurement of B-type natriuretic peptide in the emergency diagnosis of heart failure

N Engl J Med $\underline{347}, 161-7$

Masaki T (2004): Historical review: Endothelin.

Trends Pharmacol Sci $\underline{25}$, 219-24

Masaki T, Vane JR, Vanhoutte PM (1994): International Union of Pharmacology nomenclature of endothelin receptors.

Pharmacol Rev $\underline{46}, 137-42$

Masson S, Latini R, Anand IS, Barlera S, Judd D, Salio M, Perticone F, Perini G, Tognoni G, Cohn JN (2006): The prognostic value of big endothelin-1 in more than 2,300 patients with heart failure enrolled in the Valsartan Heart Failure Trial (Val-HeFT).

J Card Fail 12, 375-80

McMurray JJ, Stewart S (2000): Epidemiology, aetiology, and prognosis of heart failure. Heart $\underline{83}$, 596-602

McMurray JJ, Ray SG, Abdullah I, Dargie HJ, Morton JJ (1992): Plasma endothelin in chronic heart failure.

Circulation $\underline{85}, 1374-9$

McMurray JJ, Teerlink JR, Cotter G, Bourge RC, Cleland JG, Jondeau G, Krum H, Metra M, O'Connor CM, Parker JD (2007): Effects of tezosentan on symptoms and clinical outcomes in patients with acute heart failure: the VERITAS randomized controlled trials.

JAMA 298, 2009-19 
Meeran K, O'Shea D, Upton PD, Small CJ, Ghatei MA, Byfield PH, Bloom SR (1997): Circulating adrenomedullin does not regulate systemic blood pressure but increases plasma prolactin after intravenous infusion in humans: a pharmacokinetic study.

$\mathrm{J}$ Clin Endocrinol Metab $\underline{82}, 95-100$

Morgenthaler NG, Struck J, Thomas B, Bergmann A (2004): Immunoluminometric assay for the midregion of pro-atrial natriuretic peptide in human plasma.

Clin Chem $\underline{50}$, 234-6

Morgenthaler NG, Struck J, Alonso C, Bergmann A (2005): Measurement of midregional proadrenomedullin in plasma with an immunoluminometric assay.

Clin Chem $\underline{51}, 1823-9$

Morgenthaler NG, Struck J, Alonso C, Bergmann A (2006): Assay for the measurement of copeptin, a stable peptide derived from the precursor of vasopressin.

Clin Chem $\underline{\text { 52, }}$ 112-9

Mosteller RD (1987): Simplified calculation of body-surface area.

N Engl J Med 317, 1098

Mueller T, Gegenhuber A, Poelz W, Haltmayer M (2003): Comparison of the Biomedica NTproBNP enzyme immunoassay and the Roche NT-proBNP chemiluminescence immunoassay: implications for the prediction of symptomatic and asymptomatic structural heart disease.

Clin Chem $\underline{49}$, 976-9

Mueller T, Gegenhuber A, Poelz W, Haltmayer M (2005): Diagnostic accuracy of B type natriuretic peptide and amino terminal proBNP in the emergency diagnosis of heart failure.

Heart $\underline{91}, 606-12$

Naughton MT (2003): Sleep disorders in patients with congestive heart failure.

Curr Opin Pulm Med $\underline{9}$, 453-8

Owan TE, Hodge DO, Herges RM, Jacobsen SJ, Roger VL, Redfield MM (2006): Trends in prevalence and outcome of heart failure with preserved ejection fraction.

N Engl J Med 355, 251-9 
Papassotiriou J, Morgenthaler NG, Struck J, Alonso C, Bergmann A (2006): Immunoluminometric assay for measurement of the C-terminal endothelin-1 precursor fragment in human plasma.

Clin Chem $\underline{52}, 1144-51$

Paulus WJ, Tschöpe C, Sanderson JE, Rusconi C, Flachskampf FA, Rademakers FE, Marino P, Smiseth OA, De Keulenaer G, Leite-Moreira AF (2007): How to diagnose diastolic heart failure: a consensus statement on the diagnosis of heart failure with normal left ventricular ejection fraction by the Heart Failure and Echocardiography Associations of the European Society of Cardiology.

Eur Heart J $\underline{28}, 2539-50$

Piechota M, Banach M, Jacoń A, Rysz J (2008): Natriuretic peptides in cardiovascular diseases.

Cell Mol Biol Lett $\underline{13}, 155-81$

Pio R, Martinez A, Unsworth EJ, Kowalak JA, Bengoechea JA, Zipfel PF, Elsasser TH, Cuttitta $F$ (2001): Complement factor $H$ is a serum-binding protein for adrenomedullin, and the resulting complex modulates the bioactivities of both partners.

J Biol Chem 276, 12292-300

Preibisz JJ, Sealey JE, Laragh JH, Cody RJ, Weksler BB (1983): Plasma and platelet vasopressin in essential hypertension and congestive heart failure.

Hypertension $\underline{5}$, I129-38

Redfield MM, Jacobsen SJ, Burnett JC Jr, Mahoney DW, Bailey KR, Rodeheffer RJ (2003): Burden of systolic and diastolic ventricular dysfunction in the community: appreciating the scope of the heart failure epidemic.

JAMA $\underline{289}, 194-202$

Redfield MM, Rodeheffer RJ, Jacobsen SJ, Mahoney DW, Bailey KR, Burnett JC Jr (2004) Plasma brain natriuretic peptide to detect preclinical ventricular systolic or diastolic dysfunction: a community-based study.

Circulation $\underline{109}$, 3176-81 
Schunkert H, Hense HW, Muscholl M, Luchner A, Kürzinger S, Danser AH, Riegger GA (1997): Associations between circulating components of the renin-angiotensin-aldosterone system and left ventricular mass.

Heart $\underline{77}, 24-31$

Shah R (2007): Endothelins in health and disease.

Eur J Intern Med 18, 272-82

Singh Ranger G (2002): The physiology and emerging roles of antidiuretic hormone.

Int J Clin Pract $\underline{56}, 777-82$

Stoiser B, Mörtl D, Hülsmann M, Berger R, Struck J, Morgenthaler NG, Bergmann A, Pacher $R$ (2006): Copeptin, a fragment of the vasopressin precursor, as a novel predictor of outcome in heart failure.

Eur J Clin Invest $\underline{36}, 771-8$

Struck J, Morgenthaler NG, Bergmann A (2005): Proteolytic processing pattern of the endothelin-1 precursor in vivo.

Peptides $\underline{26}, 2482-6$

Sudoh T, Kangawa K, Minamino N, Matsuo H (1988): A new natriuretic peptide in porcine brain.

Nature $\underline{332}, 78-81$

Sugo S, Minamino N, Kangawa K, Miyamoto K, Kitamura K, Sakata J, Eto T, Matsuo H (1994): Endothelial cells actively synthesize and secrete adrenomedullin.

Biochem Biophys Res Commun 201, 1160-6

Tahara A, Tomura Y, Wada K, Kusayama T, Tsukada J, Ishii N, Yatsu T, Uchida W, Tanaka A (1998): Effect of YM087, a potent nonpeptide vasopressin antagonist, on vasopressininduced protein synthesis in neonatal rat cardiomyocyte.

Cardiovasc Res $\underline{38}, 198-205$

Tribouilloy C, Rusinaru D, Mahjoub H, Soulière V, Lévy F, Peltier M, Slama M, Massy Z (2008): Prognosis of heart failure with preserved ejection fraction: a 5 year prospective population-based study.

Eur Heart J $\underline{29}$, 339-47 
Tschöpe C, Kasner M, Westermann D, Gaub R, Poller WC, Schultheiss HP (2005): The role of NT-proBNP in the diagnostics of isolated diastolic dysfunction: correlation with echocardiographic and invasive measurements.

Eur Heart J 26, 2277-84

Van Beneden R, Gurné O, Selvais PL, Ahn SA, Robert AR, Ketelslegers JM, Pouleur HG, Rousseau MF (2004): Superiority of big endothelin-1 and endothelin-1 over natriuretic peptides in predicting survival in severe congestive heart failure: a 7-year follow-up study.

J Card Fail 10, 490-5

van Heerebeek L, Borbély A, Niessen HW, Bronzwaer JG, van der Velden J, Stienen GJ, Linke WA, Laarman GJ, Paulus WJ (2006): Myocardial structure and function differ in systolic and diastolic heart failure.

Circulation 113, 1966-73

Vasan RS, Benjamin EJ, Levy D (1995): Prevalence, clinical features and prognosis of diastolic heart failure: an epidemiologic perspective.

J Am Coll Cardiol 26, 1565-74

Wachter R, Lüers C, Kleta S, Griebel K, Herrmann-Lingen C, Binder L, Janicke N, Wetzel D, Kochen MM, Pieske B (2007): Impact of diabetes on left ventricular diastolic function in patients with arterial hypertension.

Eur J Heart Fail $\underline{9}$, 469-76

Wang TJ, Larson MG, Levy D, Leip EP, Benjamin EJ, Wilson PW, Sutherland P, Omland T, Vasan RS (2002): Impact of age and sex on plasma natriuretic peptide levels in healthy adults.

Am J Cardiol $\underline{90}, 254-8$

Weitzberg E, Ahlborg G, Lundberg JM (1991): Long-lasting vasoconstriction and efficient regional extraction of endothelin-1 in human splanchnic and renal tissues.

Biochem Biophys Res Commun 180, 1298-303

Xu D, Emoto N, Giaid A, Slaughter C, Kaw S, deWit D, Yanagisawa M (1994): ECE-1: a membrane-bound metalloprotease that catalyzes the proteolytic activation of big endothelin1.

Cell $\underline{78}, 473-85$ 
Yamamoto T, Kimura T, Ota K, Shoji M, Inoue M, Sato K, Ohta M, Yoshinaga K (1992): Central effects of endothelin-1 on vasopressin release, blood pressure, and renal solute excretion.

Am J Physiol 262, E856-62

Yanagisawa M, Kurihara H, Kimura S, Tomobe Y, Kobayashi M, Mitsui Y, Yazaki Y, Goto K, Masaki T (1988): A novel potent vasoconstrictor peptide produced by vascular endothelial cells.

Nature $\underline{332}, 411-5$

Yu CM, Cheung BM, Leung R, Wang Q, Lai WH, Lau CP (2001): Increase in plasma adrenomedullin in patients with heart failure characterised by diastolic dysfunction.

Heart $\underline{6}, 155-60$

Zile MR, Brutsaert DL (2002): New concepts in diastolic dysfunction and diastolic heart failure: Part II: causal mechanisms and treatment.

Circulation $\underline{105}$, 1503-8

Zile MR, Baicu CF, Gaasch WH (2004): Diastolic heart failure--abnormalities in active relaxation and passive stiffness of the left ventricle.

N Engl J Med 350, 1953-9 


\section{Danksagung}

Mein Dank gilt zunächst Herrn Dr. med. F. Edelmann, meinem Betreuer. Er war zu jeder Phase der Arbeit und besonders während der Auswertung und Niederschrift eine große und außergewöhnlich geduldige Unterstützung und trug mit seinen Anregungen sehr zum Gelingen dieser Dissertation bei.

Ich danke Herrn Prof. Dr. med. B. Pieske für die Überlassung des interessanten Themas und die Übernahme des Referates.

Weiterhin möchte ich mich bei der Firma B.R.A.H.M.S. AG (Hennigsdorf, Deutschland) für die zügige und lückenlose Durchführung der speziellen Laboranalytik bedanken.

Außerdem bedanke ich mich bei allen Mitarbeitern sowie Doktorandinnen und Doktoranden des KNHI und den zahlreichen an Diast-CHF teilnehmenden Patienten.

Mein Dank gilt weiterhin insbesondere meinen Mitdoktoranden Herrn Fabian Gabriel und Herrn André Duvinage für die gute und kollegiale Zusammenarbeit in allen Belangen.

Schließlich bedanke ich mich bei meinen Eltern, Frau Karola Rahn und Herrn Norbert Rahn, die die Arbeit mit viel Ausdauer orthografisch korrigiert haben. 